\title{
Evaluation and control of occupational health risks : an integrated strategy applied to chemical, physical and ergonomic stressors
}

Citation for published version (APA):

Kant, IJ. (1994). Evaluation and control of occupational health risks : an integrated strategy applied to chemical, physical and ergonomic stressors. [Doctoral Thesis, Maastricht University]. Datawyse / Universitaire Pers Maastricht. https://doi.org/10.26481/dis.19940622ik

Document status and date:

Published: 01/01/1994

DOI:

10.26481/dis.19940622ik

Document Version:

Publisher's PDF, also known as Version of record

Please check the document version of this publication:

- A submitted manuscript is the version of the article upon submission and before peer-review. There can be important differences between the submitted version and the official published version of record.

People interested in the research are advised to contact the author for the final version of the publication, or visit the DOI to the publisher's website.

- The final author version and the galley proof are versions of the publication after peer review.

- The final published version features the final layout of the paper including the volume, issue and page numbers.

Link to publication

\footnotetext{
General rights rights.

- You may freely distribute the URL identifying the publication in the public portal. please follow below link for the End User Agreement:

www.umlib.nl/taverne-license

Take down policy

If you believe that this document breaches copyright please contact us at:

repository@maastrichtuniversity.nl

providing details and we will investigate your claim.
}

Copyright and moral rights for the publications made accessible in the public portal are retained by the authors and/or other copyright owners and it is a condition of accessing publications that users recognise and abide by the legal requirements associated with these

- Users may download and print one copy of any publication from the public portal for the purpose of private study or research.

- You may not further distribute the material or use it for any profit-making activity or commercial gain

If the publication is distributed under the terms of Article $25 \mathrm{fa}$ of the Dutch Copyright Act, indicated by the "Taverne" license above, 
EVALUATION AND CONTROL OF OCCUPATIONAL. HEALTH RISKS 



\title{
EVALUATION AND CONTROL OF OCCUPATIONAL HEALTH RISKS
}

\section{An integrated strategy applied to chemical, physical and ergonomic stressors}

\section{PROEFSCHRIFT}

\author{
ter verkrijging van de graad van doctor \\ aan de Rijksuniversiteit Limburg te Maastricht, \\ op gezag van de Rector Magnificus, Prof. Dr. H. Philipsen, \\ volgens het besluit van het College van Dekanen, \\ in het openbaar te verdedigen op \\ woensdag 22 juni 1994 om 14.00 uur
}

door

IJmert Kant

geboren te Utrecht op 11 februari 1959

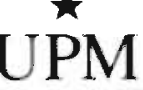




\section{Promotor:}

Prof. Dr. P.Th. Henderson

\section{Co-promotor:}

Dr. P.J.A. Borm

\section{Beoordelingscommissie:}

Prof. Dr. A. Huson (voorzitter)

Prof. Dr. J.S.M. Boleij (Landbouw Universiteit Wageningen)

Prof. Dr. F.J.H. van Dijk (Universiteit van Amsterdam)

Dr. F. Nijhuis

Prof. Dr. H.A.J. Struijker Boudier

CIP-DATA KONINKLIJKE BIBLIOTHEEK, DEN HAAG

Kant, IJmert

Evaluation and control of occupational health risks:

An integrated strategy applied to chemical,

physical and ergonomic stressors / IJmert Kant. - Maastricht:

Universitaire Pers Maastricht. - 111.

Thesis Maastricht. - With ref. - With summary in Dutch.

ISBN 90-5278-143.5

Subject headings: occupational health; risk control. 
"As for the future, the past is prologue"

\section{Gerarde}

Voor Lily 


\section{Contents}

1. Introduction

RISK EVALUATION AND CONTROL OF CHEMICAL EXPOSURE: NITROUS OXIDE

2. Monitoring of nitrous oxide in operating rooms: identification of sources and estimation of occupational exposure Modified from: Borm PJA, Kant IJ, Houben G, Rijssen-Moll van M, Henderson PTh. J Occup Med 1990;32:1112-1116

3. Simulation of nitrous oxide concentrations in operating and recovery rooms

Kant IJ, Rijssen-Moll van M, Borm PJA. Ann Occup Hyg 1990;34:575-583

RISK EVALUATION OF THERMAL DISCOMFORT

4. A comparison of current evaluation methods for thermal 49 environment applied to garage work

Kant I.J, Borm PJA. Notermans JHV. Int Arch Occup Environ Health 1988; 61:115-121

5. The effect of mental activity on thermal sensation Kant IJ, Borm PJA. Prec 5th International Conference on Indoor Air Quality and Climate, Toronto, Canada 1990;1:711-715

RISK EVALUATION OF POSTURAL. STRESS

6. Observations of working postures in garages using the Ovako Working posture Analysing System (OWAS) and consequent workload reduction recommendations Kant IJ, Notermans JHV, Borm PJA. Ergonomics 1990; 2:209-220 
7. A survey of static and dynamic work postures of operating room staff

Kant IJ, Jong de LCGM, Rijssen-Moll van M, Borm PJA. Int Arch Occup Environ Health 1992; 63:423-428

8. Analysis and improvement of work postures: development and application of a computerised OWAS method Kant IJ, Swaen GMH, Borm PJA. Ann Occup Hyg, submitted

9. General discussion

10. Summary

11. Samenvatting

Dankwoord

Curriculum Vitae

Publikaties 



\section{CHAPTER 1}

\section{Introduction}

Occupational hygiene focusses on the workplace with the aim to protect workers from health hazards related to work and to enhance the well-being of workers by adapting the work setting to human requirements. One of the essential activities in occupational hygiene is therefore the workplace investigation which analyzes workplace hazards [Cralley and Cralley 1985, Mattila 1989].

The role of workplace investigations in occupational hygiene has substantially changed over time. It was not until around the turn of this century that specific attention began to be devoted to the preventive aspects of industrial illnesses, especially to the aspects of chemical exposure [Hunter 1978]. With the development of the impingement method for collecting airborne contaminant samples and the light field dust counting technique, methods had been established for measuring airborne levels of contamination in the workplace both for estimating levels of exposure and for use as a benchmark in determining degrees of air quality improvement after controls. Using these techniques, occupational hygienists could show that it was feasible to reduce the massive workplace airborne contamination that often existed at that time. By relating the data to the health profile of the worker, it was demonstrated that reduction of the exposure level also reduced the incidence of the associated disease. Thus began the first field studies that were to have a profound influence on the collection of relevant data upon which to base permissible limits and on developing the rationale upon which the practice of occupational hygiene is predicated.

During the past decades, as industrial technology advanced, the cornplexity of the worker exposure also increased along with the professional skills needed to recognize, evaluate, control and study the effects of newer stressors. Stress factors such as improper lighting and contrast, work posture, need for strict attention for a given task, tension and many others arise in the operation of computers and video display terminals that are becoming commonplace in industry. Thus, concern for the health of the employees above and beyond that of toxicity response arise. 
Nowadays occupational hygiene is an applied science encompassing the application of knowledge from a multi-disciplinary profession including the sciences of medicine, physics, toxicology, epidemiology and engineering. The most important goal in occupational hygiene is to improve the health of working populations by preventing occupational risks that cause injury and disease. According to the World Health Organization [WHO 1991] occupational hygiene workplace investigations are dedicated to the "recognition, evaluation, and control of environmental factors or stresses, arising in or from the workplace, which may affect the health and/or well-being of workers and/or their descendants". Occupational risk analysis through workplace investigation can therefore be regarded as a tool in occupational health prevention. This preventive aspect is also a primary aim of the European Directive 89/391/EEC that prescribes companies to perform a risk evaluation and control program.

\section{RISK EVALUATION AND CONTROL IN OCCUPATIONAL HYGIENE}

Workers can be exposed to many potential hazards. Their health and wellbeing can be affected by several environmental factors, including:

- Chemical factors: exposure to chemical substances and compounds;

- Biological factors: exposure to biological substances (viruses, enzymes, micro organisms);

- Physical factors: noise and vibration, thermal climate, radiation;

- Ergonomic factors: postural load, static load of the musculoskeletal system;

- Psychosocial factors: stress, pressure of work.

Evaluation and control of occupational risks for specific workplaces can only be undertaken effectively if detailed knowledge exists about (i) the potential hazards, (ii) the causal relationship between the exposures in the occupational environment and their health effects and (iii) the occupational exposures and their sources [Fishbein 1980, Hallenbeck 1986, Ricci 1985]. Many related disciplines contribute to this knowledge. This is especially true for the occupational risks of chemical substances. Measurements of health effects from chemical exposure directly in humans either through epidemiological or clinical studies provide evidence of the toxicity and sometimes dose-response relationship in humans [Hernberg 1992]. Toxicology tests in animals and cell systems are used to study the adverse effects of chemical agents in living organisms. These toxicity tests also provide the dose-response relationship of these effects [Williams 1985]. To a certain extent these tests can predict health risks in humans. The outcome of both toxicological and epidemiological studies is used by regulatory agencies in setting up occupational exposure limits and/or standards and guidelines [Henschler 1985].

Occupational hygiene surveys are used to determine the occupational exposure(s) to environmental health stressors (chemical, biological, physical, ergo- 
nomic) in the work environment and to study the factor(s) that cause and/or affect this exposure. Depending on the type of environmental stressor, the workplace, previous information and techniques available, a risk evaluation and control program can be designed. Figure 1 shows the elements of such a program for toxic agents in the work environment. This figure also shows the contributions of related disciplines. The essence of this flowchart is also applicable to other occupational risks such as physical risks and ergonomic risks.

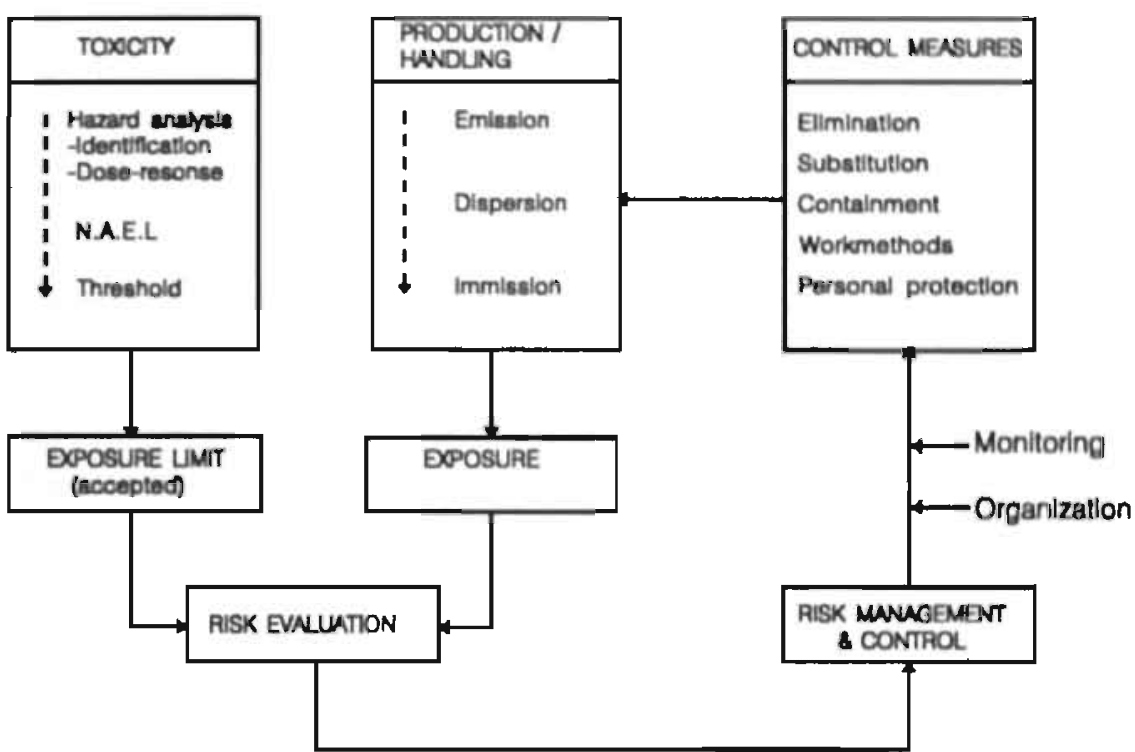

FIGURE 1: Flow-chart illustrating the place of occupational risk evaluation and control in a work environment characterised by exposure to toxic substances. The risks of chemical substances in a certain workplace are determined by the toxicity (hazard) of the agent and the occupational exposures. Risk evaluation is carried out by comparing real exposure values with the exposure limits derived from the thresholds of toxicity. The risk evaluation may lead to a margin of safety. Control measures have to be taken to reduce the occupational exposure and the concomitant risk when exposure exceeds the exposure limit.

Occupational hygiene surveys are a constitutive part of risk evaluation and control programs. They are, however, implicitly based upon tenets [Cralley and Cralley 1985] including (i) environmental health stresses in the workplace can be quantitatively measured and/or expressed in terms that relate to the degree of stress, (ii) stresses in the workplace, in general, show a dose-response relationship were the dose is a value integrating the level of exposure and the time duration of the exposure to the stress factor. Thirdly, the human 
body has intricate mechanisms of protection. For most stress agents there is some cumulative exposure that is tolerated over a working lifetime without injury to health; the No Adverse Effect Level (NAEL). Regardless of type, all exposures in the workplace should be kept within these limits. Finally, the limitation of health hazards through process design (control at the source through elimination or substitution of hazardous agents or stresses) should be the first objective in maintaining a healthful workplace. Where this is not feasible, recognised engineering methods (containment, (local) ventilation, changing work methods) should be used to keep exposures within acceptable limits. In some instances, supplemental programs such as the use of personal protective equipment and other control strategies can be applied.

Occupational hygiene is an applied science meaning that the application and interpretation are directed by problems arising in the work environment. Evaluation and control of occupational risks can be seen in terms of solving problems using the classic cascade for the determination and solution of problems [Groot de 1961]: recognition and description, analysis, solution criteria, setting priorities, establishment of solutions, selection of solutions and implementation and evaluation of effects. The elements "recognition", "evaluation" and "control" form the backbone of Occupational Hygiene and are represented in these stages. Combined with the environmental factors these stages form a matrix covering the whole scope of occupational hygiene (Figure 2).

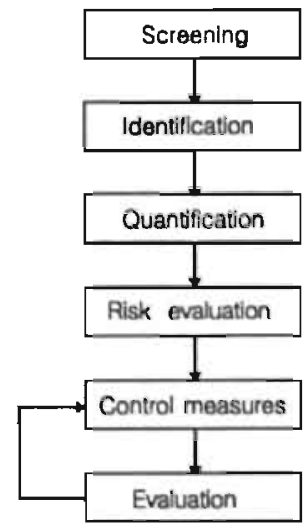

FIGURE 2: Stages in the occupational hygiene strategy.

Each stage in this stepwise approach requires different information and data to be obtained. As a consequence, in practice for each step a different strategy may be applied. Moreover, strategies may differ with the hazard studied. The recognition of environmental hazards in the workplace is the first step in this cascade. Health hazards can be recognised and identified using a retro- 
spective approach (epidemiological studies, complaints/health-effects/sickleave of workers) and/or a preventive approach (screening of the workplace). This thesis primarily focuses on the process of the risk evaluation and control, once possible health hazards are identified.

To evaluate the identified risks the environmental stressor(s) need(s) to be quantified. Strategies have been developed to measure occupational exposure to environmental stressors [Buring 1988, Piney et al. 1987]. However, in all strategies the magnitude of the survey (number of measurements) is mainly determined by the variation in exposure levels [Esmen 1982]. Subsequently, risk evaluation is carried out by comparing the exposure measured with accepted exposure limits (standards, guidelines). If the exposure exceeds exposure limits, control measures have to be taken to reduce the occupational exposure. Once control measures are implemented, the effect and efficiency of these measures can be evaluated by monitoring the exposure (see Figure 1).

So far, within occupationai hygiene practice in The Netherlandis, much attention is given to recognition and evaluation of occupational risks and less to the control of these risks [NVVA 1991]. This can partly be explained by the historical development of the profession. Contrary to countries like the Unites States and the United Kingdom, where the profession developed in the 30's from technical disciplines like chemical- and mechanical engineering [Gerhardsson 1988], occupational hygiene in The Netherlands originated from occupational medicine in the 70's [Burdorf 1991]. In this "early" period occupational hygienists mainly monitored chemical and physical factors, after which occupational physicians evaluated health risks [Tordoir 1978]. This narrow interpretation of occupational hygiene by occupational medicine is also reflected in texts of the World Health Organisation at that time, suggesting the concepts "environmental monitoring" and "occupational hygiene" to be synonymous [WHO 1973].

However, recent developments have forced occupational health care to shift from a passive health surveillance approach to an active promotion of healthy workplaces. This preventive approach is encouraged by the Dutch administration [Ministerie Sociale Zaken en Werkgelegenheid 1990] and is also the consequence of recent European occupational legislation which sets out the minimum requirements for safety and health at work throughout the European Community. The recent implementation of the framework Directive (89/391/ EEC) and a series of individual Directives (e.g. Directive 89/654/EEC, 90/269/ EEC, 90/270/EEC, 90/394/EEC, 90/679/EEC) in Dutch occupational legislation have lead to an upgrade and improvement of the Arbeidsomstandigheden Wet (Labour Conditions Law). This new "Arbowet", which became completely effective in January 1994 now requires employers to perform a risk evaluation and control program and requires from occupational hygienists a substantial contribution to the development and implementation of specific control measures on different environmental stressors in the workplace. 


\section{STRATEGIES FOR CONTROL OF EXPOSURE: STATE OF THE ART}

Contrary to the knowledge on risk evaluation, systematic expertise on development and implementation of control measures seems scarce [NVVA 1991, Swuste 1992]. Also the propagation of knowledge and expertise on this subject is minimal [Burdorf and Heederik, 1991]. A questionnaire held by the Nederlandse Vereniging voor Arbeidshygiëne (Dutch Occupational Hygiene Society) revealed that less than $20 \%$ of the Dutch occupational hygienists have experience in control measures [Burdorf 1991]. Only $10 \%$ had experience with control measures at the source (elimination and/or reduction). An investigation by the Dutch Labour Inspectorate [Spee et al. 1990] showed the majority $(76 \%)$ of the control measures in industry consisted of the supply of personal protective equipment and the application of industrial ventilation techniques. An important reason for these "end of pipe" measures/advices was the lack of expertise within companies on a systematic approach to control measures. Research in four journals on occupational hygiene (Annals of Occupational Hygiene. American Industrial Hygiene Association Journal, Maandblad voor Arbeidsomstandigheden and Journal of Occupational Medicine) revealed only a few publications on control measures in occupational hygiene. The majority were carried out by research institutes and universities [Swuste et al. 1993, Buring et al. 1990, Kant et al. 1990]. However, since $50 \%$ of the Dutch occupational hygienists work within occupational health services [Burdorf 1991], their workplace surveys are reported to the companies involved, but are rarely published. The number of publications on this subject is therefore no correct measure to describe the state of the art. However, the need for improvement of knowledge and expertise on control measures was recognised by the profession itself and was subject of recent symposia [NVVA 1991, IOHA 1992] Different areas for improvement were identified and concentrated on (i) the development of the control measures, (ii) sharing and exchange of solutions and (iii) the implementation of preventive measures within the company organisation. Recently, in several countries electronic databases were setup to enable an exchange of information on control measures [Swuste and Hale 1993] and strategies for implementation of preveritive measures have been established [Pouwels 1991, Nijenhuis 19911. This text will further concentrate on the development of control measures, which calls for a better description of the "exposure concept" [Noy 1991, Piney et al. 1987].

In environmental sciences a simple exposure concept is used: A source exposes a receptor through a process of emission and dispersion. In this concept the exposure is mainly determined by the source strength (e.g. emission rate) and the environment. Consequently, control measures are focused on the emission (elimination, substitution, containment), the dispersion (ventilation) and the receptor (personal protection equipment). However, emissions in the workplace can be very diverse, and can be influenced substantially by the 
actions of the receptor (work practice, work methods). Therefore a multiplesource concept was developed defining a source as a potential cause of exposure [Buring et al. 1992]. This definition leads to four classes of sources that determine the workers' exposure:

- agents;

- processes or appliances;

- working environment;

- work practices.

In occupational hygiene studies, agents and processes/appliances have always been regarded as sources of exposure. Workers are exposed to these sources either through direct contact, or through emission into the working environment. However in the multiple-source exposure concept the working environment (lay out, ventilation/recirculation) and work practice (methods, personal hygiene, schedules) are not only regarded as parameters that affect the exposure but also as potential sources of exposure. This multiple source concept adds a new perspective to the control of exposure. Since each of these sources may cause and/or affect the workers' exposure, control of exposure can be established for individual sources or a combination of sources. Insight in all the possible control measures, and the subsequent selection of the most efficient measure(s) requires insight in (i) the four source classes (ii) the contribution of each source class to the workers exposure and (iii) the interaction between sources.

\section{OBJECTIVES AND OUTLINE OF THIS THESIS}

As a result of the stepwise approach in occupational hygiene, many surveys are initially designed to evaluate risks. For instance, measuring of occupational exposure levels to check compliance with standards or guidelines. However, these surveys wil not reveal the sources and their contribution to the workers exposure. Results of these surveys therefore can seldom be used to establish efficient control measures. Therefore, surveys that integrate both evaluation and control of health risks may be preferable. The results of such an integrated survey can be used directly to establish control measures. Once control measures are implemented, the same design can be used to study both effect and efficiency of these measures. Moreover, if occupational exposure limits are adjusted, due to new insights, the results of earlier surveys can be used for risk evaluation and establishment of control measures in the new situation. However, to enable both evaluation of control, these surveys must reveal (i) a quantitative insight in exposure and (ii) the sources and their contribution to this exposure (multiple source concept). Such an integrated approach however, wil have consequences for both the sampling strategy and the methodology to be applied. 
The principal objectives of this thesis are:

1. To indicate how current occupational hygiene strategies for risk evaluation can be extended/modified to enable better risk control;

2. To develop methodology (simulation models, hardware) to enable an approach integrating evaluation and control.

These objectives will be approached in several workplace studies and concentrate on different stressors (chemical, physical and ergonomical) (Figure 3). The selection of the stressors studied was mainly determined by common practice (e.g. establishment of an occupational exposure limit, health complaint of workers) and is not discussed in this thesis. Although the multiple-source exposure concept was originally developed for chemical risks this concept was also applied in the control of physical and ergonomic risks.

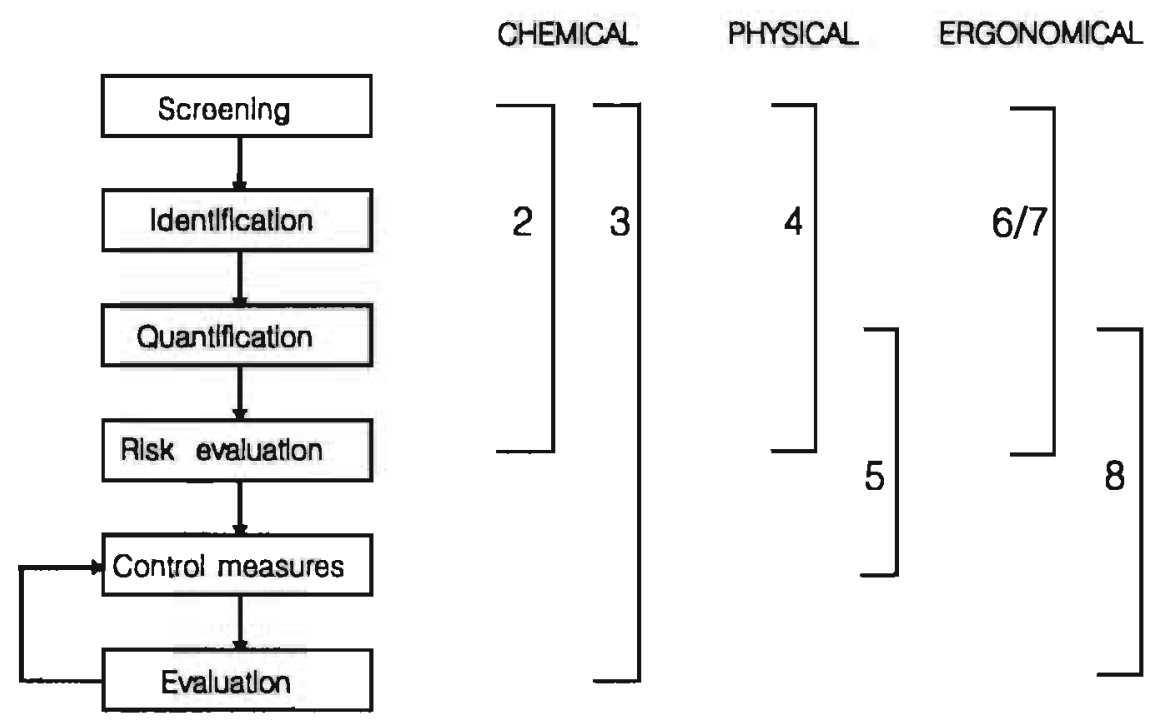

FIGURE 3: Outline of the thesis. The chapters of the thesis idepicted by the numbers) focus on different environmental stressors and different stages in the process of risk evaluation and control.

The first part of this thesis (Chapter 2 and 3) focuses on risk evaluation and control of nitrous oxide $\left(\mathrm{N}_{2} \mathrm{O}\right)$ exposure of operating room personnel. The health effects of occupational exposure to $\mathrm{N}_{2} \mathrm{O}$ are well-known and described in literature [Knill-Jones et al. 1975, Lauwerijs et al. 1981, Reijger 1980] and in many countries an occupational exposure limit for $\mathrm{N}_{2} \mathrm{O}$ has been established [Niosh 1977]. Several techniques have been developed to measure the personal exposure to $\mathrm{N}_{2} \mathrm{O}$ [Whitcher et al. 1977, Sonander et al. 1983, Trevisian 
et al. 1990]. The pollution of operating room air with trace anaesthetic gases have been subject of several studies and revealed environmental exposures exceeding the exposure limit [Gardner 1990, Gray 1988, Eisenkraft 1984, Scheepers and Ruigewaard 1991]. In these studies the mono-source concept was applied and consequently proposed control measures (anaesthetic equipment, scavenging) focused on reduction of emission. However, occupational exposure to $\mathrm{N}_{2} \mathrm{O}$ in operating rooms is not only determined by the emission (equipment, patients) but also by the general ventilation and the percentage recirculation [Whitcher 1980]. A reduction of exposure can therefore be achieved in several ways. In chapter 2 an integrated strategy is described (i) to obtain reliable exposures for different groups of operating room staff, (ii) to identify and quantify the main sources of $\mathrm{N}_{2} \mathrm{O}$ in the operating and recovery rooms and (iii) to establish control measures. The results are used for both risk evaluation and the design of control measures. Chapter 3 describes the development of a simulation model which incorporates emission, ventilation and recirculation of $\mathrm{N}_{2} \mathrm{O}$. This model was used to predict the effect of different control measures and was validated with data obtained after the control measures were implemented.

In the second part of this thesis (Chapter 4 and 5 ) detailed investigations of the evaluation of thermal climate conditions are described. Thermal clinnate conditions can cause discomfort and health effects [Berglund 1979]. However, the health stress cannot be directly measured, but only expressed in terms (e.g. temperature, air velocity) that relate to this stress. Moreover, the perception of thermal climate conditions is affected by acts of the receptor himself, like clothing and activity [Fanger 1972]. Therefore models are applied to evaluate thermal conditions [Malchaire and Mairiaux 1991, Youle et al. 1990]. However, these models differ in the type and number of parameters incorporated. Moreover standards and recommendations for thermal conditions are based on different models. As a consequence, both evaluation and control of thermal comfort may be affected by the model (= source concept) applied. Four current evaluation methods for thermal environment were applied to evaluate the thermal climate in $\mathbf{4 2}$ garages (Chapter 4 ). The results vere compared to the perception of car mechanics to select the best model for both evaluation and control of thermal climate conditions in garages. The more sophisticated models incorporate personal parameters like clothing and metabolic rate. However, following the multiple-source concept there may be more personal parameters that may affect the perception of thermal climate. In Chapter 5 a study on the effect of mental stress on the perception of thermal comfort is described and the consequences for both evaluation and control are discussed. 
The third part of this thesis (Chapter 6-8) focuses on the evaluation and control of postural stress. There are clear indications that postural stress is a major factor in the pathogenesis of musculoskeletal disorders [Chaffin et al. 1984, Corlet 1976, Keyserling 1986, Verbeek 1991]. However, except for handling and lifting of materials [EEC Directive 90/269/EEC 1992] there are no recognised criteria for the evaluation of postural load. Various observation methods have been developed to analyse working postures of which some include criteria for evaluation of the postural load. Comprehensive job analyses have been developed for detailed description [Rohmert 1979, Guelaud 1980]. Many detailed postural analysis methods have been developed for special situations and/or specific tasks; some are best suited to static jobs [Corlett et al. 1979; Aaras et al. 1988], some especially for seated jobs [Cote-Gil and Tunes, 1976], or for repetitive, non-seated jobs [Keyserling 1986], or for lifting and handling activities [NIOSH 1990]. Consequently, control measures usually focus on specific sources [Ringelberg and Halewijn 1989, Opheikens 1991]. However, postural load is, compared to other occupational stressors, strongly affected by the worker himself (work method, work practice). Following the multiple-source concept, work methods, work practice and tasks have to be regarded as sources of exposure (= postural load). Evaluation and control of postural stress therefore require an accurate and reliable description of all work postures and identification of all tasks/work methods associated with poor postures. Based on these criteria the Ovako Working posture Analysing System (OWAS) was selected and applied in two different studies. In Chapter 6 an integrated study design is presented to evaluate the postural load of garage mechanics, to identify the activities which contribute most to this stress and to compare work methods and equipment used which are essential for the risk control. The same study design was applied to study the postural stress of operating room staff (Chapter 7). Since the original OWAS method is not suited for the multiple-source approach, a computerised version of the OWAS method was developed and used in both studies to enable the analysis of tasks, work methods and/or equipment. In Chapter 8 this system and its applications are described.

Finally, in Chapter 9 a general discussion is presented.

\section{REFERENCES}

Berglund LG (1979): Thermal acceptability, ASHRAE transactions II, New York, 825-834. Burdorf L (1991): Beheersmaatregelen in de arbeidshygiëne. Verslag NVVA symposium "Arbeidshygiëne, van werkplekanalyse naar oplossingen", 9-13, NVVA, Den Haag.

Burdorf L., Heederik D (1992): Toekomst van de Arbeidshygiëne in Nederland. Arbeidsom standigheden 67 ; $17-20$.

Buring E (1988): Concept voorlichtingsblad meetstrategie: Enige achtergronden voor een meetstrategie. MT-TNO rapport R88/022a. 
Buring E, Belt van de R, Wal van der JF (1990): Dust control measures in dutch brickworks. Ann Occup Hyg 5; 483-497.

Buringh E, Noy D, Pouwels H. Swuste P (1992): A systematic implementation of control measures for airborne contaminats in workplace air. Staub-Reinhaltung der Luft 52; 347 351.

Chaffin DB, Andersson GBJ (1984): Occupational biomechanics. John Wiley \& Sons, New York.

Corlett EN, Bishop RP (1976): A technique for assessing postural discomfort. Ergonomics 19 (2); 175-182.

Corlett EN, Madely SJ, Manenica I (1979): Posture targetting: a technique for recording working postures. Ergonomics 22; 357-366.

Cote Gil HJ, Tunes E (1976): A technique method for sitting posture. Appl Ergonomics 20 (1): 53-57.

Cralley LJ, Cralley LV (1985): Patty's industrial hygiene and toxicology, Volume III, Theory and Rationale of industrial hygiene practice. John Wiley \& Sons, New York.

EEC European Directive 89/391/EEC (1989): On the introduction of measures to encourage improvements in the health and safety of workers at work. Official Journal of the European Communities, L-183.

EEC European Directive 89/654/EEC (1989): Directive on workplaces. Official Journal of the European Communities, L-393.

EEC European Directive 90/269/EEC (1990): Directive on the manual handling of loads where there is a risk particularly of back injury to workers. Official Journal of the European Communities, L-156.

EEC European Directive 90/270/EEC (1990): Directive on display screen equipment. Official Journal of the European Communities, L-156.

EEC European Directive 90/394/EEC (1990): Directive on carcinogenic substances. Official Journal of the European Communities, L-374

Eisenkraft JB (1984): Operating Room Pollution. Mt Sinai J Med 5; 564-568.

Esmen NA (1982): Mathematical basis for an efficient sampling strategy. In: VA Arple \& BYH Liu (eds): Aerosols in the mining and industrial work environment, volume I. Ann Arbor Science, Ann Arbor; 271-282.

Fanger PO (1972): Thermal comfort. Ana!ysis and applications in environmental engineering. McGraw-Hil, New York.

Fishbein L (1980): Overview of some aspects of quantitative risk assessment. $J$ Toxicol Environ Health 6; 1275-1296.

Gardner RJ (1989): Inhalation anaesthetics-exposure and control: A statistical comparison of personal exposures in operating theatres with and without anaesthetic gas scavenging. Ann Occup Hyg 33; 159-173.

Gerhardsson G (1988): The future of occupational hygiene, an international overview. Ann Occup Hyg 1; 1-19.

Guélaud F et al. (1980): Pour une analyse des conditions de travail ouvrier dans l'enterprise, 3e ed. Colin, Paris.

Gray WM (1988): Occupational exposure to nitrous oxide in four hospitals. Anaesthesia 44; 511-514.

Groot de AD (1961): Methodologie, grondslagen van onderzoek en denken in de gedragswetenschappen, Mouton, 's-Gravenhage.

Hallenbeck WH, Cunningham KM (1986): Quantitative risk assessment for environmental and occupational health. Lewis Publishers Inc, Chelsea, Michigan, USA.

Henschler D (1985): Development of occupational limits in Europe. Ann Am Conf Ind Hyg Vol. 12; 37-40. 
Hernberg S (1992): Introduction to occupational epidemiology. Lewis Publishers Inc, Chelsea, USA.

Hunter D (1978): The diseases of occupations. Hodder and Stoughton, London, United Kingdom.

IOHA (1992): First international scientific conference of the International Occupational Hygiene Association (IOHO) 7-9 december, Brussels, Belgium.

Kant IJ, Borm PJA, Houben G, Rijssen-Moll van M (1990): Beroepsmatige blootstelling aan lachgas in operatiekamers. Tijdschr voor Toegepaste Arbowetenschap 3, $\mathrm{nr} 1$.

Keyserling M (1986): Postural analysis of the trunk and shoulders in simulated real time. Ergonomics 29 (4); 569-583.

Knil-Jones RP, Newman BJ, Spence AA (1975): Anaesthetic practice and pregnancy. Controlled survey of male anaesthetists in the United Kingdom. The Lancet 25; 807-809.

Lauwerys R, Misson CB, Borlee I, Bouckaert A, Lechat MF, Temmerman P (1981): Anaesthetic health hazards among Belgian nursses and Physisians. Int Arch Occup Environ Health 48; 195-203.

Malchaire J, Mairiaux P (1991): Strategy of analysis and interpretation of thermal working conditions. Ann Occup Hyg 3; 261-272.

Mattila M (1989): Improvement in the occupational health programme in a Finnisch construction company by means of systematic workplace investigations of job load and hazard analysis. Am J Ind Med 15; 61-72.

Ministerie Sociale Zaken en Werkgelegenheid (1990): Kabinetsstandpunt naar aanleiding van de interimrapportage van de Tripartiete Werkgroep Volumebeleid Arbeidsongeschiktheidsregelingen, Den Haag.

National MAC Committee: Report of experts (1985): Rapport inzake grenswaarde lachgas. Werkgroep van deskundigen van de Nationale MAC Committee $\{$ Report on exposure limits for nitrous oxide. Working group of experts of the National MAC Committee) Voorburg, The Netherlands.

Nijenhuis E (1991): Een stappenplan voor arbeidshygiënisch onderzoeks-en advieswerk: meer aandacht voor de procedure van aanpak. Verslag NVVA symposium "Arbeidshygiëne, van werkplekanalyse naar oplossingen", 75-81, NVVA, Den Haag.

NIOSH (National Instutute for Occupational Savety and Health) (1977): Criteria for a recommendent standard: occupational exposure to waste anaesthetic gases and vapors. DHEW Publication No. (NIOSH) 70-140, NIOSH, Cincinnati, USA.

NIOSH (National Instutute for Occupational Savety and Health). (1990): Revised work practices guide for manual lifting. Draft document, NIOSH, Cincinnati, USA.

Noy D (199 1): Inzicht in blootstelling. Verslag NVVA symposium "Arbeidshygiëne, van werkplekanalyse naar oplossingen", 75-81, NVVA, Den Haag.

NV'VA (1991): Beheersmaatregelen in de Arbeidshygiëne, tekst van de voordrachten op het symposium "arbeidshygiëne, van werkplekanalyse naar oplossingen", georganiseerd door de Nederlands Vereniging voor Arbeidshygiëne op 1 november 1990 te Amsterdam/A. Burdorf (samenst.). NVVA, Den Haag.

Opheikens A (1991): Oplossingen houdings- en rugbelasting niet per se ingewikkeld. Maandblad voor Arbeidsomstandigheden 11; 715-717.

Piney M, Alesbury RJ, Fletcher B (1987): Controlling airborne contaminants in the workplace. BOHS Technical Guide no. 7, Science Revieuws Limited, Leeds, UK.

Pouwels H (1991): Invoeringsstrategieën. Verslag NVVA symposium "Arbeidshygiëne, van werkplekanalyse naar oplossingen", 35-43, NVVA, Den Haag.

Rejiger VS (1980): Een studie naar de betekenis van luchtverontreiniging met anaesthesiegassen in het operatiekomplex (Consequences of air pollution with anaesthetic gases in operating theatres) PhD Thesis, University of Leiden, De Kempenaer, Oegstgeest, The Netherlands. 
Ricci PF (1985): Principles of health risk assessment. Prentice-Hall Inc, Englewood Cliffs, New Jersey, USA.

Ringelberg JA, Halewijn IMAJ (1989): Tillen van zware lasten, waar zijn de grenzen. Maandblad voor Arbeidsomstandigheden 5; 304-307.

Rohmert W, Landau K (1979): Das Arbeitswissenschaftliche Erhebungsverfahren zur Tatigkeitanalyse. Huber, Stuttgart.

Scheepers P, Ruigewaard P (1991): Het vrijkomen van Lachgas op zes operatie afdelingen: oorzaken en oplossingen. Verslag NVVA sympoșium "Arbeidshygiêne, van werkplekanalyse naar oplossingen", 49-54, NVVA, Den Haag.

Spee T. Swuste P, Burdorf A (1990): Control of occupational exposure to toxic substances. Staub-Reinhaltung der Luft 50; 361-363.

Sonander H, Stenqvist O, Nilsson K (1983): Exposure to trace amounts of nitrous oxide. Evaluation of urinary content monitoring in anaesthetic practice. $\mathrm{Br} \mathrm{J}$ Anaesth $55 ; 1225$ 1229.

Sonander H. Stenqvist O. Nilsson K (1983): Urinary $\mathrm{N}_{2} \mathrm{O}$ as a measure of biologic exposure to nitrous oxide anaesthetic contamination. Ann Occup Hyg 1; 73-79.

Swuste P. Kromhout H, Drown D (1993): Prevention and control of chemical exposures in the rubber manufacturing industry in The Netherlands. Ann Occup Hyg 2; 117-134.

Swuste P. Hale A (1993): Databases on measures to prevent occupational exposure. Ministerie van Sociale Zaken en Werkgelegenheid, S151, Staatsdrukkerij en Uitgeverijbedrijf, Den Haag.

Swuste P, Buringh E (1993): Arbeidshygienische maatregelen zijn vaak triviaal. Arbeidsomstandigheden $67 ; 17-20$.

Trevisian A, Gori GP (1990): Biological monitoring of nitrous oxide exposure in surgical Areas. Am J Ind Med 17; 357-362.

Tordoir WF (1978): Bedrijfsarts en bedrijfshygienist (editorial). TSG 56; 823.

Williams PL。Burson JL. (1985): Industrial Toxicology: Safety and Health Applications in the Workplace. Van Nostrand Reinhold, New York, USA.

Whitcher C, Piziali RL (1977): Monitoring Occupational Exposure to inhalation Anesthetics. Anesth Analg 56; 778-785.

Whitcher C (1980): Methods of Control, edited by EN Cohen, in Anesthetic exposure in the workplace. PSG Publishing Company, Littleton, USA.

Verbeek.JHAM (1991): Arbeidsongeschiktheid op grond van rugklachten en andere aandoeningen van het bewegingsapparaat !Occupational diability as a result of Backpain and other musculoskeletal disorders) PhD thesis, University of Amsterdam, The Netherlands.

WHO (World Health Organisation) (1973): Environmental and health monitoring in occupational health. WHO Technical report series No.55, Geneva.

WHO (World Health Organisation) (1991): The occupational hygienist in Europe; The development of the profession, Copenhagen (WHO Regional office-draft publication).

Youle A, Collins KJ, Crockford GW, Fishman DS, Parsons KC, Sykes J (1990): The Thermal Environment. BOHS Technical Guide no. 8, Science Reviews, Leeds, UK. 


\section{RISK EVALUATION AND CONTROL OF CHEMICAL EXPOSURE: NITROUS OXIDE}





\section{CHAPTER 2}

\section{Monitoring of nitrous oxide in operating rooms: Identification of sources and estimation of occupational exposure*}

\section{ABSTRACT}

In an academic hospital, nitrous oxide $\left(\mathrm{N}_{2} \mathrm{O}\right)$ levels were measured continuously and detailed workplace observations made in three different operating rooms for 18 days. The study was designed (i) to determine the exposure of different categories of staff to nitrous oxide, (ii) to localize and quantify the emissions, and (iii) to establish control measures. Nitrous oxide levels appeared to be highly time and place dependent; all staff, except for surgeons, were exposed to $\mathrm{N}_{2} \mathrm{O}$ levels (8-hour time-weighted average) above 25 parts per million. The most important contributor to total release of $\mathrm{N}_{2} \mathrm{O}$ was the ventilator (about $70 \%$ ), especially during artificial respiration of the patient. Measurement of $\mathrm{N}_{2} \mathrm{O}$ levels after intervention showed a reduction in the area surrounding the ventilator of about $80 \%$, thereby reducing occupational exposure of all staff to below 18 parts per million.

\section{INTRODUCTION}

In The Netherlands, about $5 \%$ of the hospital staff works in operating rooms (ORs) [NZI 1986] and therefore is potentially exposed to volatile anaesthetics like nitrous oxide $\left(\mathrm{N}_{2} \mathrm{O}\right)$ [Beynen et al. 1978], halothane and isoflurane. In March 1987, the Dutch government proposed a threshold limit value (TLV) for nitrous oxide following internationa! standards of $25 \mathrm{ppm}$. However, detailed knowledge of $\mathrm{N}_{2} \mathrm{O}$ exposure in operating theatres is scarce.

Because $\mathrm{N}_{2} \mathrm{O}$ levels in the OR vary widely with time and place [Beynen et al. 1978, Rejger 1980l, stationary area monitoring seems not to be the method of first choice. The variations in $\mathrm{N}_{2} \mathrm{O}$ levels are so great that personal monito-

\footnotetext{
* Modified from: Borm PJA, Kant IJ, Houben G, Rijssen-Moll van M. Henderson PTh.

$\checkmark$ Occup Med 1990:32:1112-1116.
} 
ring of inhaled air with diffusion samplers as done by Gardner [1989] is also probably not adequate. Adsorption tubes cannot be used because sampling pumps are not allowed in the sterile zone [Campbell et al. 1980, Cox et al. 1984]. Furthermore, it appears that $\mathrm{N}_{2} \mathrm{O}$ adsorbs poorly to most well-known adsorbents. Moreover, biomonitoring methods described in volunteer studies [Sonander et al. 1983a, 1983b] have not been validated in workplace conditions.

To circumvent these problems, stationary monitoring using a MIRAN-1 A analyzer was used to screen intensively different zones of a number of ORs during 18 surgical programs (days). Although very time-consuming, this approach made it possible to (i) identify exposure sources, (ii) study place and time dependence of $\mathrm{N}_{2} \mathrm{O}$ levels, (iii) calculate occupational exposure and (iv) relate the environmental exposure to biological monitoring data in urine samples. For calculations in (iii) and (iv), the exposure levels were transformed into personal exposure by a time-place distribution approach. Although the approach of this study is less suitable for a routine check of $\mathrm{N}_{2} \mathrm{O}$ levels, the data generated a strategy for rapid screening of ambient exposure and suggests measures that can be taken to reduce exposure.

\section{MATERIALS AND METHODS}

\section{Workplace description}

The study was carried out in the Academic Hospital of Maastricht, which has an operating room complex with 10 ORs, one recovery room and several additional rooms. Ventilation and air-conditioning systems are separate from those serving the rest of the hospital. Ventilation in all ORs is delivered by the laminar flow system (air-change rate $=17$ to $20 \mathrm{~h}^{-1}$ ), and part of exhausted air is recirculated depending on the outside temperature. All ORs are supplied with scavenging: 9 ORs use a Servo $900 \mathrm{~B}$ ventilator and one room a type C Servo (Siemens). Three operating rooms were selected for our study; one OR used for otorhinolaryngological surgery and two ORs used for general surgery.

\section{Study population and sampling strategy}

Surgeons, anaesthetists, anaesthesia assistants and circulating/instrument nurses are the professional groups active in ORs during the operating program. Each group has specific tasks, most of these tasks confined to specific areas in the OR. Pilot surveys showed that $\mathrm{N}_{2} \mathrm{O}$ levels are highly place and time dependent (Figure 1). 
ZONE 2

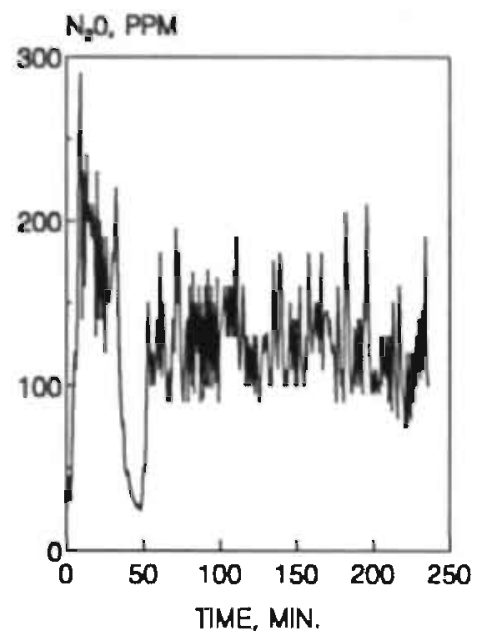

ZONE 3

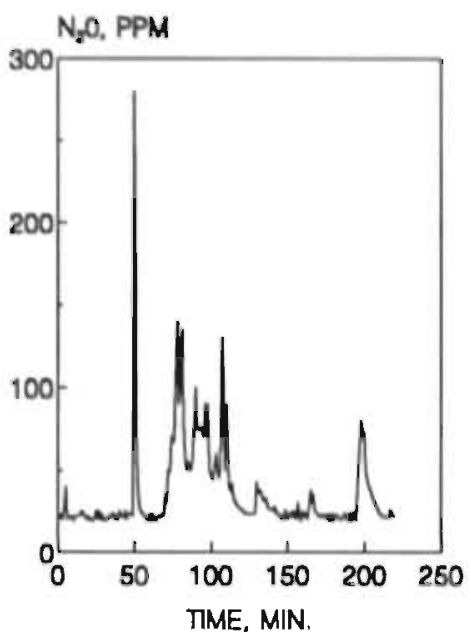

FIGURE 1: Nitrous oxide concentrations vs time for two different zones within one operating room. (For descriptions of zones see legend of Figure 2)

Therefore, a specific environmental monitoring strategy was set up:

- The OR was subdivided into three different zones (see Figure 2):

Zone 1 was an area outside the plenum, yet not close to the ventilator. Circulating nurses worked here. Zone 2 was another area outside the plenum and close to the ventilator. Anaesthetists and assistants worked here. Zone 3 was an area underneath the plenum. During operations, surgeons and instrument nurses worked in this area. In addition, zone 4 was determined as an area with "background" exposure outside the OR.

- A multi-moment analysis during 18 days ( 31 hours observation) revealed the time-zone distribution of each professional group.

- Zone concentrations of $\mathrm{N}_{2} \mathrm{O}$ were determined during a number of complete operating programs, during which operation characteristics and anaesthetic handling were carefully recorded.

- Ventilation and recirculation were measured during the whole study period.

This strategy makes it possibie to interpret data on occupational exposure and zone concentrations, elucidate the relation between zone levels and anaesthetic procedures, and determine the effect of the general ventilating system on $\mathrm{OR}$ and background concentration. 


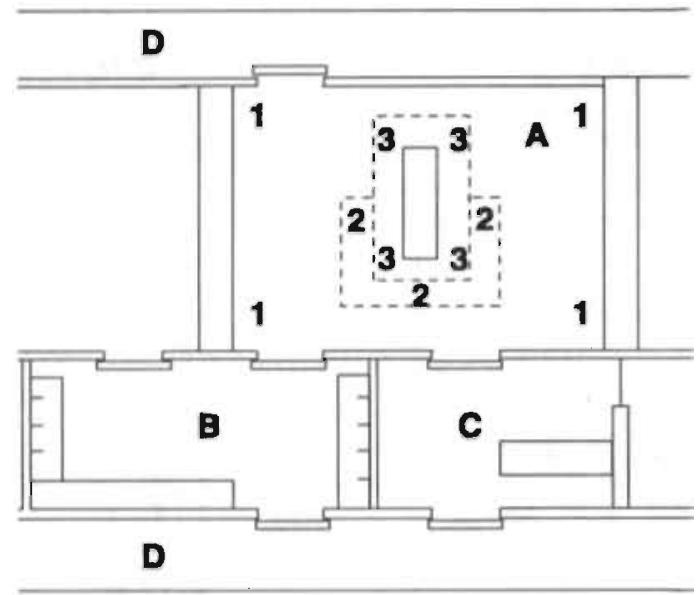

FIGURE 2: Zones in the operating rooms as defined in our monitoring program.

A, operating room; B, washroom; C, induction room; D, corridors.

\section{Monitoring $\mathrm{N}_{2} \mathrm{O}$ exposure}

Stationary monitoring was done using a MIRAN-1A gas analyzer (Foxboro) measuring $\mathrm{N}_{2} \mathrm{O}$ levels at a wavelength of $7.6 \mu \mathrm{m}$ and an optical pathway of $0.7 \mathrm{~m}$. The detection limit is $0.5 \mathrm{ppm}$, and under these conditions, interference with other airborne components is negligible. For instance, $8 \mathrm{ppm}$ halothane ( 1.5 times TLV) results in an extra $2.9 \mathrm{ppm}$ " $\mathrm{N}_{2} \mathrm{O}$ ". The MIRAN was calibrated with a closed pump system injecting different gas volumes of medical nitrous oxide and was decontaminated daily with a chlorohexidine/ethanol solution and equipped with a long suction pipe that, for measurements in zone 1 and 2 , was attached to a stand $1.5 \mathrm{~m}$ high (breathing zone). For measurements in zone 3, the suction pipe was attached to the operating lamp. In each zone, measuring took place during several complete operating days (about 5 hours/ day). The output signal was recorded on a flatbed recorder (Kipp BD40) and at 30-second intervals stored in a computerfile (RECOM, $640 \mathrm{~KB}, \mathrm{AD}$ converter). Additional data for the correct interpretation of the obtained results, e.g., circulation and percentage of recirculation, were also registered.

Biological monitoring was done on spot urine samples collected from workers who had been active in the measuring zone of that day, just before and immediately after work.

Nitrous oxide was determined by gas chromatography within three hours of sampling in the headspace using the method described by Sonander et al. [1983a]. The concentration of $\mathrm{N}_{2} \mathrm{O}$ in urine was determined by the use of the partition coefficient of $\mathrm{N}_{2} \mathrm{O}$ over urine and air $(0.65)$ and the calibration curve for gaseous diluted $\mathrm{N}_{2} \mathrm{O}$. 


\section{RESULTS}

\section{General}

As already mentioned, time- and place dependence of nitrous oxide levels in operating rooms is significant (see Figure 1). The mean time-weighted concentrations of $\mathrm{N}_{2} \mathrm{O}$ in the different zones are listed in Table 1. To compare these data with TLV values, the time-weighted mean of each day was calculated and transformed to 8-hour TWAs, incorporating the background level (zone 4). This shows that TWAs exceed the TLV value in 12 of 18 days $(67 \%)$, in some cases even up to fourfold.

TABLE 1: Mean-time concentrations of nitrous oxide in the zones (Figure 2) of the operating theatres.

\begin{tabular}{ccc}
\hline Zone & $\mathrm{N}_{2} \mathrm{O}$ concentration, ppm & Days of measurement \\
\hline 1 & 41.2 & 8 \\
2 & 99.6 & 6 \\
3 & 32.6 & 4 \\
$4^{*}$ & 15 & \\
\hline
\end{tabular}

*Background concentration

\section{Professional exposure}

Stationary (zone) data were used to calculate "occupational" exposure to $\mathrm{N}_{2} \mathrm{O}$ using the data on times spent in each zone and the mean zone levels, as illustrated in Table 2. The 8-hour TWAs of all professional groups are listed, showing that anaesthesia assistants have the highest exposure to $\mathrm{N}_{2} \mathrm{O}$. The obvious reason is that both level and duration of the exposure are high for these workers. On an 8-hour basis, the surgeons have the lowest exposure. Biological monitoring of the different professional groups showed only weak correlations between environmental exposure (ppm-hour) and urinary excretion of nitrous oxide (Table 3 ). Only for surgeons was there a statistically significant correlation $(R=.61, P<.03)$ between inhaled dose and concentration in post-work urine samples.

\section{Sources of nitrous oxide}

One of the benefits of environmental continuous monitoring is that the concen. tration levels can be related to specific work activities and/or sources. This enabled us to associate levels caused by specific anaesthetic procedures and to calculate the contribution of specific activities to total $\mathrm{N}_{2} \mathrm{O}$ release. Table 4 shows that the highest concentrations are measured while using masks (167 $\mathrm{ppm}$ ); the main source for overall release (and exposure), however, is the artificial respiration of the patient $(72 \%$ of total release). The latter reflects the 
amount of time $(49 \%)$ that artificial respiration is applied during surgical programs. The contribution of masks (without scavenging) is only $7 \%$ to total release.

TABLE 2: Nitrous oxide concentrations by zones, and the estimated exposure (8-hour TWA) for each different profession.

\begin{tabular}{|c|c|c|c|c|c|c|c|}
\hline Zone & Profession & N* & $\begin{array}{l}\mathrm{N}_{2} \mathrm{O} \mathrm{cc} \\
\text { surgice } \\
\text { ppm ir }\end{array}$ & $\begin{array}{l}\text { onc. } \\
\text { al program, } \\
\text { rangel }\end{array}$ & $\begin{array}{l}\text { Time of } \\
\text { program } \\
\text { exposure, } \\
\text { min. }\end{array}$ & $\begin{array}{l}\text { Time of } \\
\text { background } \\
\text { exposure** } \\
\text { min. }\end{array}$ & $\begin{array}{l}\text { Estimated } \\
\text { exposure, } \\
\text { 8-h TWA. } \\
\text { ppm }\end{array}$ \\
\hline 2 & $\begin{array}{l}\text { Anaesthetist } \\
\text { assistants }\end{array}$ & 6 & 99.6 & $(56.9-119.7)$ & 322 & 158 & 71.8 \\
\hline 2 & Anaesthetists & 6 & 99.6 & $(56.9-119.7)$ & 161 & 319 & 43.3 \\
\hline 1 & $\begin{array}{l}\text { Circulating } \\
\text { nurses }\end{array}$ & 4 & 41.2 & $(32.6-54.3)$ & 322 & 158 & 32.6 \\
\hline 3 & $\begin{array}{l}\text { Instrument } \\
\text { nurses }\end{array}$ & 8 & 32.6 & $(9.4-56.5)$ & 322 & 158 & 26.8 \\
\hline 3 & Surgeons & 8 & 32.6 & $(9.4-56.5)$ & 322 & 0 & 22.1 \\
\hline
\end{tabular}

- $N=$ number of surgical programs measured.

" A background concentration of 15 ppm was measured in the operating room complex, because of a partial recirculation of the ventilated air.

TABLE 3: Correlation between environmental exposure to $\mathrm{N}_{2} \mathrm{O}(\mathrm{ppm}$.h) and urinary excretion of $\mathrm{N}_{2} \mathrm{O}$ both after $\log$ transformation.

\begin{tabular}{ll}
\hline Professional group & Correlation coefficient \\
\hline Surgeons & $0.61(P=0.03), N=12$ \\
Circulating/instrument nurses & $0.54(P=0.13), N=8$ \\
Anaesthetists and assistants & $0.57(P=0.11), N=7$ \\
Total group & $0.28(P=0.14), N=27$ \\
\hline
\end{tabular}

\section{Corrective measures}

Based on our findings (Table 4) several measures were proposed to reduce $\mathrm{N}_{2} \mathrm{O}$ emission. It was calculated that these measures (technical improvements of the anaesthetic equipment and consistent use of masks with scavenging) would reduce $\mathrm{N}_{2} \mathrm{O}$ emission to $58 \%$ of the original emission. 
TABLE 4: Duration, concentration and contribution to $\mathrm{N}_{2} \mathrm{O}$ emission of the different anaesthetic activities for an "average" surgical program (derived from observations of 18 surgical programs).

\begin{tabular}{lrrcc}
\hline Activity/source & $\begin{array}{c}\text { Time, } \\
\%\end{array}$ & $\begin{array}{c}\mathrm{N}_{2} \mathrm{O} \text { conc. } \\
\text { TWA, ppm }\end{array}$ & $\begin{array}{c}\text { Contribution } \\
\text { to total } \mathrm{N}_{2} \mathrm{O} \\
\text { emission, \% }\end{array}$ \\
\hline Artificial respiration (tube with scavenging) & 48.9 & 80.3 & 72.1 \\
Spontaneous respiration (tube with scavenging) & 17.0 & 21.1 & 6.6 \\
Spontaneous respiration (mask with scavenging) & 6.0 & 44.2 & 4.9 \\
Spontaneous respiration (mask without scavenging) & 1.9 & 167.6 & 7.1 \\
Patients during intubation, extubation and transport & 16.9 & 30.0 & 9.3 \\
Rebound plenum & 9.3 & 8.2 &. \\
\hline
\end{tabular}

"Rebound immission is already incorporated in the listed values.

\section{Occupational exposure after intervention}

On the basis of our recommendations and calculations, the hospital took the following measures:

- All ventilators (type $900 \mathrm{~B}$ ) were provided with a gas-tight overflow valve leading the surplus of $\mathrm{N}_{2} \mathrm{O}$ directly to the scavenging system.

- A buffer balloon was installed to prevent releases from exhaled air, if respiratory flow exceeds scavenging flow.

- Anaesthetists and their assistants were asked, through an official letter, to avoid extreme overflow of nitrous oxide towards the patients' minute volume.

In fact, the combination of these measures was estimated to achieve a $58 \%$ reduction in $\mathrm{N}_{2} \mathrm{O}$ emission (see Table 4). Measurements were carried out one year after the first study, and six months after these measures had become common practice. Exposure was only assessed in zone 2, as a worst-case. approach, because in this zone the exposure was higher than in other zones. The mean time-weighted concentration of $\mathrm{N}_{2} \mathrm{O}$ during the surgical program in zone 2 was reduced from 99.6 to $20.3 \mathrm{ppm}$ (80\% reduction).

The reduced release into zone 2 can be used to estimate the "new" occupaticnal exposure of staff in zone 2, and other zones, as shown in Table 5. For staff working in zone 2, occupational exposure was derived via the same approach as done in Table 2. For anaesthetist assistants, this, leads to an 8hour TWA of $18 \mathrm{ppm}$. We previously showed that the exposure of this group is higher than other staff, and therefore set this occupational exposure as the maximum for other staff ( $\leq 18 \mathrm{ppm}$, Table 5). 
TABLE 5: Reduction in exposure to $\mathrm{N}_{2} \mathrm{O}$ in zone 2 (surgical program) and occupational exposure ( 8 -h TWA) before and after intervention.

\begin{tabular}{lccc}
\hline & $\begin{array}{c}\text { Before, } \\
\text { ppm }\end{array}$ & $\begin{array}{c}\text { After, } \\
\text { ppm }\end{array}$ & $\begin{array}{c}\text { Reduction, } \\
\%\end{array}$ \\
\hline Zone 2 & 99.6 & 20.3 & 80 \\
\hline Anaesthetist assistants & 71.8 & 18.0 & 75 \\
Anaesthetists & 43.3 & 15.7 & 64 \\
Circulating nurses & 32.6 & $\varangle 18.0$ & $>45$ \\
Instrument nurses & 26.8 & $\varangle 18.0$ & $>33$ \\
Surgeons & 22.1 & $<18.0$ & $>19$ \\
\hline
\end{tabular}

\section{DISCUSSION}

Nitrous oxide levels in ORs have been reported in many studies. However, most data have been obtained by spot sampling and diffusion samplers and give little information about 8-hour TWA exposure. We showed that $\mathrm{N}_{2} \mathrm{O}$ levels in ORs vary considerably with both time and place, but that exposure assessment can be achieved by an elaborate stationary monitoring and workplace observation program. Our data show considerable differences in the exposure of professional groups; all groups, except the surgeons, were exposed to $\mathrm{N}_{2} \mathrm{O}$ levels (8-hour TWA) above the TLV (25 ppm). Interestingly, the mean exposure of anaesthetists, surgeons and other staff are comparable with the data of Gardner [1989] (71, 50, and $24 \mathrm{ppm}$, respectively) in scavenged theatres using diffusive samplers. Still, from the 20 scavenged theatres in the UK stu$d y$, only six theatres had ventilation rates exceeding 15 . These data indicate that using diffusive badges to monitor $\mathrm{N}_{2} \mathrm{O}$ levels in operating theatres might underestimate exposure seriously.

The poor correlation between exposure and urinary excretion is probably caused by the fact that rapidly (within 10 seconds) fluctuating exposure levels are not reflected in nitrous oxide levels of the urinary spot samples. On the other hand, the discrepancy between the environmental (ambient air) and biological monitoring (urine) data may be due to substantial differences between persons in the rate of uptake, distribution volumes, excretion of nitrous oxide, and environmental exposure.

A major finding of this study is that $\mathrm{N}_{2} \mathrm{O}$ levels are related to specific procedures and sources. Leakages from the anaesthetic apparatus (during artificial respiration) appeared to be the main source of occupational exposure. Leakage from masks and tubes, although causing high peaks, has only a minor contribution to overall exposure. 
After intervention, the exposure of all staff was decreased to TWAs below $25 \mathrm{ppm}$. Implicitly, this means that exposure to halothane or isoflurane does not exceed recommended levels. Typical concentrations of haloalkanes are between 1 and 3 vol\% (based on the $\mathrm{N}_{2} \mathrm{O} / \mathrm{O}_{2}$ mixture). Maximal use of haloalkane agents at $3 \mathrm{vol} \%$ leads to a $\mathrm{N}_{2} \mathrm{O}$ :haloalkane ratio of 20:1. From this it can be deduced that isoflorane exposure will not exceed $1 \mathrm{ppm}$ when this agent is used at the maximal level. The approach of this study seems less suitable for a regular check of (occupational) exposure to $\mathrm{N}_{2} \mathrm{O}$ in operating theatres. However, our strategy (if valid) might be used for rapid screening: sampling in zone 2 would immediately reveal the extremes of ambient exposure. We hope that this study stimulates others in this field to use a structural approach of nitrous oxide exposure in health care.

As everyone is aware, exposure to volatile anaesthetics is not the only occupational risk to which staff is exposed. Prolonged static load, work stress, viral contamination, and climate conditions are workplace factors that must be seriously addressed. In the long run, optimal working conditions for OR staff are a benefit for both patient and hospital management.

\section{REFERENCES}

Beynen FJ, Knopp TH, Rehder K (1978): Nitrous oxide exposure in the operating room. Anaesth Anal 53; 216-233.

Campbell D, Davies PD, Halliday MM, Mac Donald I (1980): Comparison of personal pollution monitoring techniques for use in the operating room. Br J Anaesth 52:885-892.

Cox PC, Brown RH (1984): A personal sampling method for the determination of nitrous oxide exposure. Am !nd Hyg Assoc J 45; 345-350.

Gardner RJ (1989): Inhalation anaesthetics-exposure and control: a statistical comparison of personal exposures in operating theatres with and without anaesthetic gas scavenging. Ann Occup Hyg 33; 159.173.

NZI (Nationaal Ziekenhuis Instituut) (1986): Statistiek personeelssterkte 1985; Algemene ziekenhuizen, landelijke tabellen (86.490). NZI, Utrecht, The Netherlands.

Rejger VS (1980): Een studie naar de betekenis van luchtverontreiniging met anaesthesie gassen in het operatiekomplex. PhD thesis, RU Leiden, de Kempenaer, Oegstgeest, The Netherlands.

Sonander $\mathrm{H}$, Stenquist $\mathrm{O}$, Nilson $\mathrm{K}$ (1983a): Urinary $\mathrm{N}_{2} \mathrm{O}$ as a measure of biological exposure to nitrous oxide anaesthetic contamination. Ann Occup Hyg 27; 73-79.

Sonander H. Stenqvist O. Nilson K (1983b): Exposure to trace amounts of nitrous oxide. Br J Anaesth 55; 1225-1229. 



\section{CHAPTER 3}

\section{Simulation of nitrous oxide concentrations in operating and recovery rooms*}

\section{ABSTRACT}

A model was developed to predict nitrous oxide $\left(\mathrm{N}_{2} \mathrm{O}\right)$ concentrations in operating $(O R)$ and recovery rooms. The model incorporates general ventilation characteristics, percentage recirculation and the rate at which $\mathrm{N}_{2} \mathrm{O}$ is emitted into the OR (emission) for the calculation of environmental exposure. A workplace study was carried out during which $\mathrm{N}_{2} \mathrm{O}$ concentrations were measured continuously and coupled to anaesthetic activities (type and duration), air-change rate and percentage of recirculated air. The data from this study were used to calculate $\mathrm{N}_{2} \mathrm{O}$ emission.

Subsequently, the model was used to predict the effect of technical measures to reduce emissions on mean environmental exposures. After implementation of the control measures an intervention study was made to check whether the reduction in exposure was predicted by our simulation model. Subsequently the "validated" simulation model was used: (i) to calculate the exposure for different percentages of recirculation and different air-change rates, and (ii) to estimate $\mathrm{N}_{2} \mathrm{O}$ levels in another situation, i.e. an operating room in an outpatients clinic.

In short, our study shows how modelling can help both occupational hygiene and hospital management to control exposure to anaesthetic gases and to design or adapt ventilation systems of operating rooms and recovery rooms.

INTRODUCTION

Operating theatre staff are exposed to various anaesthetic gases and vapours [Beynen et al. 1978, Rejger 1980, Sonander et al. 1983]. One of the most widely used agents is nitrous oxide $\left(\mathrm{N}_{2} \mathrm{O}\right)$ which is associated with potential

- Kant IJ, Rijssen-Mol van M, Borm PJA. Ann Occup Hyg 1990;34:575-583. 
reprotoxic effects [Tannenbaum and Goldberg 1985] and with a reduction in some aspects of mental function [NIOSH 1977, Rice 1983]. Based on an update of health effects the Dutch government proposed an accepted exposure limit (MAC) for $\mathrm{N}_{2} \mathrm{O}$ of $25 \mathrm{ppm}$ [National MAC Committee 1985]. This raised a (national) interest in assessing the exposure of operating theatre staff to $\mathrm{N}_{2} \mathrm{O}$ and the efficacy of methods of prevention and control, and recent studies in The Netherlands and the UK [Borm et al. 1989, Gardner 1989] show that the average exposure of operating room personnel to $\mathrm{N}_{2} \mathrm{O}$ often exceeds the exposure limit.

Exposure to $\mathrm{N}_{2} \mathrm{O}$ in operating rooms is determined by the rate at which $\mathrm{N}_{2} \mathrm{O}$ is emitted (emission), by the general ventilation and by the percentage of recirculation, and consequently the reduction of exposure to $\mathrm{N}_{2} \mathrm{O}$ can be achieved in several ways. An understanding of the processes of emission and of ventilation is therefore crucial.

Whitcher described an equation to predict the average equilibrium concentrations of waste anaesthetic gases in operating theatres under various ventilation conditions [Whitcher and Pizialy 1977, Whitcher 1980], but his approach requires detailed data on the emission of the anaesthetic gases which are unfortunately not available for most operating rooms. This study provides a simulation model which requires workplace-related data to calculate total emission. The model can subsequently be used to predict $\mathrm{N}_{2} \mathrm{O}$ concentrations in operating and recovery rooms under various conditions. Finally we present some examples showing how to apply this model as a tool for prevention and control of exposure to gaseous anaesthetics.

\section{DEVELOPMENT OF SIMULATION MODEL}

\section{Model parameters}

In an operating room (OR) $\mathrm{N}_{2} \mathrm{O}$ can be released (i) by leakages of equipment (ventilators), (ii) by leakages of endotracheal tubes or masks during respiration and (iii) in the air exhaled by patients during in- and extubation and during transport. In the recovery room $\mathrm{N}_{2} \mathrm{O}$ is released into the environment in the patients ${ }^{\prime}$ exhaled air. These sources determine the $\mathrm{N}_{2} \mathrm{O}$ emission. However, occupational exposure to $\mathrm{N}_{2} \mathrm{O}$ in operating rooms is determined not only by the total emission but also by the general ventilation (volume of the OR, airchange rate) and the percentage of recirculation. The model and its parameters are shown schematically in Figure 1.

Mathematically, the quantity of $\mathrm{N}_{2} \mathrm{O}(\mathrm{A})$ that enters the OR per unit of time $(\mathrm{dA} / \mathrm{dt}$ ) can be described as the difference between total emission (1), plus the quantity recirculated, and the amount which is eliminated by ventilation: 


$$
\frac{d A}{d t}=(I+X \times Q \times C)-Q \times C
$$

in which:

$A=$ the quantity of $\mathrm{N}_{2} \mathrm{O}(\mathrm{mg})$

$\mathrm{Q}=$ air flow in and out the OR $\left(\mathrm{m}^{3} \cdot \mathrm{h}^{-1}\right)$

$\mathrm{I}=$ emission; rate at which non-recirculated $\mathrm{N}_{2} \mathrm{O}$ is released in the OR (mg. $\left.\mathrm{h}^{-1}\right)$

$\mathrm{X}=$ fraction of the ventilated air which is recirculated

$C=$ concentration of $\mathrm{N}_{2} \mathrm{O}$ in the air $\left(\mathrm{mg} \cdot \mathrm{m}^{-3}\right)$, assuming a well-stirred model

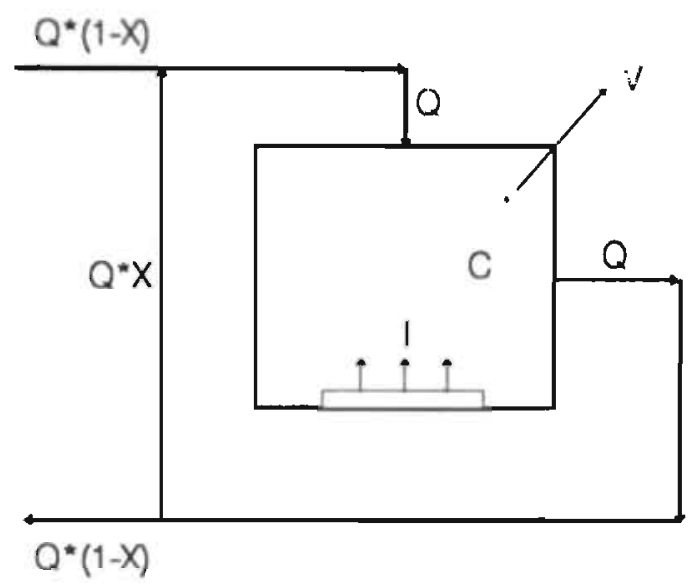

FIGURE 1: Elements of the simulation model. Air is ventilated by laminar flow (Q). A fraction $(X)$ of the ventilated air is recirculated. Nitrous oxide concentration (C) at the air outlet (well-mixed air) is the result of emission (I) and the inflow of nitrous oxide by recirculation $(\mathrm{Q} \times \mathrm{X})$.

If we substitute $A=V \times C\left(V=\right.$ the volume of the whole system in $\left.\mathrm{m}^{3}\right)$ then Equation (1) becomes:

$$
\frac{V \cdot d C}{d t}=1-Q \times C(1-X)
$$

Equation (2) is the basis of the simulation model that was incorporated into a PC using the TUTSIM-program (Technical University Twente, The Netherlands). This model is based on the assumptions that $I$ and $X$ are constant and that there is instantaneously and complete mixing of $\mathrm{N}_{2} \mathrm{O}$ throughout the OR, 
in other words that it is a "well-stirred model" [Kuang-Hui and Ness van 1974]. Moreover, the calculated concentrations are only valid for a system at equilibrium. At high X-and/or low Q-values this steady-state is reached only after several hours.

\section{Model input data (workplace study)}

In order to get input data for the simulation model, measurements were carried out in the University Hospital of Maastricht, The Netherlands. The operating room complex consisted of 10 ORs, in all of which there were scavenging systems, and one recovery room. All ORs and recovery rooms were connected to the same independent air conditioning unit. The ORs were ventilated on the laminar flow principle, air being supplied through a plenum above the operating table and removed through grates in one of the side walls (air-change rate $17 \mathrm{~h}^{-1}$ ). Up to $70 \%$ of this extracted air could be recirculated, the proportion depending on outside temperature. Owing to this (partial) recirculation gaseous air contaminants were also recirculated. Therefore the air supplied to ORs and recovery could contain $\mathrm{N}_{2} \mathrm{O}$.

A MIRAN-1A gas analyser (Foxboro) was used to measure $\mathrm{N}_{2} \mathrm{O}$ concentrations. The wavelength was set at $7.6 \mu \mathrm{m}$ and the optical pathway used was $0.75 \mathrm{~m}$. The detection limit under these conditions is $0.5 \mathrm{ppm}$ and interference by other gases or vapours is negligible. For instance, $8 \mathrm{ppm}$ halothane $(1.5 \times$ TLV $)$ would register as an extra $2.9 \mathrm{ppm}$ " $\mathrm{N}_{2} \mathrm{O}$ ". The MIRAN was calibrated with a closed-loop pump system injecting different gas volumes of medical $\mathrm{N}_{2} \mathrm{O}$ (Hoekloos, $\mathrm{N}_{2} \mathrm{O}=99.9$ vol\%, $\mathrm{H}_{2} \mathrm{O}=100 \mathrm{ppm}$ ). Under these conditions the concentration of $\mathrm{N}_{2} \mathrm{O}$ can be calculated from:

$$
\mathrm{N}_{2} \mathrm{O}(\mathrm{ppm})=178.54 \times \text { volts }-4.0\left(\mathrm{R}^{2}=0.97\right)
$$

The output signal was reported on a flatbed recorder (Kipp BD40) and also stored at $15 \mathrm{~s}$ intervals in a computer file (RECOM, AD converter). $\mathrm{N}_{2} \mathrm{O}$ was measured continuously and detailed workplace observations were done during 18 days in three different operating rooms. Since pilot experiments showed that $\mathrm{N}_{2} \mathrm{O}$ concentrations are highly dependent on the location of the samples, a specific monitoring strategy was used:

- the OR was subdivided into three different areas (zones) (Figure 2); an additional zone with "background" exposure (outside the OR) was distinguished;

- zone concentrations of $\mathrm{N}_{2} \mathrm{O}$ were determined during a number of complete operating programmes, during which the way that the anaesthetic was used was carefully recorded; and

- ventilation and recirculation were measured throughout the study period. 
This strategy made it possible to interpret zone concentrations and to elucidate the relation between zone concentrations and anaesthetic handlings [Borm et al. 1989]. The average $\mathrm{N}_{2} \mathrm{O}$ concentrations for the different zones are given in Table 1. During the study the average recirculation was $20 \%$.

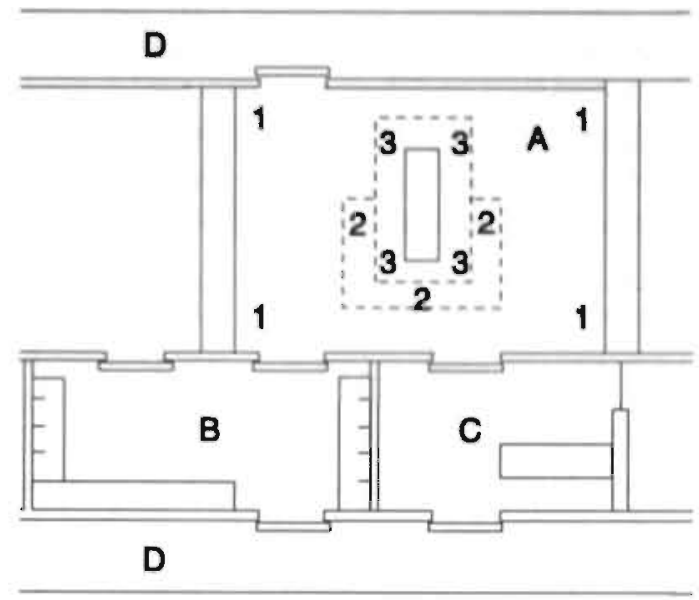

FIGURE 2: The zones in the operating rooms as defined in our monitoring programme: (A) Operating room; (B) scrub room; (C) anaesthetic room; and (D) corridors.

Zone 1: Area outside the plenurn, but not close to the ventilator. The circulating nurses work in this area.

Zone 2; Area outside the plenum, close to the ventilator. The anaesthetists and assistants work in this area.

Zone 3; Area underneath the plenum. During the operations surgeon(s) and instrumentation nurses work in this area.

Zone 4; Outside the operating theatre, but inside the operating room-complex (e.g. corridors, lunchroom, supplies).

TABLE 1: Mean time-weighted concentrations of nitrous oxide in the zones (Figure 2) of the operating rooms during use (situation before intervention),

\begin{tabular}{lccc}
\hline Zone & $\begin{array}{c}\mathrm{N}_{2} \mathrm{O} \text { concentration } \\
\mathrm{ppm}\end{array}$ & Days of measurement & $\begin{array}{c}\mathrm{N}_{2} \mathrm{O} \text { concentration * } \\
\mathrm{ppm}\end{array}$ \\
\hline 1 (well mixed air) & 41.2 & 8 & 43.9 \\
2 & 99.6 & 6 & 81.3 \\
3 & 32.6 & 4 & 36.5 \\
$4^{*}$ & 15 & & \\
\hline
\end{tabular}

* These data are corrected for the time distribution of an average surgical programme.

* Concentration caused by continuous partial recirculation of the exhausted air. 
Table 2 shows the contribution of each source to total $\mathrm{N}_{2} \mathrm{O}$ emission. Based on this work several measures were proposed to reduce $\mathrm{N}_{2} \mathrm{O}$ emission. It was calculated that these measures (technical improvements of the anaesthetic equipment and consistent use of masks with scavenging) would reduce $\mathrm{N}_{2} \mathrm{O}$ emission to $58 \%$ of the original.

TABLE 2: Duration, concentration and contribution to the emission of $\mathrm{N}_{2} \mathrm{O}$ of the different anaesthetic activities for zone 1 during an "average" surgical programme (derived from measurements and observations of 18 surgical programmes).

\begin{tabular}{|c|c|c|c|}
\hline Activity/source & $\begin{array}{c}\text { Time, } \\
\%\end{array}$ & $\begin{array}{l}\mathrm{N}_{2} \mathrm{O} \text { conc. } \\
\text { TWA, ppm }\end{array}$ & $\begin{array}{l}\text { Contribution } \\
\text { to total } \mathrm{N}_{2} \mathrm{O} \\
\text { emission, } \%\end{array}$ \\
\hline Artificial respiration (tube with scavenging) & 48.9 & 56.4 & 66.2 \\
\hline Spontaneous respiration (tube with scavenging) & 17.0 & 27.3 & 11.1 \\
\hline Spontaneous respiration (mask with scavenging) & 6.0 & 29.3 & 4.2 \\
\hline Spontaneous respiration (mask without scavenging) & 1.9 & 219.9 & 9.5 \\
\hline Patients during intubation, extubation and transport & 16.9 & 22.2 & 9.0 \\
\hline Rebound plenum * & 9.3 & 8.2 & $-*$ \\
\hline
\end{tabular}

- Contributions were calculated by dividing the time $x$ concentration multiplication of each source by the sum of all contributions, excluding the rebound from the plenum;

$$
\text { Contribution Act }=\frac{T_{i} \times C_{i}}{\sum_{i=1}^{i=5} T_{i} \times C_{i}}
$$

* Contribution of the $\mathrm{N}_{2} \mathrm{O}$ inflow through plenum is incorporated in the other values listed.

Measurements were repeated 1 year after the first study and 6 months after the improved methods became common practice. $\mathrm{N}_{2} \mathrm{O}$ concentrations were assessed in zones 1 and 2 and in the air-inlet. During the second period the recirculation averaged about $10 \%$. The mean $\mathrm{N}_{2} \mathrm{O}$ concentration in zone 1 was $20.4 \mathrm{ppm}$ (C out) and $12.3 \mathrm{ppm}$ was detected at the air inlet ( $\mathrm{C}$ in). The data obtained after implementation of the control measures were used to validate the simulation model. 


\section{COMPARISON OF REAL AND SIMULATED $\mathrm{N}_{2} \mathrm{O}$ CONCENTRATIONS (VALIDATION OF THE MODEL)}

\section{Situation before intervention}

To calculate the emission of $\mathrm{N}_{2} \mathrm{O}$ before intervention took place, the data from the workplace study were used as input parameters for the model. The "wellmixed" concentration $(\mathrm{C})$ was assumed to be average $\mathrm{N}_{2} \mathrm{O}$ concentration of zone $1(43.9 \mathrm{ppm})\left(\mathrm{V}=20 \mathrm{~m}^{3}, \mathrm{Q}=2040 \mathrm{~m}^{3} \cdot \mathrm{h}^{-1}, \mathrm{X}=0.2\right)$. Total emission

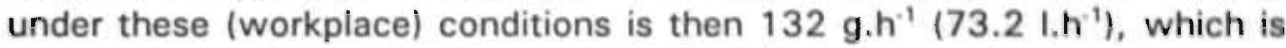
about $24 \%$ of the total $\mathrm{N}_{2} \mathrm{O}$ supply $\left(310 \mathrm{I}^{\mathrm{I}} \mathrm{h}^{-1}\right.$ ) during surgical programmes. The simulated $\mathrm{N}_{2} \mathrm{O}$ concentration at the air inlet (plenum) using the calculated emission is then $8.8 \mathrm{ppm}$, which is the same as the measured value (Table 2).

\section{Situation after intervention}

To validate the model we simulated the $\mathrm{N}_{2} \mathrm{O}$ concentration for the situation after intervention and compared this concentration with the (real) value measured after intervention. For the emission $76 \mathrm{~g} \cdot \mathrm{h}^{-1}$ was substituted, which is $58 \%$ of the original emission. Under these conditions $\left(V=120 \mathrm{~m}^{3}, \mathrm{Q}=2040\right.$ $\left.\mathrm{m}^{3} \cdot \mathrm{h}^{-1}, \mathrm{X}=0.1\right)$ the $\mathrm{N}_{2} \mathrm{O}$ concentration at the outlet $(\mathrm{C})$ was calculated to be $22.5 \mathrm{ppm}$. The mean measured $\mathrm{N}_{2} \mathrm{O}$ concentration in zone 1 after intervention was $20.4 \mathrm{ppm}$. However, during these measurements the distribution over the anaesthetic activities slightly differed from the distribution before intervention. We therefore corrected the mean measured concentration by using the distribution previously found (Table 2) and the concentrations measured during the different anaesthetic activities after intervention (specific data not shown). After this correction the real $\mathrm{N}_{2} \mathrm{O}$ concentration becomes $21.4 \mathrm{ppm}$, which is about the same as the predicted concentration (22.5 ppm) using the simulation model.

\section{APPLICATION OF THE SIMULATION MODEL}

$\mathrm{N}_{2} \mathrm{O}$ concentrations in the OR at different emissions and ventilation conditions The model was used to simulate the effect on mean environmental exposure to $\mathrm{N}_{2} \mathrm{O}$ of different percentages of recirculation and different emission of $\mathrm{N}_{2} \mathrm{O}$ (volume $120 \mathrm{~m}^{3}$, air-change rate $17 \mathrm{~h}^{-1}$ ). The results are shown in Figure 3a.

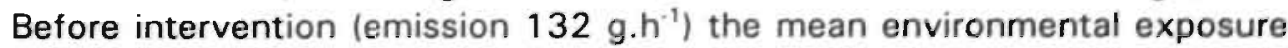
exceeded the MAC, even when $100 \%$ fresh air was supplied (no recirculation). After intervention the exposure to $\mathrm{N}_{2} \mathrm{O}$ will exceed the MAC only when more than $20 \%$ of the operating room air is recirculated. However, the mean duration of the operating programmes in the hospital studied was about $5 \mathrm{~h}$. In this case higher average percentage recirculation is permissible but it must not exceed $50 \%$. 
In a similar way we simulated the effect of different air-change rates on environmental exposure to $\mathrm{N}_{2} \mathrm{O}$ for the situation after intervention. The results are shown in Figure $3 \mathrm{~b}$, and show that the average (steady-state) exposure is inversely related to the air-change rate.

A

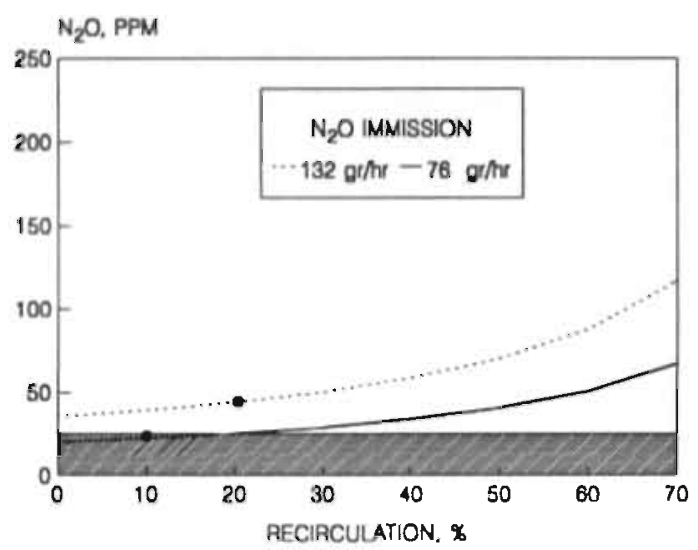

B

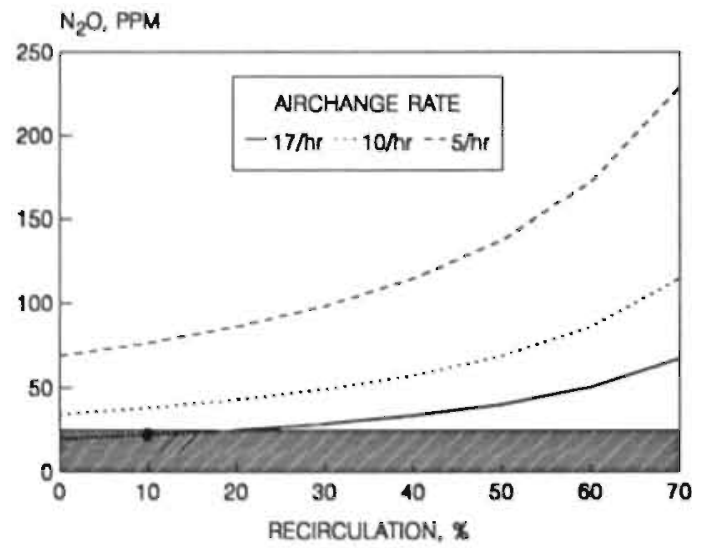

FIGURE 3

A: Effect of ventilated air on the mean $\mathrm{N}_{2} \mathrm{O}$ concentration in zone 1 of an OR $\left(V=120 \mathrm{~m}^{3}\right.$ air-change rate $\left.=17 \mathrm{~h}^{-1}\right)$ before (emission $\left.132 \mathrm{~g} \cdot \mathrm{h}^{-1}\right)$ and after intervention (emission $76 \mathrm{~g} \cdot \mathrm{h}^{-1}$ ).

B: Effect of recirculation of ventilated air on the mean $\mathrm{N}_{2} \mathrm{O}$ concentration in zone $1 \mathrm{in}$ an $\mathrm{OR}$ after intervention ( $\mathrm{V}=120 \mathrm{~m}^{3}$, emission $=76 \mathrm{~g} \cdot \mathrm{h}^{-1}$ ) at different airchange rates.

The results of real tests (depicted by the symbol $\bullet$ ) were used as input data to simulate the effect of the different parameters on the mean $\mathrm{N}_{2} \mathrm{O}$ concentration. The shaded area indicates when compliance with the MAC (25 ppm) is attained. 


\section{$\mathrm{N}_{2} \mathrm{O}$ concentrations in the recovery room}

In this study we found the recovery room to be connected to the same ventilation system as the operating rooms, so that the air supply to the recovery room may also contain $\mathrm{N}_{2} \mathrm{O}$. The $\mathrm{N}_{2} \mathrm{O}$ concentration of the air supplied is the same as the inlet concentration supplied to the ORs and depends on the percentage recirculation. During the workplace study an average $\mathrm{N}_{2} \mathrm{O}$ concentration of $26 \mathrm{ppm}$ was measured within the recovery room. The contribution of the air exhaled by patients was about $35 \%(9 \mathrm{ppm})$; the contribution of the air supply was about $65 \%$ (17 ppm). If the MAC value of $25 \mathrm{ppm}$ is not to be exceeded, the concentration of $\mathrm{N}_{2} \mathrm{O}$ in the air supplied must be less than $16 \mathrm{ppm}$. We used the simulation model to calculate which conditions of the air recirculation would meet this limit. Figure 4 shows that if the percentage recirculation does not exceed $45 \%$ the concentration of $\mathrm{N}_{2} \mathrm{O}$ in the air supplied to the recovery room will be less than $16 \mathrm{ppm}$.

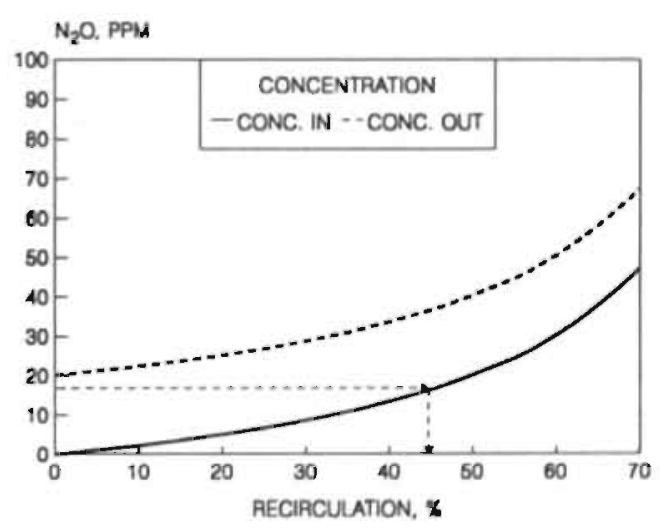

FIGURE 4: Effect of recirculation of ventilated air on the mean $\mathrm{N}_{2} \mathrm{O}$ concentrations at the inlet and outlet of an OR $\left(V=120 \mathrm{~m}^{3}\right.$, air-change rate $17 \mathrm{~h}^{-1}$, emis: sion $=76 \mathrm{~g} \cdot \mathrm{h}^{-1} \mathrm{l}$. Results were obtained with a simulation approach as described in the text. The dotted line shows the percentage recirculation to achieve compliance with the MAC in the recovery $\left(\mathrm{N}_{2} \mathrm{O}\right.$ concentration at the inlet $\left.16 \mathrm{ppm}\right)$.

Simulation of $\mathrm{N}_{2} \mathrm{O}$ concentrations in ORs in the outpatient clinic The simulation model was used to estimate $\mathrm{N}_{2} \mathrm{O}$ concentrations for another hospital workplace, an OR in the outpatient clinic of the same hospital. This room was smaller $\left(\mathrm{V}=56 \mathrm{~m}^{3}\right)$ than the ORs already studied, and there was, no recirculation $(X=0)$ : the air-change rate was the same $\left(17 \mathrm{~h}^{-1}\right)$, corresponding to an airflow (Q) of $952 \mathrm{~m}^{3} \cdot \mathrm{h}^{-1}$. In this OR small operations (e.g. tonsillectomy), in which patients were usually breathing spontaneously, predominated. 
In contrast to the ORs already studied no scavenging was applied and only mask anaesthesia was used.

We estimated that during an average surgical programme:

- $35 \%$ of the time was spent on surgery with mask anaesthesia and patients breathing spontaneously;

- $35 \%$ of the time was spent on in- and extubation and patient transport; and

- for $30 \%$ of the time no anaesthetics activities took place.

In order to calculate the emission of $\mathrm{N}_{2} \mathrm{O}$ detailed knowledge of $\mathrm{N}_{2} \mathrm{O}$ sources is essential. Since we had no actual data for this OR we extrapolated data from the ORs already studied to this workplace.

Simulation revealed that the emission of $\mathrm{N}_{2} \mathrm{O}$ during this operating programme would be $261.2 \mathrm{~g} \cdot \mathrm{h}^{-1}$. Simulation also revealed that when such a programme was to be carried out in the OR of the outpatient clinic $\| 1=261.2 \mathrm{~g} \cdot \mathrm{h}^{\circ 1}, \mathrm{~V}$ $=56 \mathrm{~m}^{3}, \mathrm{Q}=952 \mathrm{~m}^{3} \cdot \mathrm{h}^{-1}, \mathrm{X}=0$ ) the $\mathrm{N}_{2} \mathrm{O}$ concentration would be $149 \mathrm{ppm}$. Finally, the $\mathrm{N}_{2} \mathrm{O}$ concentration was simulated when during the programme mask anaesthesia with scavenging would be applied. Under these conditions the emission would be $61.5 \mathrm{~g} \cdot \mathrm{h}^{\circ 1}$ and the mean $\mathrm{N}_{2} \mathrm{O}$ concentration $35 \mathrm{ppm}$.

\section{DISCUSSION}

Measures to reduce the exposure to anaesthetic gases in operating rooms can relate to total $\mathrm{N}_{2} \mathrm{O}$ emission, air-change rate and percentage recirculation; insight into their interaction is crucial for efficient reduction of exposure. Several authors previously developed models or mathematical equations to describe the resultant effect of this interaction on environmental exposure to gaseous anaesthetics. We too have developed a model for this purpose but have validated its predictions by workplace (intervention) studies. Like all models it is based on several assumptions. One of these assumptions is that the emitted $\mathrm{N}_{2} \mathrm{O}$ is mixed instantaneously and complete over the entire OR (well-stirred model). Because of the laminar flow this assumption is certainly not valid; we therefore used the concentration of air leaving the OR (which is similar to that in zone 1) as the model "well-mixed air" concentration. Our data show however that the quantitative estimate of occupational exposure of personnel working in zone 1 (circulating nurses) is close to the measured values.

The model was used to predict the efficiency of control measures to reduce exposure to $\mathrm{N}_{2} \mathrm{O}$. Of these source control proved to be most efficient in reducing exposure to $\mathrm{N}_{2} \mathrm{O}$. Moreover, our simulations adequately predicted exposure to $\mathrm{N}_{2} \mathrm{O}$. On the other hand, simulation revealed that reducing recirculation (even to $100 \%$ fresh air, no recirculation) would never lead to compliance with the MAC. Simulation also revealed (specific data not shown) that without a substantial reduction of the $\mathrm{N}_{2} \mathrm{O}$ emission, compliance with the MAC could be obtained only by increasing the air-change rate to ca $40 \mathrm{~h}^{-1}$, which would 
be very expensive and because of the high airflow would lead to draught. This kind of information is very useful both to occupational hygienists/physicians and to hospital management in undertaking actions in an existing situation. Using the data from our general ORs, we were even able to estimate occupational exposure in an outpatients' clinic OR. Unfortunately, we were not able to measure actual concentrations there, but the predicted values are well within the range indicated in several reports on this subject [Gardner 1989, Winter and Lamprecht 1987].

In conclusion, the power of simulation models is generally underestimated. Although some data have to be gathered for the models' input, we believe that this general simulation model can be easily modified to give a tailor-made description of many workplaces where exposure to gaseous anaesthetics takes place. With such input data time and money can be saved since they allow a quantitative prediction of control measures and OR design characteristics in occupational exposure to gaseous anaesthetics.

\section{REFERENCES}

Beynen FJ, Knopp TJ, Rehder K (1978): Nitrous oxide exposure in the operating room. Anaesth Analg 53; 216-223.

Borm PJA, Kant IJ, Rijssen-Moll van M, Henderson PTh (1989): Monitoring of anaesthetic gases in operating theatres. Identifications of sources of exposure and estimation of personal uptake. In proc. Exposure monitoring in industry, pp. 3.15-3.20 KVIV Antwerp. Belgium.

Gardner RJ (1989): Inhalation anaesthetics-exposure and control: a statistical comparison of personal exposures in operating theatres with and without anaesthetic gas scavenging. Ann Occup Hyg 3; 159-173.

Kuang-Hui L, Ness van HC (1974): Section 4, reaction kinetics, reactor design, and thermodynamics. In chemical Engineers' Handbook (edited by Perry HP and Chilton HC), pp 4-10. McGraw-Hill Kogakusha, New York.

Niosh (1977): Criteria for a recommendent standard: occupational exposure to waste anaesthetic gases and vapors. DHEW Publication No. (NIOSH) 70-140, National Institute for Occupational Savety and Health, Cincinnati, Ohio, USA.

Piziali RL, Whitcher C, Sher R, Moffat RJ (1976): Distribution of wasted anaesthetic gases in operating room air. Anaesthesia 5; 487-494.

Rejger VS (1980): Een studie naar de betekenis van luchtverontreiniging met anaesthesiegassen in het operatiekomplex (Consequences of air pollution with anaesthetic gases in operating theatres) PhD Thesis, University of Leiden, De Kempenaer, Oegstgeest. The Netherlands.

National MAC Committee: Report of experts (1985): Rapport inzake grenswaarde lachgas. Werkgroep van deskundigen van de Nationale MAC Committee (Report on exposure limits for nitrous oxide. Working group of experts of the National MAC Committee) Voorburg, The Netherlands.

Rice SA (1983): Behavioural toxicity of inhalation anaesthetic agents. Clin Anaest 1; 507519.

Sonander H, Senquist: O, Nilson K (1983): Exposure to trace amounts of nitrous oxide. $\mathrm{Br}$ $J$ Anaest 55; 1225-1229. 
Tannenbaurn TN, Goldberg RJ (1985): Exposure to anaesthetic gases and reprociuctive outcome. J Occup Med 27; 659-668.

Winter CG, Lamprecht E (1987): Arbeidstoxikologische Studie zur Einsschätzung des expositionellen Risikos des Operationspersonals gegenüber Inhalations anaesthetika (Risk assessment of exposure of operaiting room personnel to inhalation anaesthetics) $\mathrm{Z}$. Gesarnte Hyg 12; 622 .

Whitcher C. Piziali RL (1977): Monitoring occupational exposure to anaesthetics. Anesth Anaig 56; 778.785.

Whitcher $C$ (1980): Methods of control, In anaesthetic Exposure in the Workplace ledited by Cohen EN), pp. 117-148. MPT Press, Lancaster, UK. 


\section{RISK EVALUATION OF THERMAL DISCOMFORT}




\section{CHAPTER 4}

\section{A comparison of current evaluation methods for thermal environment applied to garage work*}

\section{SUMMARY}

The thermal environment in 42 garages was measured and compared with the results of questionnaires completed by mechanics working in these garages. In the garages studied, the mean air temperature appeared to be rather low. Mean air velocity was moderate $10.17 \mathrm{~m} / \mathrm{s})$, with a significant variation among garages $(0.07-0.60 \mathrm{~m} / \mathrm{s})$. An accurate estimation of the metabolic activity and clothing factor was made. Four current climate standards were selected to evaluate the climate conditions of the investigated garages, i.e. L-index, L-index (comfort), PMV-index and the ASHRAE-index. It appears that the number of garages within the standards acceptable (or recommended) range varies considerably with the standard used. Converting the different standards to the same basis ( $80 \%$ acceptation) does not recluce this variation. These large differences are explained by evaluation of different parameters on which the standards are based. In order to evaluate the thermal environment in garages, Fanger's PMV-index is recommended, as it shows the greatest sensitivity $(0.75)$ combined with a similar positive predictive value (0.65) compared to the other standards. Moreover, this standard incorporates air velocity, which is shown to be crucial in evaluating the thermal environment in garages.

\section{INTRODUCTION}

To evaluate thermal environment in occupationa! settings, several standards or recommendations can be used. These standards differ with respect to the environmental factors to be measured, the incorporation of personal factors

\footnotetext{
- Kant IJ, Borm PJA, Notermans JHV. Int Arch Occup Environ Health $1988 ; 61: 115-121$.
} 
(metabolism, clothing) and the (mathematical) relation between the calculated standard and the thermal comfort. These standards also differ in application; i.e. comfort indices, indices for heat stress and cold stress [Berglund 1978, Kröling 1985, Reinders 1969]. Working in garages is, at least in the literature [ASHRAE 1981, Fanger 1972], considered as high activity exercise in a moderate thermal environment. However, there are not much data available to support this.

Recently, our department carried out a study to determine the state of health of garage mechanics in relation to their work. As a part of this study the thermal environment in $\mathbf{4 2}$ garages was measured and, in a general questionnaire, the mechanics of these garages judged the climatic conditions.

In order to evaluate thermal environment in garages, four comfort standards were taken into consideration; the L-index, the L-index (comfort), PMV-PPD inclex and ASHRAE-standard. The L-index is an index cletermined by air temperature, and water vapour pressure. The L-index is calculated from the following equation:

$$
L \text {-index }=\frac{\left(42 \times t_{a}-8 \times t_{w b}\right)}{\left(34+t_{b}-t_{w b}\right)}
$$

where $t_{b}$ is the ambient air temperature and $t_{w b}$ is the wet bulb temperature. This formula simply reduces to $\mathrm{L}$-index $=\mathrm{t}_{\mathrm{a}}$ when maximum relative humidity $(100 \%)$ is substituted $\left(t_{\mathrm{a}}=t_{\mathrm{wb}}\right)$. Therefore, the L-index can be regarded as "a temperature corrected for relative humidity". However, this parameter has no unit. Dutch occupational legislation for thermal environment at the workplace [Veiligheidswet 1934] is based on the use of the L-index, demanding an L-index at the workplace of between 12 and 29. The Dutch labour-inspection recommends a thermal environment at the workplace [Publicatieblad P-30 1983] which corresponds with an L-index range between 16 and 23 . This L-index (comfort) is based on $80 \%$ acceptation. Both indices were chosen to evaluate the thermal comfort in garages, because they are (still) widely used. In practice, measurements for mild and moderate thermal environments are often conducted and evaluated using Fanger's Predicted Mean Vote (PMV). Fanger developed a relationship in which air temperature, mean radiant temperature, relative air velocity and water vapour pressure are coupled to personal factors (metabolism, clothing) to calculate the PMV. For an exact description and physiological basis of this model we refer to the original description of Fanger [1972] and an excellent review by Olesen [1982]. For a description of the PMV at $50 \%$ relative humidity we refer to the annex of ISO-7730 [International Standard 1985]. The PMV is the predicted mean vote of a large group of people voting on the basis of a thermal sensation scale. Fanger used experimental exposure settings to evaluate the relation between the PMV and the number of people feeling dissatisfied with this thermal environment (PPD = Predicted Percentage of Dissatisfied). 
The ISO has proposed the use of the PMV-PPD index to evaluate thermal comfort of environments (ISO 7730), recommending a PPD not exceeding $10 \%$, which corresponds to $-0.5<\mathrm{PMV}<+0.5$. Probably ISO-7730 will be embodied in Dutch legislation in the near future. This, and the fact that the PMV-index is widely accepted, were the reasons for using the latter index to judge the thermal environment in garages.

The American Society of Heating, Refrigerating and Air-conditioning Engineers (ASHRAE) has formulated "tolerable temperatures" for different occupational settings [ASHRAE standard 55-81 1981]. These tolerable temperatures are based on the same parameters as the Fanger model, but instead of Fanger's qualification "satisfaction" they are based on "acceptation". For different metabolism levels and different clothing factors minimum and maximum tolerable temperatures are defined, assuming a relative humidity of $50 \%$ and an air velocity not exceeding $0.15 \mathrm{~m} / \mathrm{s}$. These "tolerable" temperatures are based on $80 \%$ acceptation of a group of workers and are only available as nomograms [ASHRAE standard 55-81 1981].

\section{MATERIALS AND METHODS}

\section{Workplace selection and description}

In The Netherlands about 60,000 people are employed in an enterprise concerned with repair and maintenance of automobiles. Most of these enterprises are small (employing fewer than 10 persons) and therefore not obliged to join an occupational health service. To our knowledge, in The Netherlands only one garage with several branch establishments has joined an occupational health service. Forty-two garages were randomly selected from a list of all garages, registered by the Chambers of Commerce, in the Southern part of Limburg, the utmost south of The Netherlands. According to this registration there are a total of 410 garages in this area. Selection was stratified with regard to the size of the enterprise, measured in the number of employees as registered by the Chambers of Commerce. After selection the enterprise was initially checked for the following criteria:

- the main activity had to be repair and maintenance;

- these activities had to concern passenger cars;

- the garage must have more than one employee. This with respect to the questionnaires.

In Table 1 a list of workplaces is provided, specified with respect to the number of employees. 
TABLE 1: An overview of the garages selected with regard to the number of employees (mechanics specified).

\begin{tabular}{ccccc}
\hline $\begin{array}{c}\text { No. of } \\
\text { employees }\end{array}$ & $\begin{array}{c}\text { No. of } \\
\text { garages }\end{array}$ & $\begin{array}{c}\text { Total no. of } \\
\text { employees }\end{array}$ & $\begin{array}{c}\text { Mechanics } \\
\text { (full-time) }\end{array}$ & $\begin{array}{c}\text { Mechanics } \\
\text { (part-time) }\end{array}$ \\
\hline $1-4$ & 20 & 60 & 37 & 12 \\
$5-9$ & 13 & 87 & 45 & 6 \\
$10-19$ & 6 & 78 & 36 & 3 \\
$\geq 20$ & 3 & 78 & 29 & 6 \\
\hline Total & 42 & 303 & 147 & 27 \\
& & & L N = 174 」 \\
\hline
\end{tabular}

\section{Workplace conditions}

Climate conditions in a garage are mainly determined by the type and subject of the work. The entry and exit of cars cause a regular opening of garage doors with a resulting change in climatic conditions depending on the weather conditions outside. Often the garage doors are kept open to limit the concentration of exhaust vapours produced by running engines inside the garage. In $31 \%$ of the garages in this study some of the mechanics also have a pumpattendant task, causing these people, especially in wintertime, to deal with large differences in temperature. This is just one example of many factors capable of causing local discomfort; others include draught, fluctuating air velocities and rather low temperatures (in wintertime). All of the 42 garages in this study could be heated in wintertime. Most of the heating apparatus were gas- or oil-fired hot air-blowers. In some cases a central heating system had been installed.

In $80 \%$ of the garages studied all mechanics, and in an additional $15 \%$ most of the mechanics (> $75 \%$ ), wore working clothes. Working clothes were in most cases ( $>90 \%$ ) overalls. In summertime the clothing consisted of underwear and overalls, while in wintertime underwear, trousers, pully and overalls constituted the workers' fashion. Therefore, we assumed the clothing factor to be $1.0 \mathrm{clo}$, when dry air temperature inside the garage was lower than $14.0^{\circ} \mathrm{C}$, and $0.8 \mathrm{clo}$ when air temperatures exceeded $14^{\circ} \mathrm{C}$. One clothing unit $11 \mathrm{clo}$ ) conforms to an insulation of clothing of $6.5 \mathrm{~W} / \mathrm{m}^{2} \mathrm{~K}$ [Fanger 1972]. Literature data on the metabolic rate of garage work vary from $116 \mathrm{~W} / \mathrm{m}^{2}$ [ASHRAE 1981] to $175 \mathrm{~W} / \mathrm{m}^{2}$ [Fanger 1972], which correspond respectively with light construction work and heavy machine work. Since metabolic rate has a substantial effect on both the PMV and ASHRAE, an accurate estimation of the metabolic activity for garage work was made. As part of the total study the activities in the garage were observed using a working posture analysing system, discriminating all activities into ten basic activities. Using these obser- 
vations it was possible to calculate the fraction of the total workday for each of the basic activities. One of the major activities in garages is the repair of motorcars. Because of the use of modern equipment and tools and the improved accessibility of engine parts nowadays, we estimated the metabolic rate of this activity as the same as light construction work: $116 \mathrm{~W} / \mathrm{m}^{2}$ [ASHRAE 1981]. The other activities (Table 2) correspond to metabolic rate scaled in ISO 7730 [International standard 1985]. The mean metabolic activity for garage work $\left(109 \mathrm{~W} / \mathrm{m}^{2}\right)$ was calculated as a time weighted mean of all activities (Table 2 ).

TABLE 2: Main activities performed by mechanics in garage work and their corresponding metabolic rates. The data are the result of $38 \mathrm{~h}$ of observation in 22 garages.

\begin{tabular}{lccc}
\hline Activities & $\begin{array}{c}\text { Percent } \\
\text { of } \\
\text { workday }\end{array}$ & $\begin{array}{c}\text { Metabolic rate } \\
\left(\mathrm{W} / \mathrm{m}^{2}\right)\end{array}$ & $\begin{array}{c}\text { Time-weighted } \\
\text { metabolic rate } \\
\left(\mathrm{W} / \mathrm{m}^{2}\right)\end{array}$ \\
\hline Repair of motorcars & 72.2 & 116 & 83.8 \\
Walking to get spare parts/ tools & 10.3 & 93 & 9.6 \\
Repair/construction at workbench & 13.1 & 93 & 12.2 \\
Administration/work deliberation & 4.4 & 70 & 3.1 \\
\hline & 100.0 & Time-weighted mean: & 109.2 \\
\hline
\end{tabular}

\section{Climate measurements}

Climate measurements were carried out in the period of November 1986 . June 1987.

In each of the 42 selected garages the following environmental parameters were determined:

- dry air temperature and air velocity, both measured with a Digitab-100 anemo-thermometer (resolution $0.1^{\circ} \mathrm{C}$ respectively $0.01 \mathrm{~m} / \mathrm{s}$ );

- relative humidity of the air, measured with Vaisala HMI-14 humidity meter (resolution $0.5 \%$ ).

Because these parameters (particularly air velocity) vary from place to place, measurements were carried out at several (standard) places inside the garage. Since climate conditions in garages greatly depend on the weather conditions outside, the latter were also measured. The measurements at each different place were carried out over a short period $(10 \mathrm{~min})$, always at a height of $1.1 \mathrm{~m}$. Significant fluctuations in air velocity were observed during the measurements. Therefore, in addition to the mean value, minimum and maximum values were recorded. No fluctuations were observed during the measurement 
of relative humidity and air temperature. All measurements were carried out at the same time of the day: $12.00-14.00 \mathrm{~h}$. In a pilot. study in five garages (data not shown), the mechanics were not exposed to heat radiation; mean radiation temperature was the same as the mean dry air temperature. Therefore, we considered measuring dry air temperature to be sufficient.

\section{Questionnaires}

Being part of the total study, mechanics (full-time or part-time) completed questionnaires in which they answered questions about their health and their occupational environment, including the climatic conditions. The response was $96 \%(167$ out of 174$)$.

Seven questions referring to the climatic condition were used.

In my occupation I experience much hindrance due to:

- cold

- heat

- changes in temperature

- draught

- lack of fresh air

- dry air

- humid air.

Each of these seven questions could only be answered on a four-point scale (0-3) corresponding with the following:

3 - I fully agree

2 - I rather agree

1 - I little agree

0 - I do not agree

\section{RESULTS AND DISCUSSION}

To our knowledge this is the first study investigating the potential use of different climatic standards for garage work. Moreover, our calculated data are related to questions concerning acceptation of the thermal environment. Since the mechanics spend most of the working day $(72.2 \%)$ near the lifting bridge(s) and/or grease pit(s), only the climatic data of these places were used for the evaluation of the thermal environment in garages. For those garages with more than one lifting bridge and/or pit the mean value for each parameter was calculated.

For each of the garages studied the L-index and PMV-value were calculated using the clothing factor and metabolic activity as described previously. Table 3 shows the mean of environmental parameters and the calculated climatic 
indices in all $\mathbf{4 2}$ garages. Table 4 lists the same parameters for those garages that were visited in wintertime (November - March). These values clearly indicate that in garages (especially in wintertime) rather low temperatures occur. Comparison of the mean indoor and outdoor air temperatures shows that the indoor air temperature is only $2.4^{\circ} \mathrm{C}$ higher than the mean outdoor temperature. This is caused by the regular opening of the doors and also by the insufficient heating capacity in some garages. With a mean value of $0.17 \mathrm{~m} / \mathrm{s}$ and peak values up to $0.6 \mathrm{~m} / \mathrm{s}$, the air velocity in garages is quite high and able to cause thermal discomfort (draught). This was confirmed by the questionnaires: $41 \%$ of the mechanics complained of draught during their work. No large differences in mean air velocity were observed between the winter period and the whole period of investigation.

TABLE 3: Outdoor temperature, mean environmental parameters measured in garages ( $\mathrm{N}$ = 42) and the calculated climate standards L-index and PMV.

\begin{tabular}{lcc}
\hline Climate parameter & Mean & \multicolumn{2}{c}{ Range } \\
\hline Outdoor air temperature $\left({ }^{\circ} \mathrm{C}\right)$ & 13.3 & $4.7-23.0$ \\
Indoor air temperature $\left({ }^{\circ} \mathrm{C}\right)$ & 15.3 & $8.9-23.3$ \\
Relative humidity $(\%)$ & 57 & $24.0-84.0$ \\
Air velocity $(\mathrm{m} / \mathrm{s})$ & 0.17 & $0.07=0.60$ \\
L-index & 14.4 & $8.8-20.2$ \\
PMV $\left(109 \mathrm{~W} / \mathrm{m}^{2}\right)$ & -0.5 & $-3.0-2.13$ \\
\hline
\end{tabular}

TABLE 4: Outdoor temperature, mean environmental parameters measured in garages visited in wintertime $(N=29)$ and the corresponding $L$-index and PMV.

\begin{tabular}{lcc}
\hline Climate parameter & Mean & Range \\
\hline Outdoor air temperature $\left({ }^{\circ} \mathrm{C}\right)$ & 11.8 & $4.7-18.6$ \\
Indoor air temperature $\left({ }^{\circ} \mathrm{C}\right)$ & 14.2 & $8.9-19.3$ \\
Relative humidity $(\%)$ & 54 & $24.0-82.0$ \\
Air velocity $(\mathrm{m} / \mathrm{s})$ & 0.15 & $0.07-0.60$ \\
L-index & 13.4 & $8.8-17.3$ \\
PMV $\left(109 \mathrm{~W} / \mathrm{m}^{2}\right)$ & -0.82 & $-3.0-0.87$ \\
\hline
\end{tabular}

On the face of it, the climatic conditions in the garages seem rather cold and are probably exacerbated by high air velocities. In order to obtain an initia! evaluation of the thermal environment by means of the climatic standards 
selected, all data were fed into different standards. Only the data with a mean air velocity lower than $0.15 \mathrm{~m} / \mathrm{s}$ were used (29 garages) to calculate the ASHRAE-standard, since this is one of the criteria to apply this standard. All garages could be used to calculate the other standards. Subsequently, we calculated how many garages could meet the requirements of the different standards. The results of these exercise are shown in Table 5. The number of garages fulfilling the requirements of the different standards differs greatly. This means that the choice of a certain climatic standard has a tremendous effect on the evaluation of the climatic conditions. For example, judgement using the PMV would imply consequences for $67 \%$ of the garages, while application of the (legal) L-index would leave only $21 \%$ of all garages out of range.

TABLE 5: Number of garages that meet the requirements of different climatic models used in occupational hygiene.

\begin{tabular}{llcccc}
\hline Climate standard & Basis & $\begin{array}{c}\text { Corresponding } \\
\text { range }\end{array}$ & $\mathrm{N}^{\circ}$ & \multicolumn{2}{c}{$\begin{array}{c}\text { Garages within } \\
\text { range }\end{array}$} \\
\cline { 4 - 6 } & & $16 .-23$ & 42 & 15 & 35.7 \\
\hline L-index (comfort) & $80 \%$ acceptation & No. & $\%$ \\
PMV (109 W/m $\left.\mathrm{m}^{2}\right)$ & $10 \%$ dissatisfaction & $-0.5-+0.5$ & 42 & 14 & 33.3 \\
ASHRAE $\left(109 \mathrm{~W} / \mathrm{m}^{2}\right)$ & $80 \%$ acceptation & $15.4-20.6$ & 29 & 12 & 41.4 \\
L-index & Unknown & $12 .-29$ & 42 & 33 & 78.6 \\
\hline
\end{tabular}

"No. of garages where the standard could be applied. The use of the ASHRAE standard" is limited to those workplaces where mean air velocity does not exceed $0.15 \mathrm{~m} / \mathrm{s}$; $(\mathrm{N}=29)$.

As a next logical step we checked the overlap between the evaluation by the different standards. For those garages that met with the requirements of a certain standard we calculated whether these climatic data could also come up to the other three standards. The results are shown in Table 6.

Apart from the L-index it appears that only a few garages fulfill the other standards: for example only seven garages out of 15 satisfying the L-index icomfort) standard, also satisfying the PMV-standard (see Tabie 6, note b). Interesting to note, however, is that about the same is true for the reverse relation: $50 \%$ of the PMV qualified workplaces would be rejected when applying the L-index (comfort) standard (Table 6 , note $\mathrm{c}$ ). This is caused by the different parameters the models are based upon. The L-index is only based on the air temperature and relatively humidity and is not influenced by the air velocity. Therefore it is possible that garages with a rather low temperature and low air velocity are judged acceptable using the PMV-standard but not using the 
L-index. On the other hand, there are garages with a combination of air temperature and relative air humidity coping with the L-index limits, but due to a high air velocity they are out of the recommended PMV-standard range.

TABLE 6: Fractional overlap of the evaluation of climatic conditions in the garages by different current standards.

\begin{tabular}{lccccc}
\hline Climate standard & $\begin{array}{c}\text { Percent within } \\
\text { recommended } \\
\text { range }\end{array}$ & $\begin{array}{c}\text { L-index } \\
\text { (comfort) }\end{array}$ & $\begin{array}{c}\text { PMV } \\
\left(109 \mathrm{~W} / \mathrm{m}^{2}\right)\end{array}$ & $\begin{array}{c}\text { ASHRAE } \\
\left(109 \mathrm{~W} / \mathrm{m}^{2}\right)\end{array}$ & L-index \\
\hline L-index (comfort) & 36 & 1 & $0.47^{\circ}$ & 0.53 & 1 \\
PMV $\left(109 \mathrm{~W} / \mathrm{m}^{2}\right)$ & 33 & $0.50^{\circ}$ & 1 & 0.50 & 1 \\
ASHRAE $\left(109 \mathrm{~W} / \mathrm{m}^{2}\right)$ & 41 & 0.67 & 0.58 & 1 & 1 \\
L-index & 79 & 0.45 & 0.42 & 0.36 & 1 \\
\hline
\end{tabular}

"It is interesting to note that when climatic conditions can cope with the L-index (com * fort), PMV or ASHRAE these conditions are always within the legal L-index range (fractional overlap in this column always 1 !).

- Means that only $47 \%$ of the garages which satisfy the L-index (comfort) standard fulfill Fanger's PMV range. However, the reverse is also true:

- $\mathbf{5 0 \%}$ of the PMV qualified workplaces are rejected when using the L-index (comfort) for judgement.

When investigating the effect of air velocity in detail we observe (Figure 1) an almost perfect correlation $(R=0.88)$ between the $L$-index and the PMV calculated from the data of the investigated garages. On a theoretical basis such a relationship can be easily predicted, observing it in workplace conditions is quite different.

However, this straight line is only valid when mean air velocity does not exceed $0.20 \mathrm{~m} / \mathrm{s}$. The insert shows that substantial deviations, depending on air temperature, occur for those garages where the mean air velocity exceeds this critical value. As shown in the insert, the deviations increase when air temperature decreases. This would imply that in contradiction to Dutch legislation, permitting the use of the L-index for air velocities up to $1.0 \mathrm{~m} / \mathrm{s}$, this standard should only be permitted below $0.2 \mathrm{~m} / \mathrm{s}$. Actually, in 19 of the 42 garages investigated the mean air velocity did exceed the value of $0.2 \mathrm{~m} / \mathrm{s}$. However, comparing the different, standards in this way is hazardous. These standards are not only based on different types and numbers of parameters, but are also based on different qualifications for the thermal sensation, being "acceptation" for the L-index and ASHRAE and "satisfaction" in Fanger's model. 


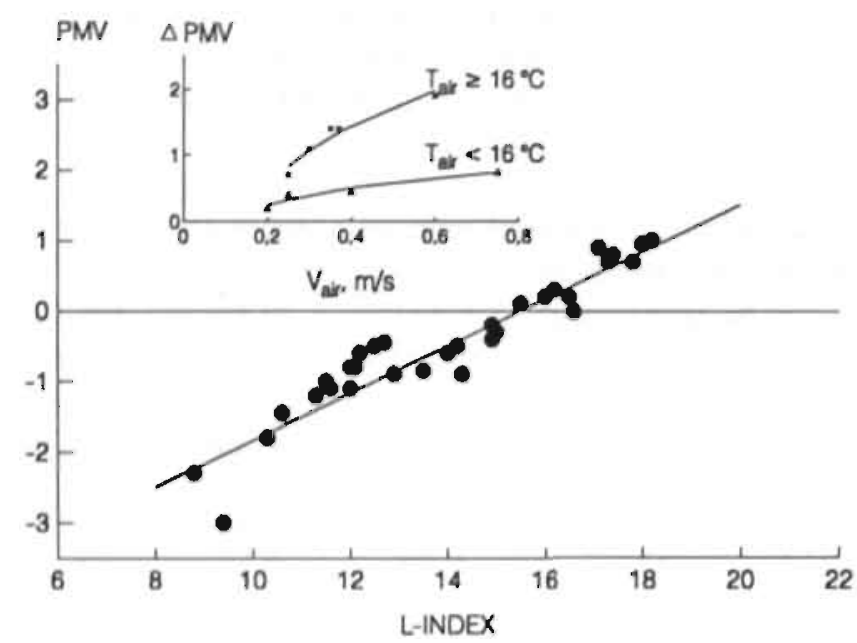

FIGURE 1: Relationship between the calculated $\mathrm{L}$-index and PMV-values for all garages where the mean air velocity $<0.20 \mathrm{~m} / \mathrm{s}$ (symbol $\bullet, N=32$ ). Both climate standards are significantly correlated when all data are used $(R=0.78$, $\mathrm{N}=42$ ) but the best correlation is obtained when those garages exceeding a $0.2 \mathrm{~m} / \mathrm{s}$ air velocity are left out $(R=0.88, N=32$, presented line). The PMV was obtained using a metabolic rate of $109 \mathrm{~W} / \mathrm{m}^{2}$ (Table 2) and Iclo values of 0.8 and 1.0 when mean inside temperature is higher or lower than $14^{\circ} \mathrm{C}$. The insert shows that the deviation from this relationship idiscriminating two temperature intervals; Temp. $<16^{\circ} \mathrm{C}$ symbol $₫$, Temp. $\geq 16^{\circ} \mathrm{C}$ symbol $\mathbf{m}$ ) is directly related to the mean air velocity.

In this respect, an interesting contribution was published by Berglund [1979] who compared different climatic standards quantitatively by converting the different qualifications used to the most elementary judgement, i.e. "thermal sensation". He showed, for instance, that $80 \%$ acceptation corresponds with a range between -1.2 and +1.35 on the Thermal Sensation Scale. Since the PMV-scale of Fanger's model coincides with the Thermal Sensation Scale, $80 \%$ acceptation corresponds with a PMV-range between -1.2 and +1.35 (note that $80 \%$ "satisfaction" according to Fanger's model is limited by a PMV-range between -0.8 and +0.8 ). The study mentioned enables us to compare the selected climatic standards on the same basis ii.e. $80 \%$ acceptation) and was used to construct Figure 2.

The position of line $\mathrm{A}$ is determined by the combination of the $80 \%$ acceptation interval calculated by Berglund and the recommended range for the $\mathrm{L}$-index $(16-23$, see Table 5$)$, already confined by a $80 \%$ acceptation demand. The same is done for the recommended temperatures according to ASHRAE standards $\left(\right.$ met $=90 \mathrm{~W} / \mathrm{m}^{2}$, Iclo 0.8 ). 


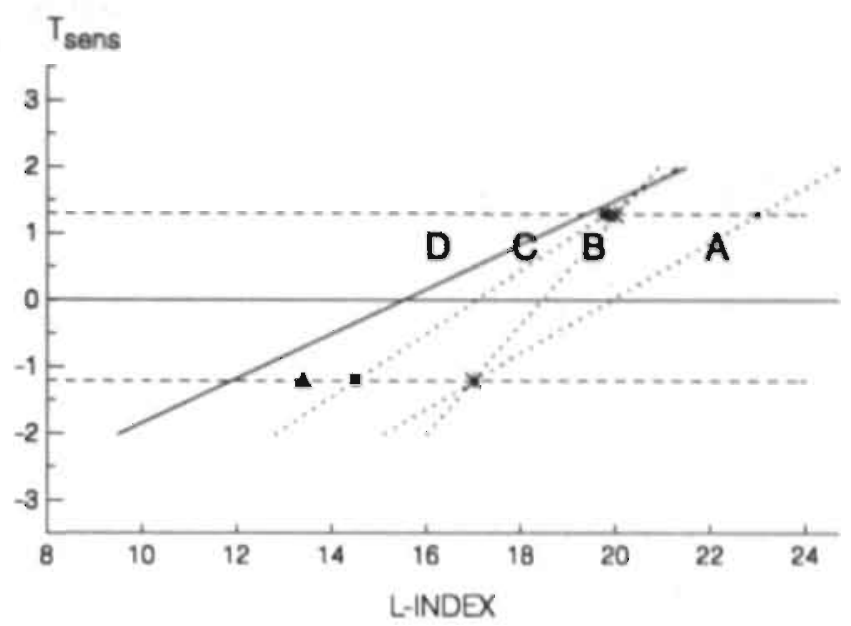

FIGURE 2: Relationship between the Thermal Sensation and the different climate standards (all based on $80 \%$ acceptation) transformed into corresponding L-indices.

Line $A$ represents the $L$-index (comfort) and is determined by the combination of the $80 \%$ acceptation interval [Berglund, 1972] and the recommended range for this standard (16-23).

Line B represents the ASHRAE standard using a metabolic rate of $90 \mathrm{~W} / \mathrm{m}^{2}$ and Iclo $=0.8$, and is determined by the combination of the same interval and the recommended temperatures, transformed to the corresponding L-index (17-20). Line $C$ represents the ASHRAE standard for the conditions in garages. A metabolic rate of $109 \mathrm{~W} / \mathrm{m}^{2}$ and an Iclo value of 0.8 for high temperatures and 1.0 for low temperatures was used. Line $\mathrm{C}$ is determined by the $80 \%$ acceptation interval and the recommended temperatures, transformed to the corresponding L-index (14.5-18.7).

Line $D$ is the line obtained by curve fitting experimentally determined PMV and L-index values.

All data are used $(N=42)$. The symbol $(\star)$ depicts the mean thermal sensation scored in the questionnaires in relation to the mean $\mathrm{L}$-index measured in garages during wintertime.

To allow presentation in the same figure, these temperatures were transformed to the corresponding L-index (17-20) and are presented in Line B. The personal parameters are valid for light work with normal clothing worn. However, we estimated mean metabolism of a garage worker to be $109 \mathrm{~W} / \mathrm{m}^{2}$ and Iclo values to be $0.8\left(>14^{\circ} \mathrm{C}\right)$ and $1.0\left(<14^{\circ} \mathrm{C}\right)$ (Table 2, Materials and methods). Using these values, line $C$ was obtained. Line $D$ is the line obtained by curve fitting the experimentally determined PMV and L-index values (see also Figure 1).

Comparing lines $B$ and $C$ (both based on ASHRAE) shows that both slope and intercept of these lines are influenced by metabolic activity and the clothing 
worn. In a way this is a trivial consequence of man's heat balance, which allows a lower ambient temperature at a higher metabolic activity. When a metabolic rate of $90 \mathrm{~W} / \mathrm{m}^{2}$ and a clothing factor of 1.0 (at low temperatures) and 0.5 (at high temperatures) are used, line $B$ (ASHRAE) is close to line A. This forwards the hypothesis that the recommended $\mathrm{L}$-index range is implicitly based on a metabolism of about $90 \mathrm{~W} / \mathrm{m}^{2}$ and an Iclo of $1.0-0.5$. This would mean that not only a restriction with regard to air velocity $(<0.2 \mathrm{~m} / \mathrm{s}$ ) has to be taken into account for the use of the recommended L-index, but that the use of this index is also limited to moderate metabolic activity and to normal or light clothing. This, in turn, implies that using the L-index (comfort) to evaluate the thermal environment in garages would lead to wrong conclusions. The latter is confirmed by the results of the questionnaires.

As already mentioned, a comparison was made between the climatic standards and the results of the questionnaires. This comparison was based upon the question regarding the hindrance of cold. In addition to temperature, air velocity also influences the mean score of this question. This question was therefore assumed to have the best correspondence with the thermal sensation. The mean score for hindrance of cold in garages for all 167 mechanics in this study was 1.15 (Table 7). Assuming the four-point scale used in the questionnaires responds with the Thermal Sensation Scale, the climate in garages in the period of this study is scored as -1.15 . This value is fitted in Figure 2 using the mean value of only the winter period (L-index $=13.4$, Table 4$)$. This point is more likely to fit the PMV- or ASHRAE-lines than the L-index (comfort) line.

TABLE 7: Score on questionnaires $(N=167)$, response $96 \%$.

\begin{tabular}{lcc}
\hline $\begin{array}{l}\text { Staternent: } \\
\text { I experience much hindrance of: }\end{array}$ & Mean scoren \\
\hline 1 Cold & 1.15 & 1.11 \\
2 Heat & 0.60 & 0.96 \\
3 Changing temperature & 1.21 & 1.15 \\
4 Draught & 1.30 & 1.15 \\
5 Lack of fresh air & 0.24 & 0.56 \\
6 Dry air & 0.30 & 0.60 \\
7 Humid air & 0.60 & 0.96 \\
\hline
\end{tabular}

"For qualitative description see "materials and methods".

Moreover, the percentage of garages having acceptable climatic conditions according to the questionnaires corresponds well to the percentage of garages judged acceptable by the PMV or ASHRAE standards (Table 8). In this table 
the number and percentages of the garages that fulfill the requirements of the different standards are shown. For this comparison the L-index (legal) was omitted since it is not possible to convert the basis of this index to $80 \%$ acceptance.

TABLE 8: Number and percentages of garages that fulfill the requirements of the climatic standards. All standards are converted to the same basis ( $80 \%$ acceptation).

\begin{tabular}{lccccc}
\hline Climate standard & Range & $N^{*}$ & \multicolumn{2}{c}{ Garages within the range } \\
\cline { 4 - 5 } & & & 42 & 15 & 35.7 \\
\hline L-index (comfort) & 16 & -23 & 42 & 32 & 76.2 \\
PMV $\left(109 \mathrm{~W} / \mathrm{m}^{2}\right)$ & $-1.2-+1.35$ & 29 & 12 & 41.4 \\
ASHRAE $\left(109 \mathrm{~W} / \mathrm{m}^{2}\right)$ & $15.4-20.6^{6}$ & 42 & 28 & 66.7 \\
Questionnaires & $-1.2-+1.35$ & 42 &
\end{tabular}

" No. of garages where the standard could be applied. The use of the ASHRAE standard is limited to those workplaces where mean air velocity does not exceed $0.15 \mathrm{~m} / \mathrm{s}$ ( $N=29$ ).

- Assuming the 4-point scale used in the questionnaires corresponds with the thermal sensation scale.

Finally, the analysis is completed by calculation of the sensitivity, specificity and Positive Predictive Value (PPV) of the climatic screening methods. In order to do so, the results of the questionnaires were taken as the final independent standard (Table 9).

It is clear from this table that all three evaluation methods have about the same positive predicted value $(0.65)$. Sensitivity and specificity, however, differ considerably among the standards when applied to garage work. Fanger's PMV shows the highest sensitivity $(0.75)$, while application of the ASHRAE standard shows the highest specificity $(0.50)$. We would like to stress that the appropriateness of applying a standard must be related to the purpose or goals of a measuring program. Only when the goals are clearly identified, can the standard be chosen.

If the major purpose of the measurements is to identify those workplaces that will meet with the $80 \%$ acceptation demand with a minimum number of false negative results, than the standard should be highly sensitive. As this purpose conforms to the practical issue of checking fulfillment of climatic standard criteria, obviously the PMV would be the recommended choice.

On the other hand, if the major purpose is to identify those garages with miserable climatic conditions with a minimum of false positives, then the standard applied should have a high PPV. The latter conforms to the general goal of survey studies. 
TABLE 9: Sensitivity, specificity and Positive Predictive Value (PPV) of climatic screening methods to classify conditions in garages $(N=42)$ as to whether they are acceptable for $80 \%$ of the employed mechanics.

\begin{tabular}{lccc}
\hline Climate standard & Sensitivity $^{\mathrm{b}}$ & Specificity $^{\mathrm{b}}$ & PPV $^{\mathrm{b}}$ \\
\hline L-index (comfort) & 0.36 & 0.21 & 0.64 \\
PMV & 0.75 & 0.21 & 0.66 \\
ASHRAE" & 0.46 & 0.50 & 0.65 \\
\hline
\end{tabular}

- Note that in this calculation all $\mathbf{4 2}$ garages are included, irrespective of the mean air velocity

b Sensitivity, specificity and PPV were derived from a general cross-table relating the predicted acceptable $(+)$ and not acceptable $(-)$ garages to the score of the questionnaires.

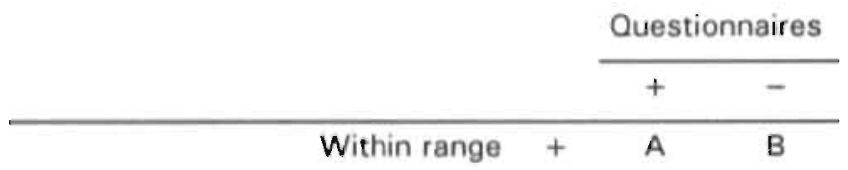

Climate standard

\begin{tabular}{ll} 
Out of range & - C \\
\hline Sensitivity & $=A /(A+C)$ \\
Specificity & $=D /(D+B)$ \\
PPV & $=A /(A+B)$
\end{tabular}

Since the PVV of all three standards is almost equal, no preference is indicated by this parameter. However, the results of this study clearly show that climatic conditions in garages can be evaluated at best by a climatic index incorporating air velocity, metabolic activity and clothing worn; therefore, only PMV and ASHRAE are valid.

In contrast to the PMV, the ASHRAE standard is restricted to air velocities below $0.15 \mathrm{~m} / \mathrm{s}$ and is therefore limited in its application. Fanger's model enjoys the advantage of being carefully described and is embodied into ISOstandard 7730 for evaluating moderate thermal environments.

In conclusion, we propose Fanger's model to evaluate the thermal environment in garages.

\section{REFERENCES}

ASHRAE standard 55-8.1 (1981): Thermal environmental conditions for human occupancy. American Society of Air-conditioning Engineers Inc. Atlanta, USA.

Berglund LG (1979): Thermal acceptability. ASHRAE transactions Il, New York, pp 825-834. Berglund LG (1978): Mathematical models for predicting the thermal comfort response of building occupants. ASHRAE transactions AT 78-7a, New York. 
Fanger PO (1972): Thermal comfort. Analysis and application in environmental engineering. Mc Graw-Hill, New York.

International standard ISO-7730 (1985): Moderate thermal environments-determination of the conditions for thermal comfort. International Standards Organisation, Geneva.

Kröling P (1985): Gesundheits- und Befindensstörungen in klimatisierten Gebăuden. Verlag W. Zuckschwerdt, München-Bern-Wien.

Olesen BW (1982): Thermal comfort, technical review. Bruel \& Kjaer, Naerum, Denmark. Publicatieblad P-30, Design and lay out of workplaces (1983): Dutch Labour inspection. Voorburg, The Netherlands.

Reinders H (1969): Mensch und Klima. Klima, Klima physiologie, Klimatechnik. VDI-Verlag. Düsseldorf.

Veiligheidswet (1934): Nederlandse Staatswetten nr. 57. Schuurmans en Jordens, Den Haag, The Netherlands. 



\section{CHAPTER 5}

\section{The effect of mental activity on thermal sensation*}

\section{ABSTRACT}

In order to determine the effect(s) of mental activity on thermal sensation scored on Fanger's PMV scale, a workplace study among staff in operating rooms was done. Climate conditions in these rooms are ideally controlled, but the tasks, education and mental activity of different categories of staff vary widely. Our data show that the difference between measured PMV and the thermal sensation perceived is significantly dependent upon the perceived mental activity.

\section{INTRODUCTION}

Several models can be applied to evaluate or predict thermal comfort during indoor work [ASHRAE 55-81 1981, Berglund 1978, Fanger 1972, international standaro ISO 7730 1985, Kant et al. 1988]. All models incorporate environmental climate parameters (ambient air temperature, relative humidity, air velocity), while the more sophisticated models (e.g. Fanger's-PMY [1972], ASHRAE [1982]) also include personal parameters like metabolic activity and clothing. The latter parameters are often estimated from detailed observations and registration of clothing worn. However, if work is very exacting, thermal sensation and thermal comfort may deviate caused by a "metabolic" activity imposed by high perceptive-mental load. Using the conventional models to judge thermal comfort in such cases would lead to incorrect conclusions. In order to determine the effects of mental activity on thermal sensation as judged by Fanger's model, we selected a workplace situation in which climate conditions are ideally controlled while mental activity among working staff varies widely. Such a situation is encountered in hospital operating rooms.

- Kant IJ, Borm PJA. Prec. 5th International Conference on Indoor Air Quality and Climate, Toronto, Canada, 1990;1:711-715. 


\section{METHODS}

This study was carried out in the University Hospital of Maastricht, The Netherlands. Its operating room complex consists of 10 operating rooms (ORs), one recovery room and several other rooms (lunchroom, offices, stores). The ORs are plenum ventilated (air-change rate 17-20 $\mathrm{hr}^{-1}$ ). Three operating rooms were selected: one used by Throat-Nose-Ear surgery and two ORs, used for general surgery.

Four different categories of staff were included: surgeons, anaesthetist assistants, instrumentation nurses and circulating nurses. These different groups have specific tasks, education, clothing and metabolic activity. Anaesthetists were not included since they often change from one OR to an other OR during operating programs. Therefore estimating climate parameters and metabolic activity would be very difficult.

Environmental climate parameters (ambient air temperature, radiant temperature, relative humidity, air velocity) were measured in 3 operating rooms (total measurement time: 15 days, $5 \mathrm{hr} /$ day) according to ISO 7730 standards. Data were sampled and stored every 10 minutes.

Personal parameters (metabolic rate, clothing) were estimated as follows. During this study the work postures of operating room personnel were recorded using the Ovako Working posture Analysing System [Kant et al. 1990]. From this ergonomic study detailed information about the activities and the time spent to these activities was gained. These data were used to calculate a mean metabolic rate for each of the professional groups, as described previously [Kant et al. 1988].

For each group the clothing factor (icl) was estimated from an empirical relation as described by McCullough [1985], using a standard set of clothing of each group.

$$
|c|=0.255 \times \text { weight }-0.00874 \times X-0.00510 \times Y+0.919 \quad \text { (clo) }
$$

in which:

Weight $=$ total garment weight (excl. shoes); $\mathrm{Kg}$

$\mathrm{X} \quad=$ percentage of the bodysurface uncovered.

$\mathrm{Y}=$ percentage of the bodysurface covered with one layer

At the end of each operating program staff, was asked to complete questionnaires about their thermal sensation and the mental activity during that working day. None of the subjects was aware of the purpose of this study, as it was nested in a survey of exposure to anaesthetic gases. 
Perception of the thermal climate conditions was scored on Fanger's thermal sensation scale $(-3,+3)$ :

$-3=$ cold

$-2=\mathrm{cool}$

$0=$ neutral

$+1=$ slightly warm

$-1=$ slightly cool

$+2=$ warm

$+3=$ hot

Perceived mental activity (during the operating program) was scored at the end of the day on a 4-point scale (0-3):

$0=$ no exacting work;

1 = slightly exacting work;

2 = during certain moments of the program very exacting work;

$3=$ during the whole program very exacting work.

\section{DATA EVALUATION AND STATISTICS}

Predicted Mean Votes (PMV) were calculated and compared to thermal sensation scored in questionnaires using non-parametric statistics. A Kruskal-Wallis test was applied to investigate the effect of category of staff and perceived mental activity on PMV. The difference between calculated and perceived (reported) PMV was evaluated using MANOVA, with profession as a covariate.

\section{RESULTS}

The estimated metabolic rate (during a surgica! program) and the clothing factors (|c|) of the different categories of staff are shown in Table 1. The clothing factor of both surgeons and instrumentation nurses is double that of circulating nurses and anaesthetist assistants, due to the sterile apron that the first groups have to wear.

TABLE 1: Estimated metabolic rate and clothing insulation for different categories of staff.

\begin{tabular}{lcc}
\hline Staff category & $\begin{array}{c}\text { Metabolic rate } \\
\left(\text { Watt } / \mathrm{m}^{2}\right)\end{array}$ & $\begin{array}{c}\text { Clothing insulation } \\
\text { (clo) }\end{array}$ \\
\hline Surgeons & 106.5 & 1.0 .1 \\
Instrumentation nurses & 110.7 & 1.01 \\
Circulating nurses & 94.8 & 0.49 \\
Anaesthetist assistants & 88.1 & 0.49 \\
\hline
\end{tabular}


Using the personal parameters (Table 1) a mean PMV was calculated for each category of staff per operating program. These data were compared with the thermal sensation scored on the PMV-scale on 97 occasions. Data are shown in Table 2 as group means. Exploratory data analysis showed significant differences (paired Mann-Whitney $U$-test, $P<0.002$ ) between reported and calculated PMV. Non parametric statistics were applied since neither reported nor calculated PMV values fitted a normal distribution. A Kruskal-Wallis test showed that both PMVs are dependent on the category of staff (P $<0.002)$. The PMV reported in the questionnaire was also dependent of the scored perception of mental activity ( $T=10.2, P<0.02)$.

TABLE 2: Calculated PMV, reported PMV and reported mental activity of 4 categories of staff as experienced during operating.

\begin{tabular}{lcccc}
\hline Staff category & N & $\begin{array}{c}\text { PMV } \\
\text { calculated }\end{array}$ & $\begin{array}{c}\text { PMV } \\
\text { questionnaire }\end{array}$ & $\begin{array}{c}\text { Mental activity } \\
\text { questionnaire }\end{array}$ \\
\hline Surgeons & 35 & 0.973 & 0.457 & 0.628 \\
Anaesth. assistants & 17 & 0.048 & -0.294 & 0.824 \\
Instrument. nurses & 18 & 0.908 & 1.055 & 0.388 \\
Circulating nurses & 27 & 0.187 & 0.259 & 0.444 \\
\hline Total / (mean) & 97 & $10.580)$ & $10.3811)$ & $(0.567)$ \\
\hline
\end{tabular}

Next, we calculated the difference between reported and calculated PMV for 97 observations and observed that these data fitted in a normal distribution (Kolmogorov-Smirnov test, $\mathrm{P}=0.33$ ). A Multifactor Analysis of Variances (MANOVA) using "category of staff" as a covariate, showed that perceived mental activity explained the variance in the data significantly $(F=6.0$, $P<0.001)$.

Therefore, we concluded that, irrespective of background education and its resultant occupation in the $\mathrm{OR}$, mental activity was a major determinant of the difference between calculated and reported PMV.

A graphical illustration of this relation is given in Figure 1, from which it can be seen that the deviation from the calculated PMV increases as (perceived) mental activity increases. 


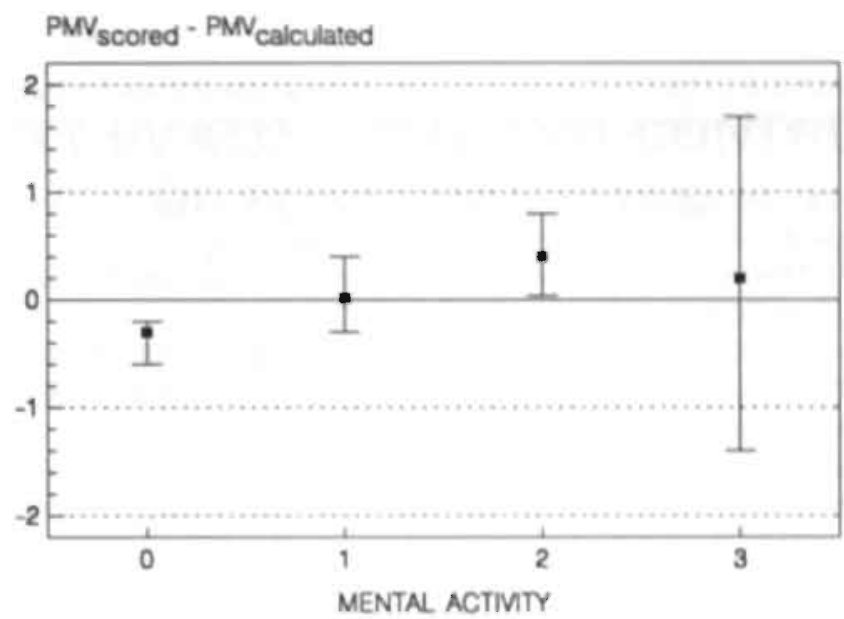

FIGURE 1: Diagram of the mean difference between scored and calculated PMV versus mental activity. Bars indicate the $95 \%$ confidence interval.

\section{DISCUSSION}

To our knowledge this is the first study investigating the effect of mental activity on thermal sensation under workplace conditions. Workers in operating rooms are an ideal group to investigate this question in practice. The climate offered is very constant with regard to time and place, and even during short breaks the climate conditions are similar. Clothing within all categories of staff is almost uniform due to strong hospital regulations. Therefore it is unlikely that any error is caused by fluctuations in the above parameters. A clear advantage over an experimental study is that perceptive-mental load is caused by the work itself and not by a computer, randomly imposing the subject to various tests.

Since the study was nested in a survey investigating exposure to nitrous oxide and work postures of staff, none of the subjects was aware of the purpose of this (nested) study. Bias caused by previous knowledge can therefore be neglected. Perhaps there are much better criteria or questionnaires to determine perceptive-mental load and even methods to correct for level of education and skills. Still, the setup of this study enabled us to conclude that perceived mental activity is an important determinant of thermal sensation. Those using Fanger's model to judge thermal comfort for workers with jobs imposing such load should keep this in mind. Maybe this investigation initiates new research in this field and we think it should be directed towards an independent and reliable estimate of "mental activity" perceived by the worker imposed by a certain task. 


\section{REFERENCES}

ASHRAE standard 55-81 (1981): Thermal environmental conditions for human occupancy. American Society of Heating. Refrigerating and Air-conditioning Engineers Inc. Atlanta, USA.

Berglund LG (1978): Mathematica! models for predicting the thermal comfort response of building occupants. ASHRAE transactions AT78-7a, New York.

Fanger PO (1972): Thermal comfort. Analysis and applications in environmental engineering. McGraw-Hil, New York.

International standard ISO 7730 (1985): Moderate thermal environments-determination of the PMV and PPD indices and specification of the conditions for thermal comfort. International Standards Organisation, Geneva.

Kant IJ, Borm PJA, Notermans JHV (1988): A comparison of current evaluation methods for thermal environment applied to garage work. Int Arch Occup Environ Health 61; 115 121.

Kant IJ, Borm PJA, Notermans JHV (1990): Working postures in garages observed using OWAS. Recommendations to reduce workload. Ergonomics, in press.

Karhu O, Harkönen R, Sarvali P, Vepsalainen P (198,1): Observing working postures in indus= try: Examples of OWAS application. Appl Ergonomics 12.1; 13-17.

MfcCullough EA, Jones BW, Huck PEJ (1985): A comprehensive Data Base for estimating clothing insulation. ASHRAE transact 91, 2a; 29-47. 


\section{RISK EVALUATION AND CONTROL OF POSTURAL LOAD}





\section{CHAPTER 6}

\section{Observations of working postures in garages using the Ovako Working posture Analysing System (OWAS) and consequent workload reduction recommendations*}

\section{ABSTRACT}

The working postures of mechanics $(N=84)$ in 42 garages were observed using the Ovako Working posture Analysing System (OWAS). During observation, both working postures and work activities were recorded. A computer program was developed for the data analyses. Using this program it is possible to calculate the working posture load for each work activity and the contribution of a specific activity to the total working posture load. This is a substantial extension of the original OWAS method. Five out of 19 observed postures of the body members were classified as Action Category 2, which suggests they were slightly harmful to the musculoskeletal system and likely to cause discomfort. Of the so-called typical working postures, $31.9 \%$ was classified in Action Category 2, suggesting that during a substantial part of the working day typical working postures occur which are at least slightly harmful to the musculoskeletal system. Moreover, those work activities principally causing the workload to fall in OWAS' higher Action Categories were identified. For each of these three work activities an alternative work method was observed. The data show that in all three work activities the use of a vehicle lift reduces the number of poor working postures thereby reducing the load on the musculoskeletal system.

\section{INTRODUCTION}

The relationship between poor, ergonomically deficient design in the workplace and diseases of the musculoskeletal system has been demonstrated in several studies [e.g. Wely van 1970], and illustrative case reports have been published [Perrot 1961].

\footnotetext{
•Kant IJ, Notermans JHV, Borm PJA. Ergonomics 1990; vol 33, 2:209-220.
} 
Prolonged static loads are probably the major factor in modern working life in causing most work-related musculoskeletal disorders [Andersson 1985, Grandjean and Hünting 1977, Hettinger 1985, Kelsey et al. 1979, Monod 1985]. Measures for the prevention of such musculoskeletal injuries might involve various ergonomic measures aimed at reducing the load on the locomotor system by altering the design of equipment in the workplace.

The work of a garage mechanic can be shown to include many poor working postures, and contains a substantial static load. The repair and maintenance of car engines demand a working posture with the back in a bent position for prolonged periods. Working underneath the car using a vehicle lift or grease pit also creates poor working postures and high static load, since work is, in the main, overhead. Working postures in garages therefore seem responsible for discomfort and disorders of the musculoskeletal system; however, no data are available to support this.

The Department of Occupational Medicine at the University of Limburg has recently carried out a study to determine the health status of garage mechanics in relation to their work. As a part of this study the working postures of mechanics in 42 garages were recorded $(N=84)$ using the Ovako Working posture Analysing System (OWAS). This study, recording both working postures and work activities, was designed (i) to identify activities with poor working postures; (ii) to compare different work methods; and (iii) to estimate the effect of using optimal work methods on average daily workload. For this purpose the OWAS method was extended with a computerized data analysis, enabling working postures to be related to work activities.

\section{MATERIALS AND METHODS}

\section{Workplace selection and description}

In The Netherlands about 60,000 people are employed in enterprises concerned with the repair and maintenance of automobiles. Most of these enterprises are small, employing less then 10 people, and therefore not obliged, under Dutch law, to join an occupational health service scheme. Forty-two garages were selected randomly from a list of all garages on the southern part of Limburg, which is in the utmost south of The Netherlands, as registered by the regional Chambers of Commerce. According to this register, a total of 410 garages existed in this area. Selection was stratified with regard to the size of the enterprise, measured in terms of the number of employees. After selection each enterprise was checked to ensure the following criteria were fulfilled: (a) the main activity should be general repair and maintenance of private cars; and (b) the garage should have at least one employee (apart from the owner). Table 1 provides a list of workplaces, specified with respect to the number of employees. 
TABLE 1: An overview of the selected garages with regard to the number of employees (mechanics specified).

\begin{tabular}{ccccc}
\hline $\begin{array}{c}\text { Number of } \\
\text { employees }\end{array}$ & $\begin{array}{c}\text { Number of } \\
\text { garages }\end{array}$ & $\begin{array}{c}\text { Total number of } \\
\text { employees }\end{array}$ & $\begin{array}{c}\text { Full-time } \\
\text { mechanics }\end{array}$ & $\begin{array}{c}\text { Part-time } \\
\text { mechanics }\end{array}$ \\
\hline $1-4$ & 20 & 60 & 37 & 12 \\
$5-9$ & 13 & 87 & 45 & 6 \\
$10-19$ & 6 & 78 & 36 & 3 \\
$\geq 20$ & 3 & 78 & 29 & 6 \\
\hline Total & 42 & 303 & 147 & 27 \\
\hline
\end{tabular}

\section{OWAS method}

For the analyses of working postures during garage work, Basic OWAS was used. This method deals only with the load on the musculoskeletal system caused by poor working postures. Other sources contributing to the total ergonomic body burden, e.g., vibrations, which in some cases may be of importance [Hansson et al. 1987], are neglected.

The original OWAS method was developed by the Ovako Oy Steel Co. in Finland, and has been described in several papers [Karhu et al. 1977, Stoffert von 1985]; only a few applications of OWAS have been published [Karhu et al. 1981, Rohmert 1988]. The OWAS method is based on work-sampling (variable or constant interval sampling), which provides the frequency of, and time spent in, each posture. In Table 3 the elements of this Basic OWAS System are shown. Eighty-four different combinations are possible, and are defined as typical working postures. A scale with respect to the harmifulness of these typical working postures was developed by the Ovako Oy Steel Co., and described in detail by other investigators [Stoffert von 1985].

Four Action Categories $(A C)$ are distinguished:

AC 1 - normal posture: no actions required;

AC 2 - the load of the posture is slightly harmful: actions to change the posture should be taken in the near future;

AC 3 - the load of the body is distinctly harmful: actions to change the posture should be taken as soon as possible;

AC 4 - the load of the posture is extremely harmful: actions to change the posture should be taken immediately.

The percentage frequency of the postures of the body members, i.e. the position of the back, arms, legs, and the head, can be calculated separately and can also be classified into these four Action Categories [Stoffert von 1985]. 


\section{Sampling strategy}

In each of the 42 garages selected two mechanics were observed $(N=84)$. In garages with more than two mechanics, the subjects were selected at random. The observation time for each mechanic was $45 \mathrm{~min}$, during which 90 data at intervals of $30 \mathrm{~s}$ were collected. The part of the working day in which the mechanics were observed was also taken at random. Two observers were involved, and inter-observer variability was $4 \%$ with respect to final percentages. For each observation, both the working posture and the work activity were recorded. To enable subsequent analyses of working postures related to work activities, all activities that occurred were divided into ten basic work activities. The latter and the determination of inter-observer variability, were achieved from a pilot study using eight mechanics in four garages (total observation time: $8 \mathrm{~h}$ ). The same study showed that work forces applied seldomly exceeded $100 \mathrm{~N}(10 \mathrm{kgf}$, see Table 3); therefore the work force applied was not recorded during subsequent observations.

A list of the basic work activities as defined in the study is given in Table 2 .

TABLE 2: A list of basic work activities performed by garage mechanics during an average routine working day and the time (as a percentage of the working day, $8 \mathrm{~h}$ ) spent on these activities.

Basic activity"

Percentage of working day

Working underneath the motorcar; using a vehicle lift in lifted position

14.0

Working underneath the car; using a grease pit

Working at the front, the rear or the side of the car: car on floor or on vehicle lift in down position

Working at the front, the rear or the side of the car: car on vehicle lift in lifted position

Working inside the car

Working under the bonnet; car on floor or on vehicle lift. in down position

Working under the bonnet; car on vehicle lift in lifted position

Working at the workbench

Walking or moving to get parts, tools etc.

Administration, work planning

6.6

Total

100.0

- These activities were discriminated and defined in a pilot-study involving eight mechanics in four different garages. 
TABLE 3: Elements of the basic OWAS and percentages and resulting scores in Action Categories of postures of the body members during the work of a garage mechanic.

\begin{tabular}{cc}
\hline OWAS code & $\begin{array}{c}\text { Percentage of Action } \\
\text { working day Category* }\end{array}$ \\
\hline
\end{tabular}

\begin{tabular}{ll}
\hline Back & 1. Straight \\
& 2. Bent \\
& 3. Twisted \\
& 4. Bent and twisted
\end{tabular}

Arms/ 1. Both arms under the shoulder level not

shoulders touching the body

2. One arm at or above the shoulder level

3. Both arms at or above the shoulder level

$\begin{array}{rr}60.0 & 1 \\ 30.3 & 2 \\ 6.4 & 1 \\ 3.3 & 1 \\ 100.0 & \end{array}$

$\begin{array}{rc}65.7 & 1 \\ 19.6 & 1 \\ 14.7 & 1-2 \\ 100.0 & \\ 3.5 & 1 \\ 72.3 & 1 \\ 5.5 & 1 \\ 4.6 & 1.2 \\ 0.4 & 1 \\ 3.6 & 1 \\ 10.1 & 1 \\ 100.0 & \end{array}$

Head

1. Free

55.7

1

2. Bent forward

22.5

3. Bent to ane side

12.7

4. Bent backward

6.8

5. Twisted

2.3. 100.0

Weight/

1. $<10 \mathrm{~kg}$

strength ** 2. $>10 \mathrm{~kg}<20 \mathrm{~kg}$

3. $>20 \mathrm{~kg}$

- The OWAS category for a posture of a certain body member depends on both type and percentage. The transition to a higher Action Category is set at a certain percentage. However, around this percentage there is a transitional area of $10 \%$. Postures of the body members falling in this area are depicted by $1-2$, etc.

* A pilot study showed that applied. workforces seldomly exceeded $100 \mathrm{~N} \mathrm{(10} \mathrm{kgf);}$ therefore, the workforce applied was not recorded during subsequent observation.

During the pilot study we noticed that mechanics apply alternative work methods to severa! work activities. This also played a role in the definition of basic work activities. Consistent registration of alternative work methods and equipment used was performed to compare the effect of different work methods on working postures during those activities which contribute most to poor working posture. 


\section{OWAS data analysis}

When using OWAS to facilitate the improvement of working conditions, it is crucial that poor working postures can be related quantitatively to specific work activities. In theory, this is possible, because for each observation the activity was recorded. However, in practice it is almost impossible when performed manually. To the authors' knowledge there are no computer programs available for OWAS data analysis [Wangenheim 1987], and so a computer program for the data analysis in this study was developed. All observations (working posture code and associated activity) were stored pair-wise in one data file. This file was used to calculate (i) the average time spent by a mechanic in the ten basic activities; (ii) the incidence of poor, typical working postures; and (iii) the percentage frequency of the postures of the body members. After identification of those work activities contributing most to total workload, separate files per work activity were made.

Subsequently, the effect of alternative work methods (within each activity) on workload was studied. Finally, the program was used to predict average workload under optimal work methods. To enable a quantitative description of such improvements, two extremes were compared: typical working postures during a workday of a car mechanic using the optimal work methods in all three activities causing poor work postures (best case) compared to postures caused by the same work if the better method is never used (worst case). This was done by a theoretical simulation of an artificial working day, in which the time spent on both work methods for each of the three work activities was constant; however, for the worst case we assumed that during these three periods the worst methods were used.

\section{RESULTS}

A total of 7,154 observations were collected and used to calculate the percentage of time spent in the ten basic work activities distinguished in the pilot study (Table 2). The distribution of the work activities presented can be considered as an average working day for mechanics in garages. However, substantial inter-individual deviations from this "average working day" may occur, depending on equipment available and the mechanic's limited task.

\section{Postures of the body members}

The number and percentage of the body members were calculated and classified into the OWAS Action Categories (Table 3). It is clear that for garage work the poor postures of the body members (AC 2 or more) are the back in bent position $(30.3 \%$ of the working day); the position of the arms at or above the shoulder level $(14.7 \%)$; the position of the legs when kneeling $(4.6 \%)$; and the position of the head bent forward $(22.5 \%)$ or bent backward $(6.8 \%)$. 
These postures are all classified as AC 2, meaning that they are slightly harmful, and action to change the work posture should be taken in the near future. The distribution of these five poor working postures over the activities for an "average working day" (Figure 1) shows that working under the bonnet with the car on the floor is responsible ( $54 \%$ ) for the back being in a bent position.

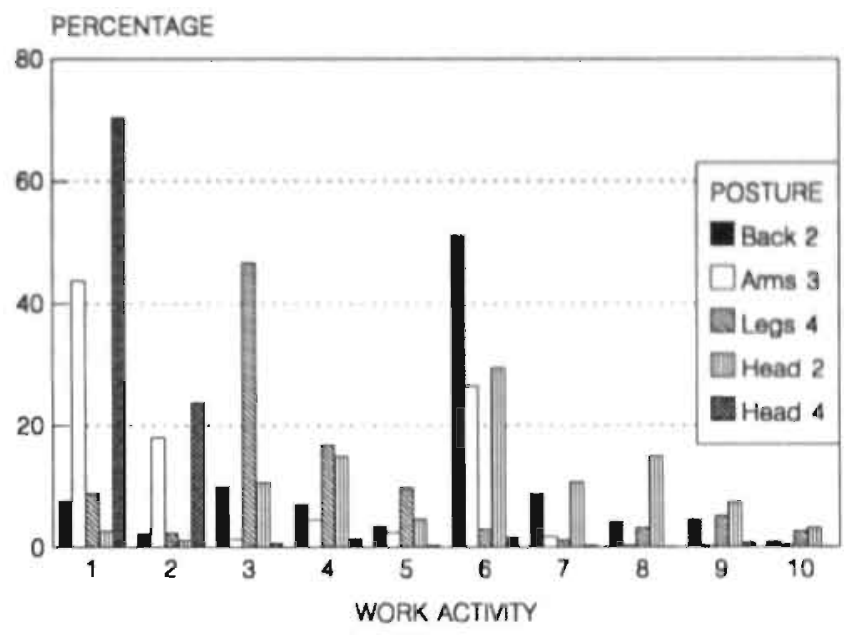

FIGURE 1: Distribution of observed poor postures of the body members (see Table 3 for description) over a mechanic's "average working day".

Activity 1: underneath the car; using a vehicle lift.

2: underneath the car; using a grease pit.

3: front, rear, or at the side of the car; car on floor.

4: front, rear, or at the side of the car; car on vehicle lift.

5: inside the car.

6: under the bonnet; car on floor.

7: under the bonnet; car on vehicle lift.

8: at workbench.

9: walking or moving to get tools, spare parts etc.

10: administration, deliberation.

Working underneath the car using a vehicle lift ( $43 \%)$ and working under the bonnet with the car on the fioor $(26 \%)$ are the mean activities causing the arms to be at or above shoulder level. Working at the side of the car with the car on the floor causes $(46 \%)$ the workers' knees to be bent. Working under the bonnet with the car on the floor explains $(32 \%)$ the head being in the bent forward position. 
From these calculations it is clear that, when only the postures of the body members are taken into account, working underneath the car using a vehicle lift, working under the bonnet (car on floor), and working at the side of the car (car on floor) are the main causes of poor working postures.

\section{Typical working postures}

Of the total number of observations, $63.2 \%$ fits into $A C 1,32.0 \%$ into $A C 2$, $3.6 \%$ into $A C 3$, and $1.2 \%$ into $A C 4$. This means that in garage work slightly harmful typical working postures occur during a substantial part of the working day.

In order to study the relationship between posture and activity the distribution of all the typical working postures over these activities was calculated. For each work activity the data were clustered into the four Action Categories shown in Figure 2.

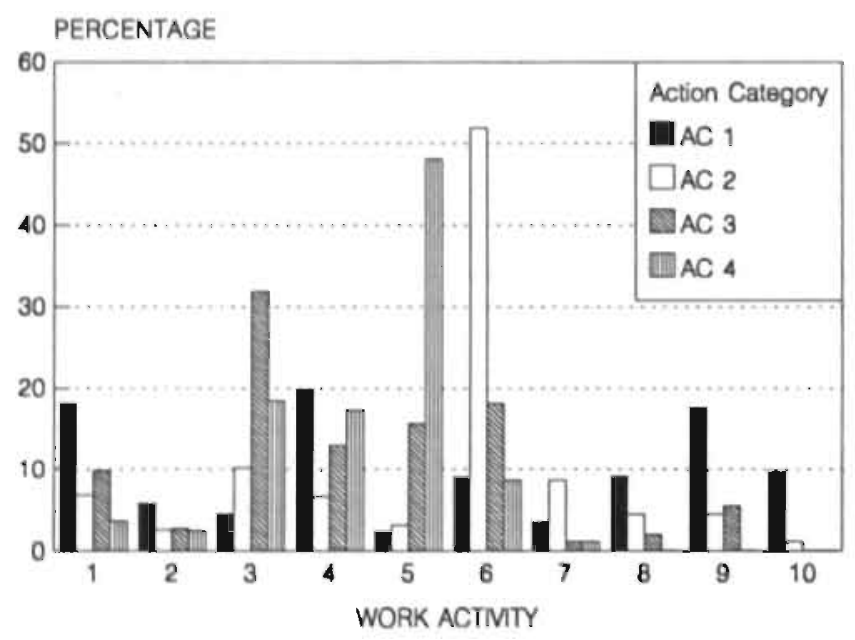

FIGURE 2: Distribution of typical working postures over all mechanics' activities during an "average working day". The 84 different typical working postures were clustered into four Action Categories. For a description of the activities see the caption for Figure 1.

These calculations show that the harmful typical working postures (AC 2, 3 and 4) during an "average working day" mainly occur while working:

- at the front, rear, or the side of the car (car on floor);

- at the front, rear, or the side of the car (vehicle lift in a raised position);

- under the bonnet (car on floor):

- in the car. 
When the results of both the postures of the body members and the typical working postures are taken into account ( $A C 2$ or higher), several work activities undertaken by car mechanics are considered by OWAS criteria to be slightly harmful to the musculoskeletal system. Briefly, the activities contributing most to the workload of an average working day (both in typical working postures and/or postures of the body members) are:

- working at the front, rear or the side of the car;

- working underneath the car;

- working under the bonnet (car on floor);

- working in the car.

\section{Alternative work methods}

Two work methods were observed during maintenance and repair activities underneath the car (i.e. to the gearbox, suspension, and exhaust). One involved a grease pit, the other a vehicle lift.

Also, two work methods were observed during repair and maintenance activities at the front, rear or side of the car (i.e. tyres and brakes). Again in one method a vehicle lift was used to bring the car to the required height; in the other method the car remained standing on the floor.

Most of the repair and maintenance of the car engine (i.e. dynamo, spark plugs, and tuning) demand an open bonnet, enabling the mechanic to reach the engine. Again, two work methods were observed when mechanics were working under the bonnet; in one method, the mechanic leaves the car on the floor, while in the other the car is brought to the required height with a vehicle lift.

In all three cases the mechanic's choice of a certain work method is determined mainly by the presence and/or availability of the correct equipment (i.e. vehicle lifts). Other tools are not discussed, since they are not relevant to the work postures imposed by these three work activities. In all garages except one, one or more vehicle lifts were present. In total 106 vehicle lifts of four different types were seen, with different types of lifts sometimes present in the same garage. In 16 garages (38\%) one or more grease pits were encountered. The total number of pits $(N=25)$ comprized 18 standard and 7 combined pits (two or three pits that are interconnected). Vehicle lifts and grease pits have different work heights, the lifts providing the advantage of work height adjustment (Table 4).

\section{Working underneath the car}

In Table 5 the number and percentage Occurrences of the postures of the body members for both work methods are listed and classified into Action Categories. 
TABLE 4: Numbers and dimensions of the different types of grease pits and vehicle lifts found in a garage survey study of 42 garages.

\begin{tabular}{llccc}
\hline & Type & Number & $\begin{array}{c}\text { Mean maximal } \\
\text { height }(\mathrm{cm})\end{array}$ & $\begin{array}{c}\text { Range Maximal } \\
\text { heigth }(\mathrm{cm})\end{array}$ \\
\hline Vehicle lift & 1-column & 14 & $186^{*}$ & $176-190$ \\
& 2-column & 28 & $185^{*}$ & $160-195$ \\
& 4-column & 61 & $177^{*}$ & $156-180$ \\
& jack-knife & 3 & $107^{*}$ & $60-180$ \\
& total & 106 & & $127-172$ \\
Grease pit & standard & 18 & $148 *$ & $152-168$ \\
& combined & 7 & $160^{* *}$ & \\
& total & 25 & & \\
\hline
\end{tabular}

- Distance measuredi between floor and chassis, of the car.

- Distance measured between floor and vehicle lift or bottom of the grease pit. The distance between floor and chassis is dependent on the type of car and adds, on average, about $30 \mathrm{~cm}$ to the listed heights.

TABLE 5: Postures of the body members imposed by working underneath the car when using a vehicle lift or a grease pit.

\begin{tabular}{|c|c|c|c|c|c|}
\hline \multirow{2}{*}{\multicolumn{2}{|c|}{$\begin{array}{l}\text { Postures of the } \\
\text { body members }\end{array}$}} & \multicolumn{2}{|c|}{ Vehicle lift } & \multicolumn{2}{|c|}{ Grease pit } \\
\hline & & $\%$ & Action Category & $\%$ & Action Category \\
\hline \multirow[t]{4}{*}{ Back } & 1 & 75.2 & 1 & 64.9 & 1 \\
\hline & 2 & 16.6 & 1 & 15.0 & 1 \\
\hline & 3 & 7.7 & 1 & 18.3 & $1-2$ \\
\hline & 4 & 0.5 & 1 & 1.8 & 1 \\
\hline \multirow[t]{3}{*}{ Arms } & 1 & 16.2 & 1 & 9.3 & 1 \\
\hline & 2 & 37.8 & 2 & 33.6 & 2 \\
\hline & 3 & 46.0 & 2 & 57.1 & 2 \\
\hline \multirow[t]{7}{*}{ Legs } & 1 & 1.1 & 1 & 1.8 & 1 \\
\hline & 2 & 91.4 & 2 & 85.6 & 2 \\
\hline & 3 & 2.0 & 1 & 8.7 & 1 \\
\hline & 4 & 2.9 & $1-2$ & 2.4 & $1-2$ \\
\hline & 5 & 0.2 & 1 & 1.2 & $1-2$ \\
\hline & 6 & 1.6 & 1 & 0.3 & 1 \\
\hline & 7 & 0.8 & 1 & 0.0 & 1 \\
\hline \multirow[t]{5}{*}{ Head } & 1 & 39.5 & 1 & 36.7 & 1 \\
\hline & 2 & 4.4 & 1 & 5.4 & 1 \\
\hline & 3 & 19.8 & 1 & 21.3 & 1 \\
\hline & 4 & 34.1 & 2 & 34.5 & 2 \\
\hline & 5 & 2.2 & 1 & 2.1 & 1 \\
\hline
\end{tabular}

- See note (Table 3) 
When using a pit the position of the back is more often in the bent sideways or twisted position (3) and the position of the legs is more often with the knee's bent (4), as compared to the method using a vehicle lift. These postures are classified in AC 2 when using a pit and in AC 1 when using a lift. A comparison of both methods based on postures of the body members reveals the pit to be the worst method. This can be explained by differences in work height. Grease pits were found to have mean work heights of 148 $\mathrm{cm}$ (standard) and $160 \mathrm{~cm}$ (combined) (see Table 4). Small mechanics can adjust their work height by using a pallet. Tall mechanics, are forced to bend their knees and/or their back.

When comparing the two work methods only minor differences were observed in the occurrence of poor typical working postures (Figure 3A).

\section{Working at the side of the car}

The percentages and the resulting Action Categories of the postures of the body members that occur during the two observed work methods greatly differ (specific data not shown). When the car is on the floor, the back is more often in a bent and twisted position (4) compared to the method using a vehicle lift. The position of the legs is more often with the knees bent $(4$ and 5$)$ or kneeling (6), while the head is more often in a bent forward position (2). All postures mentioned above are classified in a higher Action Category, meaning that the working postures imposed by the "floor method" are more harmful than the method using a lift.

The two work methods for working at the side of the car also greatly differ with respect to the occurrence of poor typical working postures (Figure $3 \mathrm{~B}$ ). When using a vehicle lift $82 \%$ of the typical working postures fit into $A C 1$, $14 \%$ in AC 2, only $3 \%$ in $A C 3$ and $1 \%$ in AC 4 . When no lift is used, $38 \%$ of the typical working postures fit into $A C 1,44 \%$ in $A C 2,15 \%$ in $A C 3$, and $3 \%$ in $A C 4$. This means that the typical working postures imposed by the "floor method" are far more harmful. Therefore, this method has to be regarded as the worst of the two.

\section{Working under the bonnet}

Again, applying the vehicle lift proves useful in minimizing harmful working postures during work under the bonnet (no specific data shown). With the car on the floor the position of the back is more often in a bent position (2) and in a bent and twisted position (4). Moreover, the position of both arms regularly crosses the shoulder level ( 2 and 3 ). The incidence of those postures is such that they rate a higher Action Category. However, when regarding the position of the head we observed that mechanics working on lifted cars hold their heads often in a bent forward position (2), resulting in AC 2-3. This means a worsening as compared to working at the unlifted car, where the head is 
more in a free position (1) falling into $A C 1$ and more in a bent sideways position (2), falling into AC 1-2.

The two work methods differ greatly with respect to the incidence of poor typical working postures (Figure $3 \mathrm{C}$ ). Although the use of a vehicle lift substantially reduces the incidence of harmful working postures, the percentage of typical working postures that fit into AC 2 is still high $(54 \%)$. The latter implies that even the better method for this task remains slightly harmful.

A

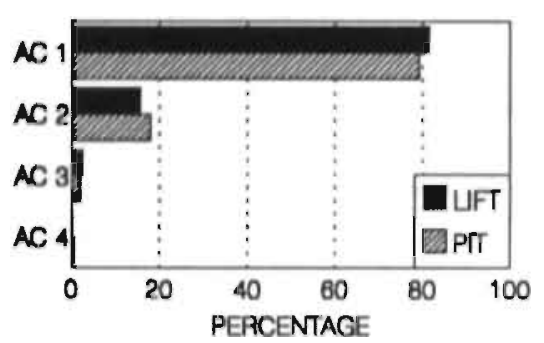

$\mathrm{B}$

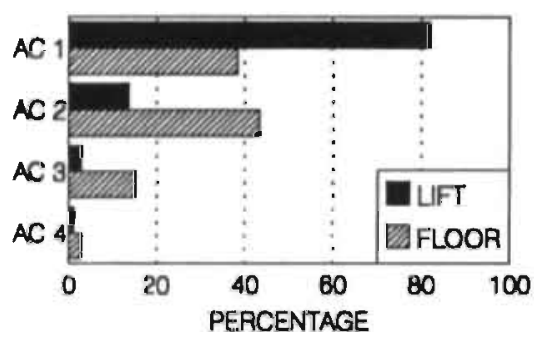

C

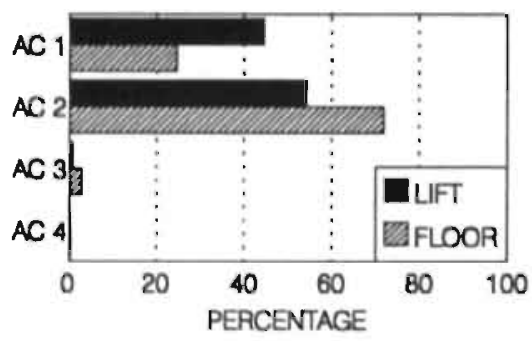

FIGURE 3: Comparison of three work tasks performed in two different ways (with or without using a vehicle lift (bridge)l showing the distribution of their typical working postures over the Action Categories.
A: activities underneath the car:
B: activities at the side of the car:
C: activities under the bonnet.

\section{Effects on daily incidence of poor working postures}

Using vehicle lifts in all three activities substantially reduces the incidence of poor postures of the body members over an "average working day". The opposite is observed when the worst methods are consistently used (data not shown). Interestingly, judgement by measuring changes in Action Categories reveals only minor changes compared to the observed (average) working day. 
This can be explained by the stepwise category setting of the OWAS Action Table. Moreover, Action Categories comprise postures of the body members and cannot register small improvements within each posture. Using the typical working postures as parameters, we see that the correct use of a vehicle lift in the three activities considerably reduces the incidence of poor typical working postures during a car mechanic's average workday (see Table 6). The reverse is true when the worst methods are implemented.

TABLE 6: Changes in typical working postures in the mechanics' average working day when work underneath, at the side of the car, and under the bonnet is performed using lifting equipment (best case) or without lifting equipment (worst case). The typical working postures were clustered into Action Categories.

\begin{tabular}{cccc}
\hline Action Categorie & $\begin{array}{c}\text { Observed work methods } \\
\%\end{array}$ & $\begin{array}{c}\text { Best Case } \\
\%\end{array}$ & $\begin{array}{c}\text { Worst case } \\
\%\end{array}$ \\
\hline 1 & 63.2 & 71.4 & 55.2 \\
2 & 32.0 & 25.4 & 37.9 \\
3 & 3.6 & 2.2 & 5.5 \\
4 & 1.2 & 1.0 & 1.4 \\
\hline Total & 100.0 & 100.0 & 100.0 \\
\hline
\end{tabular}

\section{DISCUSSION}

To the authors' knowledge this is the first study determining working postures of garage mechanics using OWAS. Moreover, different work methods for several activities have been compared in order to recommend improvements. The OWAS method appeared to be quite suitable for the study aims. Almost every working posture could be described with the elements provided by this method. It is based on working posture sampling which provides its user the necessary mobility.

The period of observation ( $1.5 \mathrm{~h}$ per garage) is, due to the great diversity of the work activities, not sufficient to describe the ergonomic situation for each garage separately. Therefore the OWAS data of all 42 garages were gathered, resulting in a description of working postures during a mechanic's "average working day".

This study indicated that four particular work activities cause poor working postures. The load imposed by three of these can be substantially reduced if a vehicle lift is used. Moreover, it. was calculated that a consistent application of the optimal work methods results in a substantial reduction of the car mechanic's ergonomic load over an "average working day". However, even 
when the optimal work methods are consistently applied, some activities still impose working postures that are harmful to the musculoskeletal system. To achieve a further reduction of this load, an improvement in garage equipment and in accessibility of engine parts seems obligatory.

The effect of optimal work handling is mostly seen in the typical working postures and less in the postures of the body members. This would imply that the effect of using a vehicle lift in the three work tasks studied is caused rather by the elimination of poor typical working postures, than by the reduction of the time spent in each poor posture.

Application of a work analysis method, only scoring postures of the body members e.g., LEST [Guélaud 1980], AET [Rohmert and Landau 1979, Rohmert 1985], van Rooyen [Rooyen van 1982,] would have never revealed the differences between work methods.

The design of this study can be used for surveys of categories of workers in order to improve work methods used. However, the extension of the original OWAS procedure, to incorporate a computerized data analysis, is a prerequisite to do so. It is hoped that this report will stimulate other investigators to use this relatively simple observation technique to study and improve working conditions which cause poor working postures.

\section{REFERENCES}

Andersson GBJ (1985): Posture, and compressive spine loading: intradiscal pressures, trunk myoelectric activities, intra-abdominal pressures, and biochemical analyses. Ergonomics 28:91-93.

Grandjean E, Hünting W (1977): Ergonomics of posture: review of various problems of standing and sitting posture. Appl Ergonomics 8; 135-140.

Guélaud F etăl. (1980): Pour une analyse des conditions de travail ouvrier dans l'enterprise, 3e ed. (Colin, Paris).

Hansson JE, Eklund L, Kihlberg S. Ostergren CE (1987): Vibration in car repair work. Appl Ergonomics 18; 57-63.

Hettinger Th (1985): Occupational hazards associated with diseases of the skeletal system. Ergonomics: 28; 69-75.

Karhu O, Kansi P, Kuorinka I (1977): Correcting working postures in industry: a practical method for analysis. Appl Ergonomics 8; 199-201.

Karhu O, Harkönen R, Sorvali P, Vepsalainen P (1981): Observing work postures in industry: examples of OWAS application. Appl Ergonomics 12; 13-17.

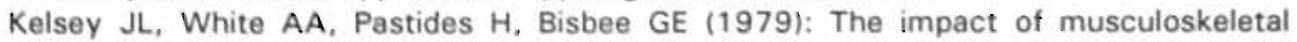
disorders on the population of the United States. J Bone \& Joint Surgery 61 A; 959-964.

Monod $H$ (1985): Contractility of muscle during prolonged static and repetitive dynamic activity. Ergonomics 28: 81-89.

Perrot JW (1961): Anatomical factors in occupational trauma. Med J Aust 3; 73-82.

Rohmert W (1985): AET: A new job analysis method. Ergonomics 28: 245-254.

Rohmert W, Landau K (1979): Das Arbeitswissenschaftliche Erhebungsverfahren zur Tătigkeitanalyse. Huber, Stuttgart. 
Rohmert W, Löwenthal I, Rükert A (1988): Körperhaltungsstudie bei Lade und Palettierungstătigkeiten auf einem Grossflughaven, Arbeitsmed. Sozialmed. Prăventivmed 23;91-96. Rooyen van R (1982): Houdingen en belastingen in de bouw. Tijdschr voor Ergonomie 7; 7-13.

Stoffert von G (1985): Analyse und Einstufung von Körperhaltungen bei der Arbeit nach der OWAS Methode. Z Arbeitswissenschaft 39; 31-38.

Wely van P (1979): Design and disease. Appl Ergonomics 1: 262-269.

Wangenheim M, Samuelson B (1987): Autonomic ergonomic work analysis. Appl Ergonomics 18; 9-15. 



\section{CHAPTER 7}

\section{A survey of static and dynamic work postures of operating room staff*}

\section{SUMMARY}

Work in health care units is associated with considerable physical strain and many musculoskeletal complaints. Most investigations have concentrated on the work of general hospital nurses; little is known about the physical stress load on other health care workers. We therefore carried out an ergonomic study amongst operating room staff in order to: (i) determine the work (posture) stress load on this particular group of health care workers and the effect of static posture on this stress, (ii) identify activities involving poor work postures, and (iii) determine differences between specialities in regard to work posture stress load. The work postures and related work activities of four different groups of staff in operating rooms (surgeons, anaesthetist assistants, instrumentation nurses and circulating nurses) were recorded and evaluated using the specified Ovako Working posture Analysing System (OWAS). Observation during the course of 18 daily surgical programmes (total number of observations: 3,714 ) in the specialities general surgery and Ear-Nose-Throat (ENT) surgery revealed that the workload according to OWAS for circulating nurses and anaesthetist assistants was not harmful. Some work postures seen among instrumentation nurses and surgeons, however, need improvement. The work posture stress load in these groups is mainly due to the high prevalence of static work postures during the activities "surgery" (surgeons) and "assisting surgery" (instrumentation nurses). Significant differences inergonomic stress load were observed between general surgeons and ENT surgeons. This survey in operating theatres relates work postures to basic activities and can be used as a starting point from which to improve work conditions in order to reduce or eliminate physical complaints among operating room staff.

* Kant IJ, Jong de LCGM, Rijssen-Moll van M. Borm PJA. Int Arch Occup Environ Health 1992;63:423-4.28. 


\section{INTRODUCTION}

Work in health care units is associated with considerable physical stress and many complaints relating to the musculoskeletal system [Buckle 1987, Howie 1982, Smulders 1985, Stilma 1982, Stubbs et al. 1983]. According to Smulders [1985], the nursing profession actually ranks second after industrial work as far as physical workload is concerned.

Most studies investigating physical stress in health care workers have concentrated on general hospital nurses and predominantly focused on the low backpain problem [Arad and Ryan 1986, Skovron 1987, Stubbs et al. 1981, 1983]. This problem is presumably caused by poor work postures, patient-lifting activities and carrying too much weight [Owen 1985, Scholey 1983, Stubbs et al. 1983, Wright 1981]. Little is known about ergonomic stress in more specific groups of hospital workers, however, such as operating room staff. These workers may also be subjected to ergonomic stress due to poor work postures and patient handling activities. Moreover, working in operating rooms also involves a considerable amount of static posture. Especially during operations, surgeons and instrumentation nurses have fixed work postures which could be responsible for discomfort and disorders of the musculoskeletal system. For this reason, extrapolating results from general hospital nurses to operating room workers is not justified.

We therefore carried out an ergonomic study among operating room staff in order to determine the range and stress load of work postures among staff in operating theatres. Work postures of four different groups of staff (surgeons, anaesthetist assistants, instrumentation nurses and circulating nurses) were recorded, using the specified Ovako Working posture Analysing System (OWAS) [Karhu et al. 1977, 1981]. Since the work postures of operating room staff, especially surgeons, may be dependant on the type of operation concerned, two specialities were included in our study: general surgery and Ear-NoseThroat (ENT) surgery: in general surgery the surgeons stand most of the time, while ENT surgeons predominantly sit while operating.

The aims of our study were:

1. To determine work posture stress load and the effect of static postures on this stress load;

2. To identify activities involving poor work postures;

3. To determine differences between specialities in regard to work posture stress load.

\section{SUBJECTS AND METHODS}

\section{Selection and description of workplaces}

This study was carried out in the operating rooms of the University Hospital in Maastricht, The Netherlands. The operating room complex consists of ten 
operating rooms, one recovery room and several other rooms (offices, stores, etc.). All operating rooms have the same dimensions and basic equipment; two of them are for general surgery and/or emergency operations, while the other are more or less reserved for specialist surgery, e.g. orthopaedic, ENT, etc. Since the work postures of operating room staff, especially surgeons, may be dependent on the type of operation being performed, we included two specialities in our study: general surgery and ENT surgery.

\section{Study population}

Different professional groups with different tasks can be distinguished within operating rooms. The ergonomic stress on these groups may depend on their tasks. Accordingly, we observed four professional groups: surgeons, anaesthetist assistants, instrumentation nurses and circulating nurses. Anaesthetists were not included. Data relating to the study subjects are given in Table 1.

TABLE 1: Number of observation periods and number of subjects studied.

\begin{tabular}{lcccccc}
\hline Professional group & \multicolumn{2}{c}{ General surgery } & \multicolumn{2}{c}{ ENT surgery } & \multicolumn{2}{c}{ Total } \\
\cline { 2 - 7 } & $\begin{array}{c}\text { Observation } \\
\text { periods }\end{array}$ & $\mathrm{N}$ & $\begin{array}{c}\text { Observation } \\
\text { periods }\end{array}$ & $\mathrm{N}$ & $\begin{array}{c}\text { Observation } \\
\text { periods }\end{array}$ & $\mathrm{N}$ \\
\hline Surgeons & 10 & 6 & 6 & 5 & 16 & 11 \\
Anaesthetist assistants & 1 & 1 & 3 & 2 & 4 & 3 \\
Instrumentation nurses & 3 & 3 & 4 & 3 & 7 & 6 \\
Circulating nurses & 3 & 2 & 1 & 1 & 4 & 3 \\
\hline Total & 17 & 12 & 14 & 11 & 3.1 & 23 \\
\hline
\end{tabular}

\section{OWAS method}

The method employed was the Ovako Working posture Analysing System. This method describes the stress load on the musculoskeletal system due to (poor) work postures using action categories. The original method was developed by the Ovako Oy Steel Company in Finland and was used in several studies [Karhu et al. 1977, 1981, Rohmert et al. 1988, Stoffert von 1985, Kant et al. 1990]. The OWAS method is based on work sampling (sampling at regular or variable intervais) and records the frequency of and time spent in each posture.

The original OWAS includes two methods:

- The basic OWAS for work of a purely dynamic character;

- The specified OWAS for work with a substantial static component. 
Following the OWAS flow chart (Figure 1), we selected the specified OWAS method, systematizing work postures in a matrix form using 4-digit codes. The position of the back ( 4 positions), arms ( 4 positions), legs 17 positions) and head (5 positions) are recorded for each observation; these elements are shown in Table 2.

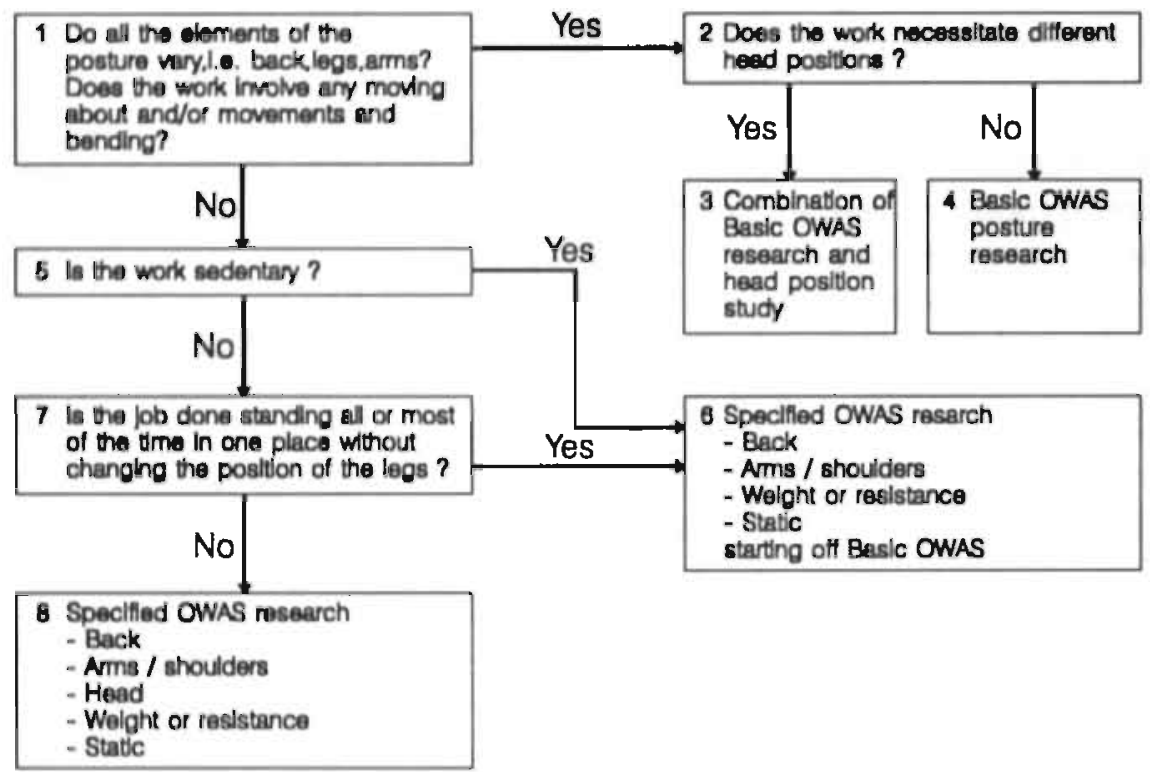

FIGURE 1: Flow chart for selection of the appropriate OWAS method. According to this flow chart the appropriate method for all professional groups in the operating theatre is the specified OWAS. For instrumentation nurses, circulating nurses and general surgeons the route is 1-5-7-6. For ENT surgeons and anaesthetist assistants the route is $1-5-6$ or $1-5-7-6$.

A separate entry is made for a part of the body in a static position at the time of observation (e.g. "bent down" instead of "bending down").

In the original description of the method, the harmfulness of the work postures was estimated by workers, work study observers and physiologists. These estimations were divided into four Action Categories (AC), which can be used for recommendations to the management as follows:

AC 1: normal posture, no action required.

$A C$ 2: the stress load of the posture is slightly harmful.

Action to change the posture should be taken in the near future.

AC 3: the stress load of the posture is distinctly harmful.

Action to change the posture should be taken as soon as possible.

AC 4: the stress load of the posture is extremely harmful.

Action to change the posture should be taken immediately. 
Using the specified OWAS method, all postures of the parts of the body are calculated as a percentage of the total number of observations and classified into the four Action Categories. Subsequently, the purely static work postures are selected, expressed as a percentage of the total number of observations and also classified into the four Action Categories. However, for the latter classification different criteria are used.

TABLE 2: Elements of the specified OWAS system and the symbols used to describe postures of the body parts in both dynamic and static postures".

\begin{tabular}{lll}
\hline Body part & OWAS-Code & Posture \\
\hline Head & 1 & Free \\
& 2 & Bent forwards \\
& 3 & Bent to the side \\
& 4 & Bent backwards \\
& 5 & Twisted \\
Legs & 1 & Sitting with legs below level of buttocks \\
& 2 & Standing on both straight legs \\
& 3 & Standing on one straight leg \\
& 4 & Standing or crouching on both feet, knees bent \\
& 5 & Standing or crouching on one foot, knee bent \\
& 6 & Kneeling on one or both knees \\
Arms & 7 & Walking or moving \\
& 1 & Arms free, shoulders not raised (dynamic), shoulders raised \\
& 2 & One arm at or above shoulder level \\
& 3 & Both arms at or above shoulder level \\
& 4 & One or both upper arms clearly away from body and below \\
& & shoulder level \\
& 1 & Straight \\
& 2 & Bent \\
& 3 & Twisted or bent sideways \\
& 4 & Bent and twisted or bent forwards and sideways \\
& &
\end{tabular}

\footnotetext{
- The distinction between a static or dynamic posture depends on the position of the part of the body at the moment of observation. The posture is dynamic when the body part is moving (e.g. bending, twisting, lifting) and static when the body part is immobile (e.g. bent, twisted, lifted) at the moment of observation.

b The position of the arms in this case is different for static and dynamic.
}

\section{Sampling strategy}

Observations were performed by three observers during 18 general and ENT surgical programmes. The mean duration of surgical programmes was $5 \mathrm{~h}$ (range 2.2-7.5 h). Observations were taken at 1-min intervals. The interobserver variability was $4 \%$ with respect to the finall percentage of all work 
postures. For each observation not only the work posture, but also the concomitant work activity was recorded. To enable subsequent analysis of work postures in relation to vvork activities, all activities in a specific job were divided into basic work activities. The division into basic activities and the determination of inter-observer variability were performed in a pilot study (total observation time: $8 \mathrm{~h}$ ). With the specified OWAS method, the staticness or otherwise of the postures is determined when the observation is made. We, however, used a different approach: Instead of determining staticness at each observation individually, we selected certain activities which contained a substantial (> 70\%) static component. These activities were taken to be "purely static" and were identified in the pilot study. The basic work activities, including their definition as dynamic or static, are shown in Table 3.

\section{Data analysis and statistics}

A special computer program, was used for the analysis of the OWAS data. Using this program, it was easy to investigate the quantitative relation between work postures and specific work activities [Kant et al. 1990]. Separate data files were created to store the observations for each professional group (work posture code and concomitant activity). The output of the program included: (i) the average time spent in the basic activities, (ii) the percentages of the postures of the body parts (static and dynamic), and (iii) the distribution of these postures in relation to the basic activities. In this way, the ergonomic stress on each group was evaluated and the activities principally contributing to that stress were identified. A $x^{2}$ test was used to compare the incidences of each work posture between general and ENT surgeons.

\section{RESULTS}

The total number of observations was 3,714. The percentages of time spent by each group in the basic work activities are show in Table 3.

\section{Postures of the parts of the body (static and dynamic)}

For circulating nurses and anaesthetist assistants, all postures of parts of the body are classified as AC 1, meaning that none are harmful to the musculoskeletai system. Among instrumentation nurses and surgeons, however, the incidence of the head-bent-forward position is high ( $27 \%$ and $54 \%$ respectively) and the posture classified as $A C 2$ and $A C 3$ respectively, i.e. slightly or distinctly harmful (Table 4). The distribution in relation to basic activities (specific data not shown) revealed that the basic activities "surgery" (surgeons) and "assisting surgery" (instrumentation nurses) accounted for $80 \%$ and $78 \%$ respectively of these poor head postures. 
TABLE 3: Basic work activities performed by different professional groups in the operating room during an "average" surgical programme and the percentage of time spent in these activities.

\begin{tabular}{|c|c|c|c|}
\hline $\begin{array}{l}\text { Staff category } \\
\text { (number of } \\
\text { observations) }\end{array}$ & Basic activity & $\begin{array}{c}\text { Static (S)/ } \\
\text { dynamic } \\
\text { (D) * }\end{array}$ & $\begin{array}{c}\text { Percentage of } \\
\text { surgical } \\
\text { programme }\end{array}$ \\
\hline \multirow{9}{*}{$\begin{array}{l}\text { Anaesthetist assistants } \\
(\mathrm{N}=593)\end{array}$} & Inducting anaesthesia & D & 3.9 \\
\hline & Transporting patients & D & 4.0 \\
\hline & Patient care & $D$ & 17.5 \\
\hline & Getting materials & D & 4.4 \\
\hline & Observation/administration & $\mathbf{S}$ & 49.0 \\
\hline & Lifting patients & D & 0.2 \\
\hline & Various acts & $D$ & 16.9 \\
\hline & Waiting for next patient & D & 0.2 \\
\hline & Cleaning equipment & D & 3.0 \\
\hline \multirow{9}{*}{$\begin{array}{l}\text { Surgeons } \\
(N=1377)\end{array}$} & Preparing patient & D & 3.6 \\
\hline & Surgery & $\mathbf{S}$ & 64.8 \\
\hline & Instructing/teaching assistants & $\mathrm{s}$ & 3.6 \\
\hline & Administration & s & 6.8 \\
\hline & Spread wound & $\mathrm{S}$ & 4.3 \\
\hline & Various acts & $D$ & 7.8 \\
\hline & Pause & D & 0.0 \\
\hline & Washing hands & $\mathrm{S}$ & 3.6 \\
\hline & Waiting for next patient & $D$ & 5.4 \\
\hline \multirow{10}{*}{$\begin{array}{l}\text { Circulating nurses } \\
(N=496)\end{array}$} & Standing by & $\mathrm{S}$ & 22.0 \\
\hline & Transporting patients & $D$ & 5.3 \\
\hline & Patient care & D & 9.7 \\
\hline & Getting materials & D & 9.7 \\
\hline & Administration & $\mathrm{S}$ & 14.1 \\
\hline & Lifting patients & D & 0.4 \\
\hline & Various acts & D & 16.5 \\
\hline & Pause & D & 5.0 \\
\hline & Cleaning operating room & D & 10.9 \\
\hline & Equipment assistance & $D$ & 6.5 \\
\hline \multirow{9}{*}{$\begin{array}{l}\text { Instrumentation nurses } \\
(N=1248)\end{array}$} & Washing hands & $\mathrm{S}$ & 1.1 \\
\hline & Laying out instrument & D & 9.4 \\
\hline & Assisting surgery & $\mathrm{S}$ & 74.1 \\
\hline & Assisting microscopy & $\mathrm{S}$ & 0.1 \\
\hline & Pause & D & 0.0 \\
\hline & Waiting for next patient & $D$ & 4.2 \\
\hline & Various acts & D & 4.4 \\
\hline & Clearing/cleaning instruments & $D$ & 6.4 \\
\hline & Administration & $\mathrm{S}$ & 0.3 \\
\hline
\end{tabular}

* Work activities with a substantial percentage $(>70 \%)$ of static postures are defined as static. The other work activities are defined as dynamic. The selection of the static activities was made in a pilot study (total observation time $8 \mathrm{~h}$ ). 
Postures of the parts of the body (static)

Assessment of the purely static work postures as compared to static plus dynamic postures revealed no new insights in relation to circulating nurses and anaesthetist assistants. However, the ergonomic stress on both surgeons and instrumentation nurses was aggravated when the static nature of the postures was taken into account (Table 4).

TABLE 4: Work postures encountered in surgeons and instrumentation nurses and classified by OWAS into Action Category (AC) 2 or higher.

\begin{tabular}{|c|c|c|c|c|c|c|c|}
\hline \multirow[t]{2}{*}{ Postures of body parts } & \multirow{2}{*}{$\begin{array}{l}\text { Posture types } \\
\text { evaluated" }\end{array}$} & \multicolumn{3}{|c|}{ Surgeons } & \multicolumn{3}{|c|}{ Instrum. nurses } \\
\hline & & $N^{b}$ & $\%^{c}$ & $A C$ & $N$ & $\%$ & $A C$ \\
\hline \multicolumn{8}{|l|}{ HEAD } \\
\hline Bent forward & Dynamic + Static & 743 & 54 & 3 & 334 & 27 & 2 \\
\hline Bent forward & Static & 698 & 50 & 3 & 268 & 21 & 2 \\
\hline \multicolumn{8}{|l|}{ BACK } \\
\hline Bent and twisted & Static & 37 & 2 & 2 & 56 & 4 & 2 \\
\hline \multicolumn{8}{|l|}{ ARMS/SHOULDERS } \\
\hline $\begin{array}{l}\text { Both arms under the shoulder- } \\
\text { level, shoulders raised }\end{array}$ & Static & 976 & 70 & 2 & 49 & 60 & 1 \\
\hline \multicolumn{8}{|l|}{ LEGS } \\
\hline Standing on one leg straight & Static & 185 & 13 & 2 & 125 & 10 & 1 \\
\hline Total number of observations & & 1377 & & & 1248 & & \\
\hline
\end{tabular}

" Types of posture taken into account for the evaluation of stress

${ }^{b}$ Number of observations

"Frequency of specific postures (dynamic + static or static) of the body parts express as a percentage of the total number of observations for that body part

Among surgeons, the head postures (bent forward) is classified as A.C 3, but now also back posture (bent forward and twisted), arm posture (shoulders raised) and leg posture (standing on one leg) are classified as AC 2. Among instrumentation nurses, head, posture (bent forward) and back posture (bent forward and twisted) are both classified as AC 2 . Among instrumentation nurses, head posture (bent forward) and back posture (bent forward and twisted) are both classified as AC 2. Again, further analysis revealed that the basic activities "surgery" (surgeons) and "assisting surgery" (instrumentation nurses) accounted for about $80 \%$ of these poor (static) work postures. 
Ergonomic stress in general and ENT surgeons

To investigate possible differences in ergonomic stress between the two surgical specialities, calculations on postures of body parts were repeated separately for ENT and general surgeons. The incidence of several postures (both dynamic/static and purely static) were found to be significantly different between the two groups of surgeons ( $p>0.05$; Table 5).

TABLE 5: Differences in work postures of general surgeons (GS) and ENT surgeons. Work postures are expressed as percentages of the total number of observations and resulting OWAS classification.

\begin{tabular}{|c|c|c|c|c|c|c|c|c|c|c|c|c|}
\hline \multirow[t]{3}{*}{ Posture of the body parts } & \multicolumn{6}{|c|}{ Dynamic + static* } & \multicolumn{6}{|c|}{ Static ${ }^{b}$} \\
\hline & \multicolumn{2}{|c|}{ GS } & \multicolumn{2}{|c|}{ ENT } & \multirow[t]{2}{*}{$x^{5}$} & \multirow[t]{2}{*}{$P$} & \multicolumn{2}{|c|}{ GS } & \multicolumn{2}{|c|}{ ENT } & \multirow[t]{2}{*}{$x^{e}$} & \multirow[t]{2}{*}{$\mathbf{P}$} \\
\hline & $\%$ & $A C$ & $\%$ & $A C$ & & & $\%$ & $A C$ & $\%$ & $\mathrm{AC}$ & & \\
\hline \multicolumn{13}{|l|}{ BACK } \\
\hline Legs & 73 & 1 & 88 & 1 & 33.2 & $\cdots$ & 60 & 1 & 64 & 1 & 22.8 & $\cdots$ \\
\hline Bent & 16 & 1 & 8 & 1 & 13.8 & $\cdots$ & 14 & 1 & 8 & 1 & 9.2 & $\cdot$ \\
\hline Twisted & 8 & 1 & 3 & 1 & 10.3 & $\bullet$ & 8 & 1 & 3 & 1 & 6.8 & - \\
\hline Bent and twisted & 3 & 1 & 1 & 1 & 4.3 & - & 3 & 2 & 1 & 2 & 3.0 & ns \\
\hline
\end{tabular}

\section{ARMS/SHOULDERS}

LEGS

Sitting with legs under buttock $\quad 8 \quad 1 \quad 26 \quad 1 \quad 78.5 \quad \cdots$ level

Standing on both legs straight. $\quad \begin{array}{lllllll}71 & 1 & 67 & 1 & 1.5 & \mathrm{~ns}\end{array}$

Standing on one leg straight $\quad \begin{array}{llllllll}19 & 1 & & 3 & 1 & 53.4 & \cdots\end{array}$

Walking or moving

$\begin{array}{lllllll}2 & 1 & 4 & 1 & 6.2 & *\end{array}$

$\begin{array}{llllll}59 & 1 & 52 & 1 & 0.1 & \text { ns }\end{array}$

$\begin{array}{llllll}18 & 2 & 0 & -61.3 \cdots & \cdots\end{array}$

HEAD

Free.

Bent forwards

Bent to one side

Twisted

$\begin{array}{rrrrrr}29 & 1 & 46 & 1 & 34.0 & \cdots \\ 59 & 3 & 40 & 2 & 35.3 & \ldots \\ 5 & 1 & 2 & 1 & 8.9 & \cdots \\ 7 & 1 & 12 & 1 & 10.7 & \cdots\end{array}$

0 .

ns

- Percentages of static and dynamic work postures based on the total number of observations and the resulting Action Categories (criterion static + dynamic postures).

bercentage of static work postures based on the total number of observations.

s Statical significance was tested using the $\times 2$. test on the number of observations for each work posture $(\cdot P<0.05$; $\cdots p<0.01$; $\cdots P<0.001$; ns, no significant difference).

${ }^{d}$ No significant difference between the specialities general surgery and ENT surgery was found for any of the arm/shoulder position (data not shown).

General surgeons more often have their backs in (i) a bent position, (ii) a twisted position, and (iii) a bent and twisted position. Although the relative prevalences (number of recorded observations) of these dynamic postures differ 
significantly, they are all classified by OWAS into AC 1. During a surgical programme general surgeons stand on one leg more often and sit less often than ENT surgeons; the static position "standing on one leg" is classified as AC 2 for the general surgeons and AC 1 for the ENT surgeons. During a surgical programme general surgeons more often have their head in a forwards-bent position than ENT surgeons; this posture was classified as AC 3 for general surgeons and AC 2 for ENT surgeons. No significant differences were found between the two groups for any of the arm positions.

To explain these differences, we calculated the distribution of poor work postures over ali basic activities. Only minor differences were found between the two specialities. Moreover, poor work postures mainly occur ( $>80 \%)$ during the activity "surgery" for both specialities. We then calculated the time spent in basic activity "surgery" for both specialities. During a surgical programme general surgeons spent $68.1 \%$ of their time in "surgery" and ENT surgeons $57.6 \%$. Still, this difference in time distribution only partially explains the difference in ergonomic stress load.

\section{DISCUSSION}

To our knowledge, this is the first study determining the work postures of operating room staff using the OWAS. Using the OWAS method, almost every work posture could be described and the work activities principally causing the physical stress could be identified. Moreover, this observation technique provided the observers with the necessary mobility without hindering the work activities of the personnel because of the observations.

The observation period (2-3 h per subject) was not sufficient to describe the ergonomic "situation" for each subject individually. The OWAS data were therefore clustered, resulting in a description of work postures for each staff category during an "average surgica! programme".

Several studies have reported high physical stress in general nurses [Arad and Ryan 1986, Stubbs et al. 1983]. Our data indicate that surgeons and instrumentation nurses also experience substantial stress to the musculoskeletal system. This stress is aggravated by the high incidence of purely static work postures.

Our data revealed no harmful work posture stress load for circulating nurses and anaesthetist assistants. Some instrumentation nurses intermittently act as circulating nurses: the total ergonomic stress in these nurses will therefore be lower than that in nurses who only act as instumentation nurse.

Our data imply that the activity "surgery" is attended by higher ergonomic stress in general than in ENT surgery. Extrapolating our findings, this could mean that general surgeons are at higher risk for back and neck/shoulder disorders. Unfortunately, no other reports are available to confirm or refute these conclusions. 
The data presented in this paper should not be regarded as a standard for other hospitals. This study was carried out in an academic hospital operating room complex where medical students and assistants are trained and taught during surgery. Nevertheless, our data give a rough picture of the work postures related to the basic activities in operating rooms and can be used to relate complaints to work conditions. More studies in other hospitals, and using other methods, are necessary to describe and reduce the ergonomic stress on operating room staff.

\section{REFERENCES}

Arad D, Ryan MD (1986): The incidence and prevalence in nurses of low backpain: a definitive survey exposes the hazards. Aust Nurs $J 1: 44-48$.

Buckle PW (1987): Epidemiological aspects of backpain within the nursing profession. Int J Nurs Stud 4; 319-324.

Grandjean E, Hünting W (1977): Ergonomics of posture - review of various problems of standing and sitting posture. Appl Ergonomics 8 (3); 135-140.

Hettinger T (1985): Occupational hazards associated with deseases of the skeletal system. Ergonomics 28 (1): $69-75$.

Howie C (1982): Oh! my back! Nurs Times 17; 1937-1938.

Kant IJ, Notermans JHV, Borm PJA (1990): Observations of working postures in garages using the Ovako Working posture Analysing System (OWAS) and workload reduction recommendations. Ergonomics 33 (2); 209-220.

Karhu O, Kansi P, Kuorinka I (1977): Correcting working postures in indusțry. A practicaí method for analysis. Appl Ergonomics 8 (4): 199-201.

Karhu O, Harkönen R, Sorvali P, Vepsalainen P (1981): Observing working postures in industry: examples of OWAS application. Appl Ergonomics 12 (1): 13-17.

Monod $H$ (1985): Contractility of muscle during prolonged static and repetitive dynamic activity. Ergonomics 28 (1); 81-89.

Owen BD (1985): The lifting proçess and back injury in hospital nursing personell. West J Nurs Res 7: 445-459.

Perrot JW (1961): Anatomical factors in occupational trauma. Med J Aust 3: 73-82.

Rohmert von W, Löwenthal I, Rükert A (1988): Körperhaltungsstudie bei Lade- und Palettierungstätigkeiten auf einem Grossflughafen. Arbeidsmed Sozialmed Prăventivmed 23; 91 . 96.

Scholey M (1983): Back stress: the effect of training nurses to lift patients in a clinical situation. Int J Nurs Stud 1: 1-13.

Skovron ML. (1987): Work organisation and low backpain in nursing personnel. Ergonomics 30: $359-366$.

Stoffert von G (1985): Analyse und Einstufung van Körperhaltungen bei der Arbeid nach der OWAS Methode. Z Arbeitswiss 39; 31-38.

Smulders PGW (1985): Arbeidsituaties en gezondheidszorg in ziekenhuizen. Report, Nederlands Instituut voor Preventieve Geneeskunde. NIPG, Leiden (in Dutch).

Stilma J (1982): Het signaleren van fysieke belasting in de verpleging en maatregelen ter bestrijding van overbelasting. Amsterdam (in Dutch).

Stubbs DA et al. (1981): Backpain research. Nurs Times 14; 857-858. 
Stubbs DA et al. (1983): Backpain in nursing profession I and II. Ergonomics 26; 755-76; 767-779.

Wright B (1992): Lifting and moving patients (2. Training and management). Nurse Times $18: 2025-2028$. 


\section{CHAPTER 8}

\section{Analysis and improvement of work postures: Development and application of a computerised OWAS method*}

\section{SUMMARY}

Poor working postures are associated with the development of musculoskeletal disorders. Many different observation methods have been developed to analyse working posture and job tasks. OWAS (Ovako Working posture Analysing System) is a relative simple observation method for postural analysis. A computerised system for the OWAS method was developed in order to (i) improve the quality of work posture sampling, (ii) to relate work postures to specific job tasks and (iii) to minimise the time required for data analysis.

This paper describes the development of the system and its application in two ergonomic studies. It is concluded that the computerised OWAS system is a powerful tool to identify tasks with a high postural load, to develop control measures and estimate the effect of these measures.

\section{INTRODUCTION}

Musculoskeletal disorders are the largest single source of employee absenteeism and injury cost in Europe. For example; In The Netherlands over one third of all cases of occupational disability are caused by disorders concerning the musculoskeletal system [Verbeek 1991]. Still little is known about the causal relationship between inadequate working conditions and musculoskeletal disorders. Nevertheless, there are clear indications that postural stress is a major factor in the pathogenesis of musculoskeletal disorders [Chaffin et al. 1984, Corlet 1976, Keyserling 1986!.

Measures for the prevention of such musculoskeletal injuries may involve various ergonomic measures aimed at reducing the load on the locomotor system by altering the design of equipment in the workplace or changing work

*Kant IJ, Swaen GMH, Borm PJA. Ann Occup Hyg (submitted). 
methods or schedules as addressed in the Manual Handling Operations Regulations [EEC 1992]. This requires an accurate and reliable description of work postures and identification of tasks associated with poor postures.

Various observation methods have been developed to analyse working postures and work tasks. Comprehensive job analyses have been developed for detailed description [Rohmert 1985, Guelaud 1980]. Many detailed postural analysis methods have been developed for special situations; some are best suited to static jobs [Corlett et al. 1979, Aaras et al. 1988], some especially for seated jobs [Cote Gil and Tunes 1989], or for repetitive, non-seated tasks [Keyserling 1986].

Also different techniques are applied, such as direct measurements on subjects, video and observation techniques. For field measurements observation techniques are to be preferred since this technique is mobile and non intruding [Douwes and Dul 1990].

The Ovako Working posture Analysing System (OWAS) is one of the simpler observation methods for postural analysis [Karhu et al. 1977]. The OWAS method has proved to be useful in achieving improvements in the system and in preventing health problems in the steel industry [Karhu et al. 1981]. The method has also proved to function well in practice in many other different occupational settings [Rohmert 1988, Kant et al. 1990, Engels 1993]. Therefore, the Dutch Inspectorate of Labour recommended the OWAS as one of the standard tools for work posture analysis [Douwes and Dul 1990].

Although the OWAS method is an intrinsically powerful tool for the analysis and improvement of work postures, so far some disadvantages impeded wide application:

a) The observation and recording of work postures at preset intervals is a constant strain for the observer: During observation the observer has to observe the subject and timer at the same time. When using the original OWAS forms the observer must learn the elements of the system by heart;

b) Knowledge of the task carried out during different postures is required before corrective and preventive action can be taken. Although the concomitant activity can be recorded on the original OWAS forms, a quantitative relation between work postures and specific work activities cannot be obtained easily;

c) The data analysis, when performed manually is very time consuming and is very limited in its possibilities.

The aim of this project was to computerise the OWAS method in order to:

- Improve the quality of posture sampling;

- Relate work postures to specific work activities;

- Extend the data analysis;

- Minimise the time necessary for data analysis. 


\section{THE ORIGINAL. OWAS METHOD}

The OWAS method is based on work posture sampling at constant intervals, which provides information on the frequency of and time spent in each posture [Karhu et al. 1977, Stoffert von 1985]. OWAS systematises work postures using a Matrix.

Using a 4-digit code the position of the back, arms and legs and the applied force are recorded for each observation. In addition five positions of the head can be recorded. The result is that the possible positions of the individual body postures can be scored in a matrix of 84 possible working postures.

The potential harmfulness of these postures is arranged according to increasing postural load in four categories, so-called Action Categories. Measures to eliminate stressful body postures can be applied in the demonstrated order of urgency:

AC 1 - normal posture: no actions required;

AC 2 - the load of the posture is slightly harmful: actions to change the posture should be taken in the near future;

AC 3 - the load of the body is distinctly harmful: actions to change the posture should be taken as soon as possible;

AC 4 - the load of the posture is extremely harmful: actions to change the posture should be taken immediately;

The frequency distribution of the postures of body parts can be calculated separately and can also be classified into these four Action Categories.

\section{IMPROVEMENT OF THE OWAS METHOD: DEVELOPMENT OF THE SYSTEM}

The computerised version of the OWAS was developed and used during two ergonomic surveys. One was carried out among garage mechanics [Kant et al. 1990], the other among operating room staff [Kant et al. 1992]: The endresult is the WORKMAN-1 System. It constitutes a clipboard with a handheld computer (Psion Organiser LZ-64), a barcode reader and specially designed OWAS barcode observation forms and software. Figure 1 shows its principle application. Using the barcode reader the posture and related work activity are marked on the observation form and stored in the handheld computer. After completion of the observation, the data are transferred to a personal computer. A powerful PC based analysis program allows overall scores to be quickly computed and analysed in order to identify those work activities which require action to be taken.

Improvements of the OWAS method have been made at two different stages; the method of observation and the data analysis. 


\section{WORKPLACE}

OFFICE $/$

WORKPLACE

OFFICE
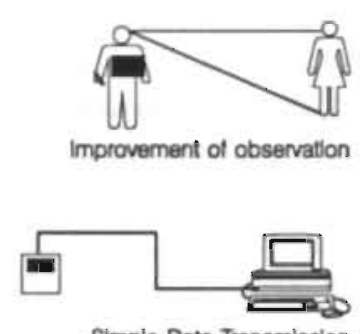

Simple Data Transmission

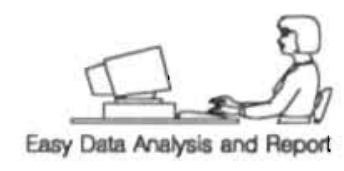

FIGURE 1: Principle application of the WORKMAN-1 system.

Work postures are șampled by the observer using a barcode reader and directly stored into the handheld computer. Data are transferred to a personal computer and analysed.

Improvement of work posture sampling:

Instead of using the original OWAS form, a special barcode form was designed. Symbols on the form help the observer to select the appropriate OWAS code for the posture of the body parts. Ten different work tasks can be described by the observer itself.

During observation the posture and related work task are marked on the observation form using the barcode reader and directly stored in the handheld computer. The input sequence is programmed, which helps the observer to record the appropriate posture and excludes the input of incorrect posture codes. An audio signal tells the user when to register/sample the posture and task of the subject observed.

\section{Improvement of data analysis:}

Instead of analysing the original OWAS forms by hand, the data are now transferred to a personal computer and analysed in minutes. The OWAS program developed for data analysis and presentation offers the following possibilities: (1) Distribution of postures into evaluation classes according to specific postures and according to body parts for all activities; (2) Distribution of postures and postures of body parts for one specific activity in/excluding time spent to this activity. All analyses can be carried out on individual or group level and can be displayed on screen or printed in tabular format. 


\section{APPLICATIONS OF THE SYSTEM}

\section{(1) Computerised OWAS applied to garage mechanics}

The work of a garage mechanic includes many poor working postures, and contains a substantial static load. The repair and maintenance of car engines demands a working posture with the back in a bent position for prolonged periods. Working underneath the car using a vehicle lift or grease pit also creates poor working postures and high static load, since work is, in the main, overhead. Working postures in garages therefore seem responsible for discomfort and disorders for the musculoskeletal system.

A study using OWAS was carried out in order to: (i) determine the average postural load of garagemechanics; (ii) compare different work methods; and (iii) estimate the effect of using optimal work methods on average daily workload.

OWAS observations were taken in 42 garages. In each garage two mechanics were observed. The observation time for each mechanic was 45 minutes, during which 90 datapoints at intervals of 30 seconds were collected. All tasks of the garage mechanics were divided into ten basic work tasks and included different work methods and equipment. A total of 7000 observations were collected and analysed using the WORKMAN-1 software. Figure 2 shows the distribution of all work postures over the OWAS Action Categories.It shows that during a substantial part of the working day work postures occur which are harmful to the musculoskeletal system (Action Category 2 or higher).

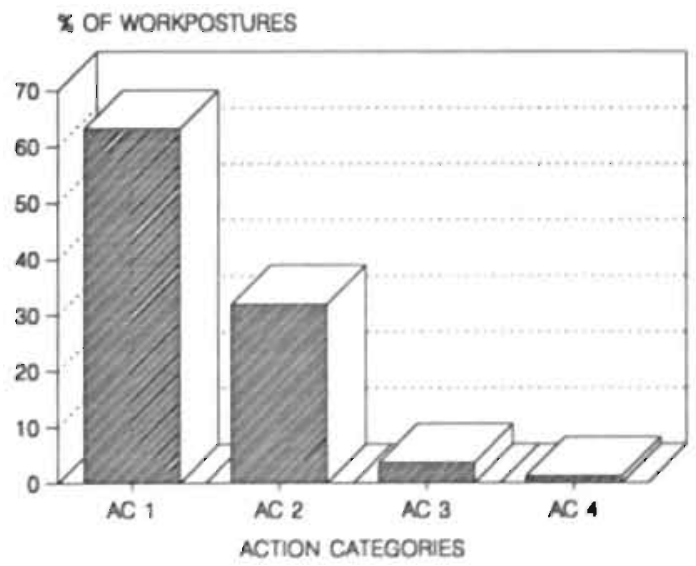

FIGURE 2: Distribution of the working postures of garage mechanics during an "average working day". Work postures were clustered into the four OWAS Action Categories. 
The WORKMAN-1 software allows its user to compare the postural load of different tasks on the same scale (time spenditure eliminated). This analysis revealed that the work method applied and equipment used for a certain task substantially influences the postural load of garage mechanics.

Figure 3 shows the distribution of the postures over the OWAS Action Categories for two different work methods. In both cases the task is the same: repair at the bottom of a car. The first method includes the use of a grease pit, the second the use of a vehicle lift. The results show clearly that the work posture load is substantially lower when using a vehicle lift.

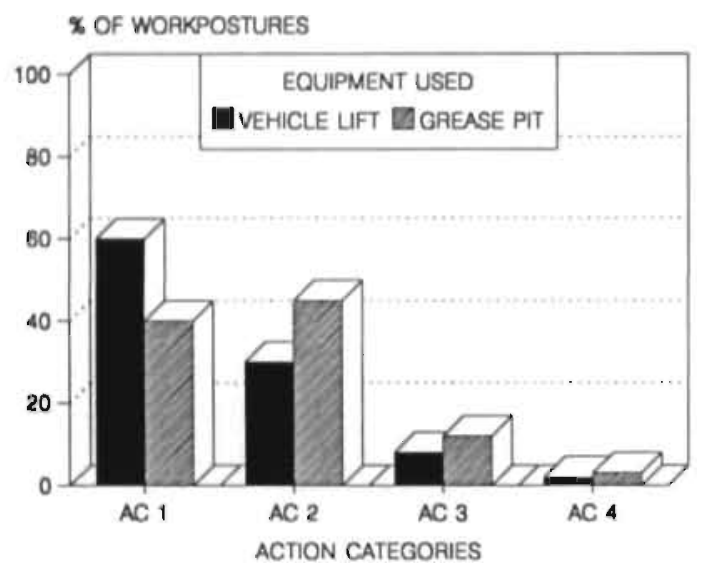

F!GURE 3: Eifect of work method applied/equipment used on working postures during mechanic's work at the side of the car. The working postures are expressed as OWAS Action Categories (AC).

In this way different work methods were compared. Using the percentage of time spent to each task it was possible to estimate the effect of the work methods on the total work posture load. Figure 4 shows the distribution of work postures over the OWAS Action Categories for three scenarios. In the first scenario mechanics consequently use the optimal work methods. The second scenario is the situation as observed and the third scenario simulates the load when the mechanics consequently use the worst work method.

This calculation shows how and how much the postural load of garage mechanics can be reduced by using the right equipment and work methods. 


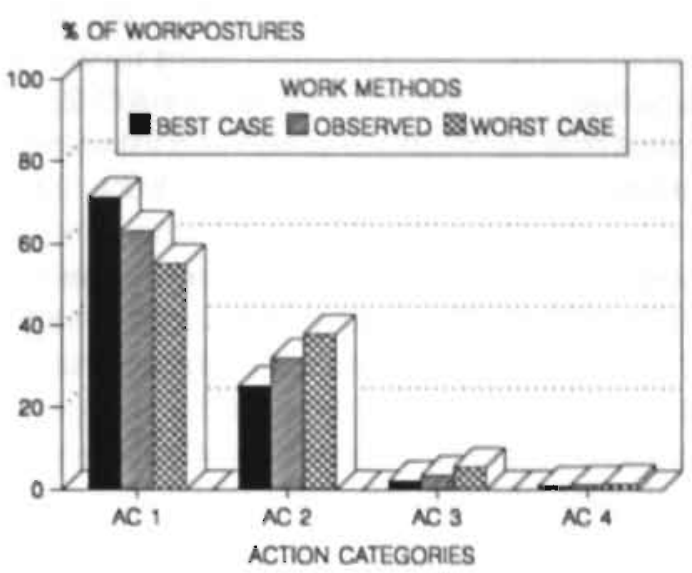

FIGURE 4: Effect of work methods applied on mechanic's postural load: (i) As observed, (ii) Best case (using lifting equipment) and (iii) Worst case (without lifting equipment). The working postures were clustered into the OWAS Action Categories (AC).

\section{(2) Computerised OWAS applied to operating room staft}

Work in health care units is associated with considerable physical strain and work related musculoskeletal complaints. Most investigations have concentrated on the work of general hospital nurses. However, little is known about physical stress experienced by other health care workers. We therefore carried out an ergonomic study amongst operating room staff in order to (i) determine the postural load on this particular group of heaith care workers, (ii) identify activities involving poor work postures and (iii) determine differences between specialities in regard to work posture stress load.

The work postures and related work task of four different staff groups in operating rooms (surgeons, anaesthetist assistants, instrumentation nurses and circulating nurses) were recorded during the course of 18 daily sur(gical programs in the special general surgery and Ear-Nose-Throat (ENT) surgery. For each group the tasks were divided into nine basic work tasks.

A total of 3714 observations were collected and analysed using the WORKMAN-1. Using the WORKMAN-1 software the postures of body parts were analysed per staff category. This analysis revealed that the postural load of circulating nurses and anaesthetist assistants was not harmful (all postures Action Category 11.

Some work postures of surgeons and instrumentation nurses however appeared to be in need of improvement. The postural load in these groups is mainly due to the high prevalence of static postures. Among surgeons; the bent forwardi head posture (bent forward) is classified as $A C 3$, while the back posture (bent forward and twisted), arm posture (shoulders raised) and the 
leg posture (standing on one leg) are classified as AC 2.

Among instrumentation nurses, head posture (bent forward) and back posture (bent forward and twisted) are both classified as AC 2.

Task analysis revealed that for both surgeons and instrumentation nurses the basic activity "surgery" accounted for about $80 \%$ of these poor work postures.

The work postures of surgeons may depend on the type of operation concerned. To investigate possible differences in postural load between the two surgical specialties, calculations on postures of body parts were repeated separately for ENT and general surgeons for the task "surgery". The prevalence of several postures were found to be significantly different between the two groups of surgeons $(P<0.05)$ also the OWAS classification of some postures differs (see Figure 5).

- During the task "surgery" general surgeons more often have their backs in a bent position and in a twisted position. Although the prevalence between the groups differs significantly, the classification of these postures in Action Categories is the same for both specialties.

- General surgeons also stand on one leg more often and sit less often; the position "standing on one leg" is classified as AC 2 for the general surgeons and AC 1 for the ENT surgeons.

- During a surgical programme general surgeons more often have their heads (i) bent forwards, (ii) bent to one side and (iii) twisted than ENT surgeons. The head bent forward position of general surgeons is classified as AC 3 and for ENT surgeons as AC 2. No significant differences were found between the two groups for any of the arm positions.

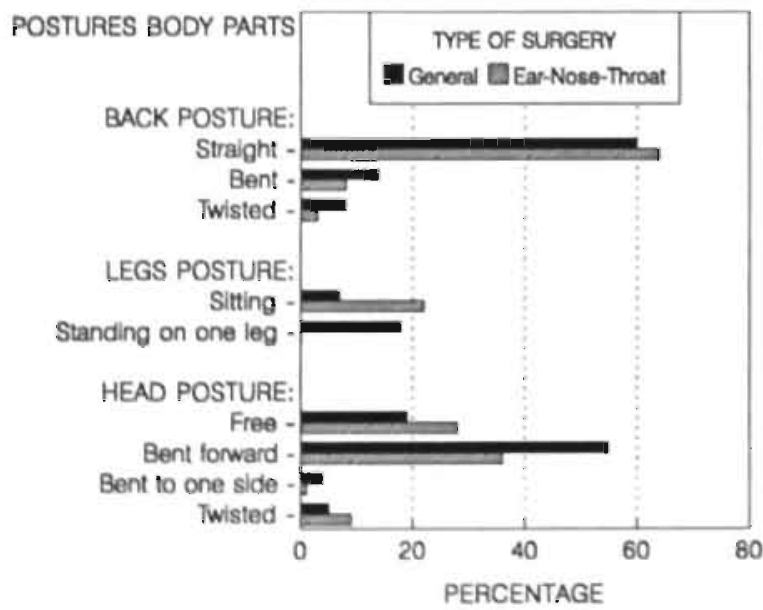

FIGURE 5: Differences in postures of body parts between surgeons of general surgery and Ear-INose-Throat. surgery. The incidences of the postures. shown differ significantly between both specialities $(\mathrm{P}<0.05)$. 


\section{DISCUSSION}

The OWAS method proved to be well suited for analysing work postures in different occupational settings. Almost every work posture could be described with the elements of the OWAS method. This observation technique provided the observers with the necessary mobility (garage mechanics) without hindering the work activities of the subjects observed (operating room staff).

The WORKMAN-1 system facilitated the process of both data collection and analysis and therefore eliminated some disadvantages of the original OWAS (see Table 1).

TABLE 1: Comparison of the original and computerised OWAS method with respect to the work posture sampling and data analysis.

\begin{tabular}{|l|c|c|}
\cline { 2 - 3 } \multicolumn{1}{c|}{} & ORIGINAL OWAS & Computerised OWAS \\
\hline WORKPOSTURE SAMPLING & $+1-$ & ++ \\
Code assignment & 1 & 2 \\
Observations/min & $+1-$ & ++ \\
Interval control & Indirect (forms) & Direct (Organiser) \\
Data storage & $6-8$ hours & +2 hours \\
\hline DATA ANALYSIS & $+1-$ & ++ \\
Time data analysis/8-hour & - & ++ \\
sampling & -- & ++ \\
Analysis of postures body & - & + \\
parts & - & + \\
Analysis of work postures & - & + \\
Task analysis & - & + \\
Group analysis & & \\
\hline
\end{tabular}

$++=$ excellent, $+=$ good, $+1-=$ sufficient, $-=$ deficient, $--=$ poor

The improved technique of work posture sampling using barcode forms with symbols leads to more and more accurate observations in the same time span. The built-in timer with audio signal results in more objective sampling. The $\mathrm{PC}$ based analysis program allows to perform a complete data analysis within minutes and makes it feasible to complete a report within 1-2 hours. Moreover, compared to the original OWAS method the software developed offers new possibilities for data analysis as shown in both studies: 
- The overall scores can be quickly computed and analysed in order to identify those postures which require action to be taken.

- Tasks which contribute most to the total postural load can also be identified.

- Analysis of data with equalised time spenditure allows a direct comparison of (i) work methods applied (garage mechanics), (ii) groups of staff (operating room staff) and (iii) different speciaities (operating room staff).

This extended data analysis makes it feasible to check the efficiency of corrective measures before they are implemented as shown in the study of garage mechanics. It is concluded that the computerised OWAS system is a powerful tool to determine the postural load, identify tasks with a contribution to this load, to determine control measures and estimate the effect of these measures.

It is hoped that this report will stimulate other investigators to use this relatively simple observation technique to study and improve working conditions which cause poor working postures.

\section{REFERENCES}

Chaffin DB, Andersson GBJ (1984): Occupational biomechanics. Jon Wiley \& Sons.

Corlett EN, Madely SJ, Manenica ! (1979): Posture targetting: a technique for recording working postures. Ergonomics 22; 357-366.

Corlett EN, Bishop RP (1976): A technique for assessing postural discomfort. Ergonomics $19(2) ; 175-182$.

Cote Gil HJ, Tunes E (1976): A technique method for sitting posture. Appl Ergonomics 20 (1): 53-57.

Douwes M, Dul J (1990): Preventie beroepsgebonden problematiek van het bewegingsappa* raat (\$91-2). Directoraat-Generaal van de Arbeid, Voorburg, The Netherlands.

EEC (1992): European Directive 90/269/EEC: On the minimum health and safety requirements for the manual handling of loads where there is a risk particularly of back injury to workers. Opficial Journal of the European Communities.

Engels J, Landeweerd A, Kant IJ (1993): An OWAS based analysis of working postures within the nursing profession. Ergonomics (in Press).

Guelaud F et al. (1980): Pour une analyse des conditions de travail ouvrier dans l'enterprise., 3e ed. Colin, Paris.

Hettinger Th (1985): Occupational hazards associated with diseases of the skeletal system. Eigonomics 28: 69-75.

Kant IJ, Jong de LCGM, Rijissen-Moll van M, Borm PJA (199.2): A survey of static and dyna. mic work postures of operating room staff. Int Arch Occup Eviron Health 63; 423-428.

Kant IJ, Notermans JHV, Borm PJA (1990): Observations of working postures in garages using the Ovako Working posture Analysing System (OWAS) and consequent workload reduction recommendations. Ergonomics 33 (2); 209-220.

Karhu D, Kansi P, Kuorinka II (1977): Correcting working postures in industry: a practical method for analysis. Appl Ergonomics 8; 199-201.

Karhu O, Harkönen R, Sorvali P, Vepsalainen P (1981): Observing work postures in industry: examples of OWAS application. Appl Ergonomics 12: 13-17. 
Keyserling M (1986): Postural analysis of the trunk and shoulders in simulated real time. Ergonomics 29 (4): 569-583.

Kivi P, Mattila M (1991): Analysis and improvement of work postures in the building industry: application of the computerised OWAS method. Appl Ergonomics 22 (1): 43-48.

Rohmert W (1985): AET: A new job analysis method. Ergonomics 28; 245-254.

Rohmert W, Landau K (1979): Das Arbeitswissenschaftliche Erhebungsverfahren zur Tătigkeitanalyse. Huber, Stuttgart.

Rohmert W, Lōwenthal I, Rükert A (1988): Körperhaltungsstudie bei Lade und Palettierungstätigkeiten auf einem Grossflughaven. Arbeitsmed Sozialmed Prăventivmed 23; 91-96.

Stoffert von G (1985): Analyse und Einstufung von Körperhaltungen bei der Arbeit nach der OWAS Methode. Z Arbeitswissenschaft 39; 31-38.

Verbeek JHAM (1991): Arbeidsongeschiktheid op grond van rugklachten en andere aandoeningen van het bewegingsapparaat (Occupational disability as a result of Backpain and other musculoskeletal disorders) PhD thesis, University of Amsterdam, The Netherlands. 



\section{CHAPTER 9}

\section{General discussion}

In this thesis the occupational hygiene approach to occupational health risk prevention is outlined. Important steps in the classic "cascade approach" are the recognition, evaluation and control of occupational hazards. As a consequence, in each stage different strategies and methods are used. Within each stage the method and strategy applied also depend on the hazard involved (chemical, physical, ergonomical). This stepwise approach is generally accepted and regarded to be efficient because of its converging effect. This is true for the recognition and evaluation stages since exposure measurements have to be carried out only for recognised hazards. A consequent separation between the evaluation and control of occupational hazards however, is less efficient. Establishment of efficient and effective control measures requires detailed insight in the different sources (including agents, work environment, process/appliance and workpractice), their contribution to the exposure and the interaction between sources: the multiple-source exposure concept. For risk evaluation however, a quantative measurement of the occupational exposure will do. Consequently, strategies for risk evaluation and risk control are not necessarily compatible and results of surveys designed for risk evaluation can seldomly be used to establish efficient control measures. If the outcome of the risk evaluation requires control actions to be taken, an additional study must be carried out using the multiple source concept. Surveys, integrating both evaluation and control may therefore be preferable.

We showed in different workplaces with different stressors (chemical exposure, thermal conditions, postural load) how surveys can be designed and applied that allow both evaluation and control of occupational hazards. Present available methods for exposure measurements were sufficient in most applications. This is more or less surprising since methods to determine chemical exposure are generally considered to be more abundant, precise and preferable. However, an elementary insight into the relation between sources and exposure (multiple source concept) appeared to be a prerequisite for the design of such integrated strategies. In most studies, a pilot study was necessary 
to obtain this elementary insight and to select the parameters to be measured. As a consequence the design of such integrated strategies set stringent conditions for the methodology applied. In case of the exposure to $\mathrm{N}_{2} \mathrm{O}$ an elaborate strategy of exposure measurements and registration of activities through observation was nessecary to obtain the information for both evaluation and control. Current methods for evaluation of occupational exposure to nitrous oxide (e.g. personal sampling) would not have mett those requirements. In case of postural stress, the integrated strategy required the registration of work postures and work activities/work methods under real working conditions. The computerised version of the OWAS method fullfilled those requirements. Other current evaluation methods which focus on specific jobs or tasks like the $\mathrm{NIOSH}$ method for handling and lifting would not have revealed this information.

During the set-up of an integrated strategy for thernal comfort there appeared to be a conflict between the (legal) requirements for evaluation and the requirements for control of this stress. Since thermal comfort cannot be directly measured, but only expressed in terms that relate to this stress, several models were used to evaluate this stress. Four current climate standards (L-index, L-index (comfort), PMV-index and the ASHRAE-index) were used to evaluate the climate conditions in garages. It appeared that the number of garages within the standards acceptable range varies considerably with the standard used. As a consequence of this, the necessity and the type of control measures are highly influenced by the standard used. For the evaluation of the thermal environment in garages, Fanger's PMV-index is recommended since it showed the best sensitivity and positive predictive value. This is more or less surprising, since Fanger's model was developed and validated for mild/ moderate thermal environments unlike the thermall environment in garages. However, Dutch occupational legislation for thermal environment at the workplace is stili based on the L-index. Our data shows that this index is less suitable to evaluate the thermal environment in garages as a typical small industrial work environment; the main reason is that this standard does not incorporate air-velocity which was shown to be crucial for the evaluation of the thermal comfort in this environment.

The integrated study design allowed an accurate estimate of the occupational stressors in all cases. In some cases this study design led to insights that could be used for future evaluation. This is demonstrated in the survey in operating rooms with respect to the occupational exposure to $\mathrm{N}_{2} \mathrm{O}$. The sampling strategy enabled an accurate estimation of exposure. All sitaff except for surgeons were exposed to $\mathrm{N}_{2} \mathrm{O}$ levels above the proposed exposure limit of $25 \mathrm{ppm}$. However, exposure to $\mathrm{N}_{2} \mathrm{O}$ in operating rooms is influenced by the percentage recirculated air. During the survey only $10-20 \%$ of the ventilated air was recirculated. The sampling strategy allowed us to estimate the occipational exposure in operating rooms for different percentages of recircu- 
lation, e.g. during wintertime (max $70 \%$ recirculation). Recently the Dutch occupational exposure limit for $\mathrm{N}_{2} \mathrm{O}$ has been reconsidered (Dutch expert committee for occupational standards, 1992) and set on $80 \mathrm{ppm}$. This MAC value became effective in February 1994 [Arbeidsinspectie 1994]. Our study design has created a database that enables us to (re)calculate restrictions of the ventilation system for this new MAC value without the need to repeat measurements.

Evaluation of thermal comfort in operating rooms forced us to study the effect of mental stress. Our data showed that the difference between measured PMV and the perceived thermal sensation was significantly dependent upon and increases with the perceived mental activity up to 0.5 points of the thermal sensation scale. Compared to the comfort limits of ISO $77301-0,5<$ PMV $<+0,5)$ this deviation is substantial. This may be important for the evaluation and control of thermal climate conditions of occupations with high mental stress (e.g. surgeons, flight control officers).

In all cases, the integrated study design revealed the sources and their contribution to total exposure which could be used to establish control measures. In Chapter 2 a survey in operating rooms is described. The sampling strategy for this purpose showed clearly that control measures for reduction of the $\mathrm{N}_{2} \mathrm{O}$ emission must be based on the total release and not on the emission rate. The activity/source with the highest $\mathrm{N}_{2} \mathrm{O}$ emission rate appeared to be the respiration mask without scavenging. This result corresponds with other studies. However, although the $\mathrm{N}_{2} \mathrm{O}$ concentration during this activity is high (167 ppm), the contribution of this activity to total $\mathrm{N}_{2} \mathrm{O}$ release is only $7 \%$. Therefore the often proposed control measures on this issue wil have only very limited effect. Based on the data of this survey a simulation model for nitrous oxide exposure in operating rooms could be developed. The model was used to predict the eifect of different control measures and was validated with data obtained after control measures were implemented. This enabled us to (re)calculate restrictions of the ventilation system for a new MAC value without repeating the measurements. In summary, this study shows how modelling can help both occupational hygiene and hospital management to control exposure to anaesthetic gases and to design or adapt ventilation systems of operating rooms and recovery rooms. Implementation of the new MAC value for $\mathrm{N}_{2} \mathrm{O}$ may have severe technical, financial and organisational consequences for several hospitals. Improvements of anaesthetic equipment and ventilation systems and adapting work methods will in some cases be necessary to comply with this new standard. Our study design/simulation model can be used for a quick screening of hospitals in The Netherlands. This will provide a good insight in the exposures to $\mathrm{N}_{2} \mathrm{O}$ and the control measures required in Dutch hospitals, enabling policy makers and hospital management to keep track of this problem. However, for this purpose the simulation model needs to be extended and validated. 
Chapters 6 through 8 describe the application of the OWAS method as a tool for the evaluation and control of postural stress. The survey with respect to the postural load of garage mechanics revealed three work activities principally causing the workload. For each of these three work activities an alternative work method was observed and it was demonstrated that in all three work activities the use of a vehicle lift will reduce the number of poor working postures. A survey among operating room staf estimated the workload for different groups of staff and also elucidated activities contributing most to this load. In summary, the design of both surveys, recording both work posture and concomitant work activity, enabled the analysis of tasks, work methods and equipment used. Such an analysis is essential for the evaluation and control of postural stress and incorporates several elements of the EEC directive 90/391/EEC "on the minimum health and safety requirements for the manual handling of loads". Therefore, we consider this to be an example how to implement this directive in Dutch legislation. However, the original OWAS method was not suited for the analyses mentioned. Therefore, a computerised version of the OWAS method had to be developed. The extended data analysis offered by this system made it feasible to estimate the efficiency of corrective measures before they were implemented.

The integrated study design appeared to be very useful for intervention studies. To calculate the net effect of the intervention (control) measures it is crucial that results can be corrected for changes in conditions not related to the intervention. However, this is only possible when the contribution of all sources to the exposure are known before intervention takes place. Application of the same integrated strategy before and after intervention, allowed us to adjust the $\mathrm{N}_{2} \mathrm{O}$ exposure measurements after intervention for differences in type and duration of anaesthetic activities and different percentages recirculation. With respect to the study on postural load the results can be regarded as a baseline measurement for future intervention studies.

In conclusion, we shawed in different workplaces with different stressors how surveys can be designed and applied that allow both evaluation and control of occupational hazards. In all three parts of this thesis, however, the sampling strategy was crucial to obtain data that can be used for intervention and risk control. Interestingly, evaluation and control could be obtained by elaborate surveys coupling exposure to emission $\left(\mathrm{N}_{2} \mathrm{O}\right)$, thermal comfort to thermal environment and postural load to work methods. In most studies, a pilot study was necessary to obtain the elementary insight into the relation between sources and exposure. As a result, in common practice these surveys will be time consuming and expensive but (i) they will result in efficient control measures and (ii) in the long run they might prove to be cost-effective. Costeffectiveness is mainly determined by the frequency of changes made in technical equipment, work methods, agents used or standards for these agents. 
It is clear that decisions on risk evaluation and control are becoming an integral part of the management such as indicated by the EEC Directive $89 / 391 /$ EEC "On the introduction of measures to encourage improvements in the health and safety of workers at work". The extended stategies and designs as examplified in this thesis might, therefore, become common practice in the future of occupational hygiene.

\section{REFERENCES}

Arbeidsinspectie (1994): De Nationale MAC-lijst 1994, publicatieblad P 145. Arbeidsinspectie, Den Haag.

Dutch Expert Committee on Occupational Standards. (1991): Health-based recommended occupational exposure limit for nitrous oxide. Report RA 2/92, Ministry of Social Affairs and Employment, Labour Inspectorate, The Hague. The Netherlands. 



\section{CHAPTER 10}

\section{Summary}

Occupational hygiene focuses on the individual workplace with the aim to protect workers from health hazards related to work and to enhance the wellbeing of workers by adapting the work (setting) to human requirements. An essential activity in occupational hygiene is the workplace investigation (survey) to analyse and prevent workplace hazards. Usually a stepwise approach of identification, evaluation and control of occupational hazards is followed using different strategies and methods in each separate step. As a result of this approach many surveys have focussed mainly on the evaluation of hazards thereby failing to provide elementary insight to establish control measures.

This thesis deals with the design of surveys that enable both evaluation and control of occupational hazards. The principal objectives of this thesis were:

1. To indicate how current occupational hygiene strategies for risk evaluation can be extended/modified in order to enable better risk control;

2. To develop methodology (simulation models, hardware) to enable an approach integrating evaluation and control.

These objectives are illustrated and evaluated in three parts containing pairwise chapters dealing with risk evaluation and control of some relevant environmental stresses (chemical exposure, thermal conditions, postural load) in the work environment.

The first part (Chapters 2 and 3 ) describes the evaluation and control of nitrous oxide exposure in operating rooms. In Chapter 2 a survey conducted in operating rooms is described. This survey was designed (i) to obtain reliable exposures for different groups of operating room staff, (ii) to identify and quantify the main sources of $\mathrm{N}_{2} \mathrm{O}$ in the operating and recovery rooms and (iii) to establish control measures. All staff except for surgeons were exposed to $\mathrm{N}_{2} \mathrm{O}$ levels above the proposed exposure limit of $25 \mathrm{ppm}$. The most important contributor to total release of $\mathrm{N}_{2} \mathrm{O}$ was the ventilator (about $70 \%$ ), especially during the artificial respiration of the patient. It was calculated that a $58 \%$ reduction in emission could be achieved by technical improvements of the 
ventilator and consistent scavenging. Measurements of $\mathrm{N}_{2} \mathrm{O}$ levels after intervention showed a reduction in the area surrounding the ventilator of about $80 \%$, thereby reducing occupational exposure of all staff to below $18 \mathrm{ppm}$. However, exposure to $\mathrm{N}_{2} \mathrm{O}$ in operating rooms is not only determined by the emission rate (sources) but also by the general ventilation and the percentage recirculation. Based on our data a simulation model for nitrous oxide exposure in operating rooms was developed. The development and application of this model, which includes $\mathrm{N}_{2} \mathrm{O}$ emission, ventilation and recirculation is described in Chapter 3. This model was used to predict the effect of different control measures and was validated with data obtained after control measures were implemented. Using this model, it was calculated that compliance with the proposed MAC value for $\mathrm{N}_{2} \mathrm{O}(25 \mathrm{ppm})$ is attained when the percentage of recirculated air does not exceed $20 \%$. In general, this survey shows how modelling can help both occupational hygienists and hospital management to control exposure to anaesthetic gases and to design or adapt ventilation systems of operating rooms and recovery rooms.

The second part of this thesis (Chapters 4 and 5 ) describes the application and modification of methods for the evaluation of thermal climate in the work environment. The thermal canditions in 42 garages were measured and evaluated using four current climate standards (L-index, L-index (comfort), PMVindex, ASHRAE-index) and compared with results of questionnaires completed by mechanics working in these garages (Chapter 4). It appeared that the number of garages within the standards acceptable range varied considerably with the standard used. As a consequence, the necessity and the type of controll measures were highly influenced by the climate standard used. The large differences can be explained by the different parameters on which the standards are based. Our findings revealed Fanger's PMV-index to be the most adequate standard for the evaluation of the thermal environment in garages. However, Dutch occupational legislation for thermal environment at the workplace is still based on the L-index. Our results show that this index is not suitable to evaluate the thermal environment in garages and comparable work environments, since this standard does not incorporate air-velocity, which we showed to be crucial in evaluating these thermal environments.

Although Fanger's PMV-index incorporates personal parameters like clothing and metabolic rate, it does not account for other personal parameters like: mental stress. In order to determine the effect(s) of mental stress on thermal sensation, a workplace study among operating room staff, including surgeons, anaesthetist assistants, instrumentation nurses and circulating nurses was performed (Chapter 5). Climate conditions in these rooms were ideally controlled, but the tasks, education and mental activity of different categories of staff varied widely. Environmental climate parameters were measured during surgical programs and personal parameters for the different occupational 
groups were estimated. Based on these data, predicted mean votes (PMV) were calculated for the different groups of staff and compared with the results of questionnaires on the perception of thermal climate and mental activity during that program. Our results show that the difference between measured PMV and the perceived thermal sensation is significantly dependent upon and increases with the perceived mental activity. This may be important for the evaluation and control of thermal climate conditions of occupations with a high mental stress (e.g. surgeons, flight control officers).

The third part of this thesis (Chapters 6-8) describes the application of the Ovako Working posture Analysis System (OWAS) as a tool for evaluation and control of postural stress. The work postures and work activities of mechanics $(\mathrm{N}=84)$ in 42 garages were observed and recorded using the basic OWAS method (Chapter 6). This survey design enabled us to calculate the work posture load, the contribution of a specific activity to total postural load and to compare different work methods. Five out of 19 observed postures of the body members and $31.9 \%$ of the typical working postures were classified as Action Category 2 suggesting that during a substantial part of the working day working postures occur which are slightly harmful to the musculoskeletal system. The work activities principally causing the workload were identified. For three work activities an alternative work method involving different usage of different garage equipment was observed (e.g. grease pit vs vehicle lift). A pairwise comparison of these work methods showed that the number of poor working postures and thereby the load on the musculoskeletal system is substantially affected by the work method applied.

In Chapter 7 an ergonomic survey amongst operating room personnel is described. The study included four different groups of staff (surgeons, anaesthetist assistants, instrumentation nurses and circulating nuirses) and two specialties (generai surgery and Ear Nose Throat (ENT)). The survey was designed to: (i) determine the postural load in this particular group of health care workers and the effect of the static posture on this load, (ii) identify activities involving poor work postures, and (iii) determine differences between specialities with regard to work postural load. The work postures and related work activities were recorded and evaluated using the specified OWAS. It was shown that the postural load of circulating nurses and anaesthetist assistants was not harmful, whereas some work postures of instrumentation nurses and surgeons need improvement. The postural load in both latter groups is mainly due to the high prevalence of static work postures during the activities "surgery" (surgeons) and "assistant surgery" (instrumentation nurses). Significant differences in postural load were observed between general surgeons and ENT surgeons.

The study design of the surveys as described in Chapter 6 and 7 , enabled the analysis of activities, work methods / equipment and professions which are 
essential for both the evaluation and control of postural stress. In order to perform this analysis a computerised version of the OWAS method was developed since the original OWAS method was not suited for this task. Chapter 8 describes the development and application of this system. It can be concluded that the computerised OWAS system is a powerful tool to determine the postural load, identify tasks with a contribution to this load and to determine control measures and estimate the effect of these measures.

By means of studies on different workplaces with various stressors (chemical exposure, thermal conditions, postural load), we demonstrated in what way surveys can be designed and applied, allowing both evaluation and control of occupational hazards. An elementary insight into the relation between sources and exposures (multiple source concept) appears to be a prerequisite for the design of such integrated strategies. In most investigations in this thesis, a pilot study was necessary to obtain this elementary insight and to select the parameters to be measured. As a consequence the design of integrated strategy sets stringent conditions for the methodology and the sampling strategy applied. The currently available methods for exposure measurement are adequate in most applications as shown in this thesis, although in one case (OWAS) methodology had to be adjusted to perform data analysis. In all three parts of this thesis the sampling strategy was crucial to obtain data which could be used for intervention and risk control. Interestingly, evaluation and control could be obtained by elaborate surveys coupling exposure to emission $\left(\mathrm{N}_{2} \mathrm{O}\right)$, thermal comfort to thermal environment and workload to work methods. Despite the fact that such integrated surveys are rather time consuming and expensive we conclude that in common practice they will result in efficient control measures and in the long run even prove to be cost effective. The more so as the integrated design provides the opportunity to anticipate changes in work methods / equipment and/or exposure limits. 


\section{CHAPTER 11}

\section{Samenvatting}

Arbeidshygiëne richt zich op de individuele werkplek met als doel werknemers te beschermen tegen faktoren die gezondheid en welzijn kunnen schaden. Werkplekonderzoek gericht op de analyse en preventie van gezondheidsbedreigende faktoren vormt daarom een essentieel onderdeel van de arbeidshygiëne. Bij dit werkplekonderzoek wordt een stapsgewijze aanpak gehanteerd van herkennen, evalueren en uiteindelijk beheersen van gezondheidsbedreigende faktoren, waarbij in iedere afzonderlijke stap verschillende strategieën en methodes toegepast worden. Als gevolg van deze stapsgewijze aanpak zijn de meeste werkplekonderzoeken gericht op de evaluatie en blift het verschaffen van informatie nodig voor het vaststellen van beheersmaatregelen vaak achterwege.

Dit proefschrift behandeld een onderzoeksopzet gericht op zowel de evaluatie als de beheersing van werkplekrisiko's.

De doelstellingen van dit proefschrift waren:

1. Aan te geven hoe de bestaande arbeidshygiënische strategie voor risikoevaluatie moet worden aangepast/uitgebreid om tot een betere beheersing van deze risiko's te komen.

2. Het ontwikkelen van methodologie (simulatiemodellen, hardware) ten behoeve van een geïntegreerde aanpak van evaluatie en beheersing.

Deze doelstellingen worden uitgewerkt en belicht aan de hand van studies naar de evaluatie en beheersing van drie relevante werkplekfaktoren, te weten chemische blootstelling, thermisch klimaat en werkhoudingsbelasting.

Het eerste deel van dit proefschrift (hoofdstuk 2 en 3) behandelt de evaluatie en beheersing van beroepsmatige blootstelling aan lachgas $\left(\mathrm{N}_{2} \mathrm{O}\right)$ in operatiekamers. In hoofdstuk 2 wordt een werkplekonderzoek in operatiekamers beschreven. Deze studie was opgezet (i) ter verkrijging van nauwkeurige blootstellingsgegevens voor de verschillende groepen operatiekamerpersoneel, (ii) om de belangrijkste lachgasbronnen in operatiekamers en verkoeverkamer te lokaliseren en te kwantificeren en (iii) ter bepaling van beheersmaatregelen. 
De $\mathrm{N}_{2} \mathrm{O}$-blootstelling was voor al het personeel, uitgezonderd de chirurgen, boven de voorgestelde MAC-waarde van $25 \mathrm{ppm}$. De grootste bijdrage aan de totale $\mathrm{N}_{2} \mathrm{O}$-emissie (circa $70 \%$ ) werd geleverd door de beademingsapparatuur, met name bij aktieve beademing van de patiënt. Berekend werd dat door technische aanpassingen aan de beademingsapparatuur en een consequent gebruik van scavenging, de emissie met $58 \%$ gereduceerd kon worden. Metingen na interventie toonden aan dat de $\mathrm{N}_{2} \mathrm{O}$-expositie in de omgeving van de beademingsapparatuur met $80 \%$ gereduceerd was. De beroepsmatige blootstelling aan lachgas bieek voor alle groepen beneden de $18 \mathrm{ppm}$ te zijn. De blootstelling aan lachgas op operatiekamers wordt echter niet alleen bepaald door de emissie (bronnen) maar ook door de algehele luchtverversing en het percentage luchtrecirculatie. Op basis van eigen onderzoeksdata werd een simulatiernodel ontwikkeld voor de blootstelling aan lachgas. In hoofdstuk 3 wordt de ontwikkeling en toepassing van dit model beschreven. Dit model werd gebruikt om de effekten van verschillende beheersmaatregelen te voorspellen en werd gevalideerd met data verkregen nadat de voorgestelde beheersmaatregelen waren verwezenlijkt. Met behulp van dit model werd berekend dat indien het percentage recirculatie niet hoger is dan $20 \%$, de voorgestelde MAC-waarde niet zal worden overschreden. Deze studie laat zien dat modellen een hulpmiddel kunnen zijn voor arbeidshygiënisten en ziekenhuismanagement bij het beheersen van de beroepsmatige blootstelling aan gas/ dampvormige anaesthetica en bij het ontwerpen cq. aanpassen van ventilatiesystemen in operatiekamers en verkoeverkamers.

In het tweede gedeelte van dit proefschrift (hoofdstuk 4 en 5) worden methoden voor de evaluatie van het thermische klimaat beschreven. In 42 garages werden de klimaatomstandigheden gemeten en beoordeeld aan de hand van vier gangbare richtlijnen (L-index, L-index (comfort), PMV-index en ASHRAEindex). De resultaten werden vergeleken met de via vragenlijsten gescoorde beleving van het klimaat van monteurs in deze garages (hoofdstuk 4). Het aantal garages dat voldeed aan de gestelde waarden bleek sterk afhankelijk te zijn van de richtlijn die werd toegepast. De noodzaak van te nemen beheersmaatregelen wordt derhalve sterk beïnvloed door de keuze van de klimaatrichtlijn. Dit kan verklaard worden door de verschillende parameters waarop deze richtlijnen zijn gebaseerd. Uit deze vergelijkende studie komt naar voren dat de beoordeling van het thermische klimaat in garages het best kan geschieden met behulp van de PMV-index. De Nederlandse wetgeving m.b.t. het thermisch klimaat op de werkplek is echter gebaseerd op de L-index. Onze resultaten tonen aan dat deze index niet geschikt is voor de evaluatie van het klimaat in garages en vergelijkbare werkplekken. De L-index houdt namelijk geen rekening met de luchtsnelheid, hetgeen van cruciaal belang bleek te zijn bij de evaluatie.

In Fanger's PMV-model zijn de persoonlijke klimaatparameters kleding en aktiviteit opgenomen. Andere persoonlijke parameters zoals mentale stress 
worden echter buiten beschouwing gelaten. Het effekt van mentale stress op de beleving van het thermische klimaat werd onderzocht in een werkplekonderzoek, uitgevoerd onder vier groepen operatiekamerpersoneel (chirurgen, anesthesie-, instrumentatie- en omloop verpleegkundigen). De klimaatomstandigheden in operatiekamers worden nauwkeurig geregeld. De taken, opleiding en mentale stress van het personeel kunnen echter sterk verschillen. Gedurende een aantal operatieprogramma's werden de omgevingsklimaatparameters gemeten. Per beroepsgroep werd een nauwkeurige schatting gemaakt van de persoonlijke parameters. Op basis van deze meetgegevens werd per operatieprogramma voor iedere beroepsgroep de PMV-waarde berekend. Deze waarden werden vergeleken met de via vragenlijsten gescoorde beleving van het klimaat en de mentale stress. De resultaten van deze studie laten zien dat het verschil tussen de berekende PMV en de beleving van het klimaat signifikant afhankelijk is van, en toeneemt met, de beleving van de mentale stress. Dit kan van belang zijn bij de beoordeling en beheersing van klimaatomstandigheden voor beroepsgroepen met een hoge mentale stress (bijvoorbeeld chirurgen, luchtverkeersleiders).

In het derde gedeelte van dit proefschrift (hoofdstukken 6-8) wordt de toepassing van de Ovako Working posture Analysing System als instrument voor de beoordeling en beheersing van werkhoudingsbelasting beschreven (OWAS). In hoofdstuk 6 wordt een werkplekonderzoek naar de werkhoudingsbelasting van garagemonteurs beschreven. In 42 garages werd de werkhouding en werkaktiviteiten van garagemonteurs geobserveerd en geregistreerd m.b.v. de "basic" OWAS-methode. De onderzoeksopzet stelde ons in staat (i) de werkhoudingsbelasting vast te stellen, (ii) de bijdrage van de verschillende aktiviteiten aan deze belasting vast te stellen en (iii) werkmethoden met elkaar te vergelijken. Vijf van de negentien deelhoudingen en $31,9 \%$ van de standaardhoudingen werden geklassificeerd in OWAS Actie Categorie 2. Dit betekent dat gedurende een aanzienlijk gedeelte van de werkdag houdingen voorkwamen die (licht) belastend zijn voor het bewegingsapparaat. De aktiviteiten die met name deze belasting veroorzaken konden worden vastgesteld. Bij drie aktiviteiten werd tevens een alternatieve werkmethode m.b.t. het gebruik van apparatuur geobserveerd (bijvoorbeeld hefbrug vs smeerkuil). Een paarsgewijze vergelijking van deze werkmethoden toonde aan dat het aantal belastende werkhoudingen en daarmee de belasting op het bewegingsapparaat aanzienlijk beïnvloed wordt door de toegepaste werkmethode.

In hoofdstuk 7 wordt een werkplekonderzoek naar de werkhoudingsbelasting van operatiekamerpersoneel beschreven. Het onderzoek omvatte vier beroepsgroepen (chirurgen, instrumentatie-, anesthesie- en omloop verpleegkundigen) en twee specialismen (Algemene Heelkunde en Keel-, Neus- en Oorheelkunde). Het onderzoek was opgezet (i) ter bepaling van de werkhoudingsbelasting van deze beroepsgroep, in het bijzonder de bijdrage van de statische werkhouding 
aan deze belasting, (ii) opsporing van aktiviteiten met belastende werkhoudingen en (iii) vergelijking van de twee specialismen m.b.t. de werkhoudingsbelasting. De werkhouding en aktiviteiten werden geregistreerd en beoordeeld m.b.v. de "specified" OWAS-methode. De resultaten van deze studie toonden aan dat de werkhouding van anesthesie- en omloopverpleegkundigen niet belastend waren. De werkhouding van chirurgen en instrumentatieverpleegkundigen daarentegen waren voor verbetering vatbaar. De werkhoudingsbelasting van laatstgenoemde groepen werd voornamelijk bepaald door het hoge aandeel van statische werkhoudingen. Dit was met name het geval gedurende de aktiviteiten "opereren" (chirurgen) en "assisteren bij operaties" (instrumentatieverpleegkundigen). De werkhoudingsbelasting van chirurgen Algemene Heelkunde bleek signifikant te verschillen met die van KNO-chirurgen. De studie-opzet van deze surveys zoals beschreven in hoofdstuk 6 en 7 stelde ons in staat de werkhoudingsbelasting te analyseren naar aktiviteit, werkmethode en beroepsgroep. Dit is essentieel voor het vaststellen van beheersmaatregelen. De oorspronkelijke OWAS-methode is echter niet geschikt voor deze analyses. Daarom werd een gecomputeriseerde versie van de OWAS-methode ontwikkeld. In hoofdstuk 8 worden de ontwikkeling en toepassing van dit systeem beschreven. Gekonkludeerd kan worden dat dit systeem een belangrijk hulpmiddel kan zijn bij (i) het vaststellen van de werkhoudingsbelasting, (ii) het opsporen van belastende taken en (iii) het ontwikkelen van beheersmaatregelen en het inschatten van het effekt van deze maatregelen.

In dit proefschrift wordt, aan de hand van onderzoek naar diverse werkplekken en verschillende belastende faktoren, aangetoond op welke wijze arbeidshygiënische surveys kunnen worden opgezet en uitgevoerd teneinde evaluatie en beheersing van werkplekrisiko's mogelijk te maken. Voor het opzetten van een geintegreerde onderzoeksstrategie bleek een gedegen inzicht in de relatie tussen bronnen en blootstelling volgens het "multiple source concept" een absolute voorwaarde te zijn. In het merendeel van de onderzoeken was derhalve een pilot-studie noodzakelijk dit inzicht te verkrijgen en om een meetstrategie vast te stellen. Een dergelijke geïntegreerde aanpak stelt echter stringente voorwaarden aan de methode en de meetstrategie. De huidige beschikbare methodes voor het meten van beroepsmatige blootstelling bleken in de meeste gevallen goed te voldoen. In één geval (OWAS) diende de bestaande methode aangepast te worden om de noodzakelijke analyses mogelijk te maken.

In alle drie de delen van dit proefschrift bleek de meetstrategie van cruciaal belang te zijn voor het verkrijgen van gegevens voor de evaluatie en beheersing van belastende faktoren. Opmerkelijk was dat evaluatie en beheersing mogelijk werd door het uitvoeren van omvangrijke werkplekonderzoeken waarbij expositie gekoppeld werd aan emissie, thermisch comfort aan de omgeving en werkhoudingsbelasting aan werkmethoden. De voorgestelde geïntegreerde aanpak is tijdrovend en kostbaar maar resulteert wel in efficiënte beheersmaat- 
regelen en zal daarom op de lange termijn wellicht kosteneffektief blijken, te meer omdat deze opzet het mogelijk maakt adequaat te reageren op veranderingen in werkmethoden/apparatuur en/of blootstellingsgrenswaarden. 


\section{Dankwoord}

Het onderzoek beschreven in dit proefschrift werd grotendeels uitgevoerd binnen de voormalige vakgroep Arbeidsgeneeskunde, later Arbeidsgeneeskunde Milieugezondheidkunde en Toxicologie (AMT) van de Rijksuniversiteit Limburg. Bij deze wil ik alle (ex)-medewerkers van deze groep hartelijk danken voor de samenwerking en hun bijdrage aan het onderzoek. Het is ook deze groep geweest waar mijn interesse voor het wetenschappelijk onderzoek werd gewekt en waar ik de ruimte kreeg het onderzoekspad te volgen met als voorlopige mijlpaal dit proefschrift. Twee collega's hebben hierbij een bijzondere en plezierige "leermeesters" rol vervuld.

Professor Pie Henderson, promotor, wil ik van harte danken voor zijn vertrouwen en deskundige begeleiding bij het schrijven van dit proefschrift. Zijn steun en bewaking van de voortgang, ook in roerige tijden, zijn voor mij van onschatbare waarde geweest.

Co-promotor Paul Borm wil ik bedanken voor de plezierige samenwerking en deskundige begeleiding bij het onderzoek en het schrijven van dit proefschrift. Mede door zijn begeleiding heb ik geleerd hoe belangrịk originaliteit en enthousiasme zijn bij het beoefenen van de wetenschap.

De in dit proefschrift beschreven studies zijn allen gebaseerd op werkplekonderzoek. Dergelijk veldonderzoek is ondenkbaar zonder de inzet, ondersteuning en medewerking van een groot aantal mensen.

Leo Vermeer en Jos Notermans wil ik hartelijk danken voor de plezierige samenwerking en hun bijdrage aan het garage-onderzoek.

Marjo van Rijssen-Moll, Guido Houben en Louis de Jong wil ik bedanken voor hun bijdrage en de plezierige samenwerking bij het onderzoek op de operatiekamers van het Academisch Ziekenhuis te Maastricht (A.ZM). Voorts wil ik de directie, afdelingshoofden, medewerkers en de technische dienst van het AZM alsmede de begeleidingscommissie bedanken voor de medewerking aan dit onderzoek. 
Onderzoek doen is één, het afronden van een proefschrift is twee. Hierbij wil ik Professor J.S.M. Boleij bedanken voor zijn waardevolle commentaar op het concept-manuscript en zijn suggesties voor verbetering. Daarnaast wil ik alle collega's van de Vakgroep Epidemiologie hartelijk danken voor de ruimte die ik het afgelopen jaar heb gekregen om het proefschrift af te ronden en mij te oriënteren op nieuw onderzoek.

Marliese Saya dank ik voor het letterlijk tot in de puntjes verzorgen van dit proefschrift. En natuurlijk de vrienden, kennissen en familieleden die ik bij tijd en wijle met mijn proefschrift-perikelen heb lastig gevallen. 


\section{Curriculum Vitae}

IJmert Kant werd geboren op 11 februari 1959 te Utrecht. Tussen 1976 en 1980 studeerde hij Chemische Techniek aan de Hogere Technische School te Hilversum. Tussen 1980 en 1982 was hij werkzaam als technisch konsulent voor het Instituut voor Reinigingstechnieken TNO te Delft. Tussen 1982 en 1986 was hij werkzaam als onderzoeksmedewerker bij Billiton Research BV te Arnhem.

In 1986 trad hij als arbeidshygiënist in dienst van de Rijksuniversiteit Limburg bij de Vakgroep Arbeidsgeneeskunde, later Arbeidsgeneeskunde Milieugezondheidkunde en Toxicologie (AMT). Tussen 1986 en 1988 volgde hij de Post H.T.O.-opleiding Bedrijfshygiëne aan de Hogeschool te Breda. Een essentieel onderdeel van zijn werkzaamheden vormde het wetenschappelijk onderzoek, waarop dit proefschrift gebaseerd is.

Daarnaast is hij sinds 1989 aktief als consultant bij ABK Consultancies BV. Sinds 1993 is hij als toegevoegd onderzoeker werkzaam bij de Vakgroep Epidemiologie. 



\section{Publikaties}

\section{FULL PAPERS}

Kant IJ, Borm PJA, Notermans JHV (1988): A comparison of current evaluation methods for thermal environment applied to garage work. Int Arch Occup Environ Health 61; 115-121.

Kant IJ, Borm PJA, Notermans JHV (1989): Thermal environment and thermal comfort in garages. A comparison of current methods. Ann Occup Hyg 33; 129-132.

Notermans JHV, Kant IJ, Vermeer LPH (1989): Asbest in het garagebedrijf. Maandblad voor arbeidsomstandigheden $65 ; 391-395$.

Borm PJA, Kant IJ, Rijssen-Moll van M, Henderson PTh (1989): Monitoring of anaesthetic gases in operating theatres. Identification of Sources of exposure and estimation of personal uptake. In: Proc. "Exposure monitoring in industry", KVIV-Antwerp, 3.15-3.20.

Kant IJ, Rijssen-Moll van M, Borm PJA (1990): Lachgas op operatiekamers. Van werkplekstudie tot modelmatige beschrijving. Techniek in de gezondheidszorg 3; 30-34.

Kant IJ, Borm PJA, Houben G, Rijssen-Moll van M (1990): Beroepsmatige blootstelling aan lachgas in operatiekamers. Tijdschr Toegepaste Arbowetenschap 3; 1-6.

Kant IJ, Borm PJA (1990): The effect of mental activity on thermal sensation, Prec. 5th International Conference on Indoor Air Quality and Climate, Toronto, Canada, Vol 1, 711-715.

Kant IJ, Borm PJA, (1990): A model to predict air quality in operating theatres, Prec. 5th international Conference on Indoor Air Quality and Climate, Toronto, Canada, Vol 4, 189-194.

Houben GJ, Diederiks JPM, Kant IJ, Notermans JVH (1990): Rationalization in garages in The Netherlands and its effects on occupational health. Work \& Stress $2 ; 179-189$. 
Rijssen-Moll van M, Nijhuis FJN, Kant IJ, Borm PJA (1990): Inventarisatie van arbeidsbeleving en arbeidsomstandigheden van operatiekamerpersoneel. Tijdschr Toegepaste Arbowetenschap 3; 42-36.

Kant IJ, Notermans JHV, Borm PJA (1990): Observations of working postures in garages using the Ovako Working posture Analysing System (OWAS) and consequent workload reduction recommendations. Ergonomics 33; 209220.

Kant IJ, Rijssen-Moll van M, Borm PJA (1990): Simulation of nitrous oxide concentrations in operating and recovery rooms. Ann Occup Hyg 34; 575583.

Borm PJA, Kant IJ, Houben G, Rijssen-Moll van M, Henderson PTh (1990): Monitoring of nitrous oxide in operating theatres. Identification of sources and estimation of occupational exposure. J Occup Med 32; 1112-1116.

Kant IJ, Jong de LCGM, Rijssen-Moll van M, Borm PJA (1992): A Survey of static and dynamic work postures of operating room personnel. Int Arch Occup Environ Health 63; 423-428.

Engels J, Landeweerd A, Kant IJ (1993): An OWAS based analysis of working postures within the nursing profession. Ergonomics (in press).

\section{ABSTRACTS}

Kant IJ, Borm PJA, Notermans JHV (1989): Thermal environment and thermal comfort in Garages. A comparisson of current methods. British Occupational Hygiene Society Conference, Birmingham, United Kingdom.

Kant IJ, Borm PJA, Notermans JHV (1989): Automatic ergonomic work analysis using OWAS. British Occupational Hygiene Society Conference, Birmingham, United Kingdom.

Kant IJ, Borm PJA (1990): Beroepsmatige blootstelling aan lachgas in operatiekamers. Studiedag SiGRA Amsterdam.

Kant IJ, Rijssen-Moll van M, Borm PJA (1991): Lachgas op operatiekamers: van werkplekstudie tot modelmatige beschrijving. Symposium NVVA "beheersmaatregelen in de arbeidshygiëne", Amsterdam.

Kant IJ, Engels J, Borm PJA (1991): Work postures of operating room personel using OWAS and computerised data analysis. Conference on Hospital ergonomics, Hopital Xavier Bichat, Parijs, France.

Kant IJ, Borm PJA (1992): Analysis and Improvement of work postures: Development and applications of a computerised OWAS method. British Occupational Hygiene Society Conference, Edingburgh, United Kingdom.

Kant IJ, Borm PJA (1993): Lachgas op operatiekamers: van werkplekstudie tot modelmatige beschrijving. Lustrum symposium NVVK, Arnhem. 

